(EDIS)

USER'S MANUAL

P. S. Smith

R. D. Short 
This report has been reprocuced directly from the beet avalluble copy.

Avellable to DOE and DOE contrectors from tho Orifice of Scientific and Techntcal information, P.O. Box 62, Oak Ridoo, TN 37831; prices aveliable from (815) 676-8401, FTS 626-8401.

Avalable to the public from the National Technical Information Service, U.S. Depertment of Commerce, 6286 Port Royal Rd., Springfield, VA 22161.

This report was prepared as an eccount of work eponsored by an econcy of the United States Covemment. Noither the Unitted States Covernment nor eny eosncy thereof, nor any of thich employece, makes any warranty, expreces or implied, or aseumes any logal liability or respondiblity for the eccuracy, com pieteneses, or veotuneses of any information, apperatus, product, or proceses dir ctoeed, or represente that its ues would not infinges privatchy ouned nightes. Poterence herein to any epecific commercial product, proceses, or eervice by trede name, tredemark, manufacturer, or otherwibe, does not neceseartly conetttute or imply its endoreement, recommendation, or favoring by the Unithed States Government or any agency thereof. The views and opinione of authore expresesed herein do not necesearlly state or reflect thoee of the United States Covernment or any agency thereot. 
Dist: UC-505, Mathematics and Computers
$\mathrm{K} / \mathrm{CSD} / \mathrm{TM}--95 / \mathrm{ReV} .1$

DE92 004110

\section{ENGINEERING DESIGN INFORMATION SYSTEM (EDIS)}

\section{USER'S MANUAL}

P. S. Smith

R. D. Short

Engincering Design Informntion Systems Section

Engineering and Production Management Systems

November 1991

COMPUTING AND TELECOMMUNICATIONS DIVISION

at

Oak Ridge K-25 Site

Post Office Box 2003

Onk Ridge, Tennessee 37831

Martin Marietta Bnergy Systems, Inc. managing the

Oak Ridge K-25 Site

Oak Ridge Y-12 Plant
Oak Ridge National Laboratory Paducah Gascous Diffusion Plant

under Contract No. DE-ACO5-84OR21400

and the

Portsmouth Gaseous Diffusion Plant under Contract No. DE-AC05-760R00001

for the

U.S. Department of Energy 


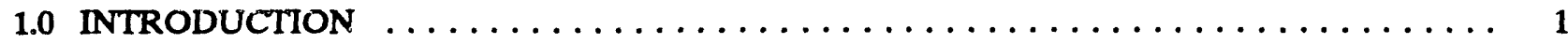

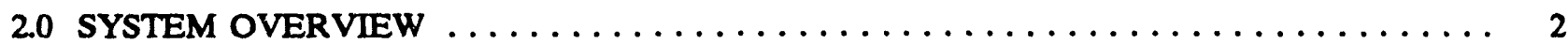

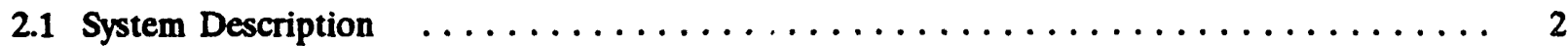

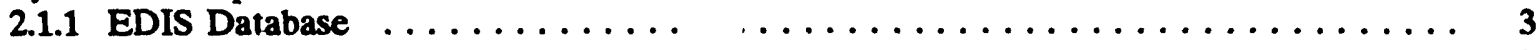

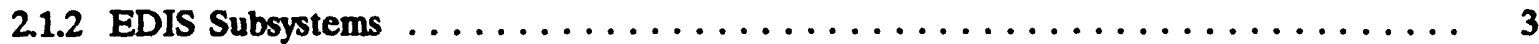

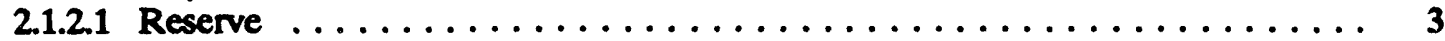

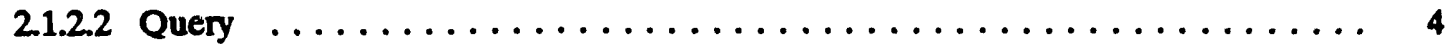

2.1.2.3 Active Design Database (ADDB) $\ldots \ldots \ldots \ldots \ldots \ldots \ldots \ldots \ldots$

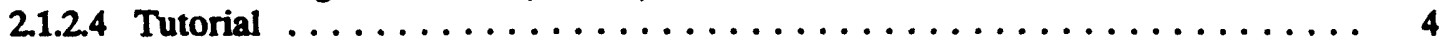

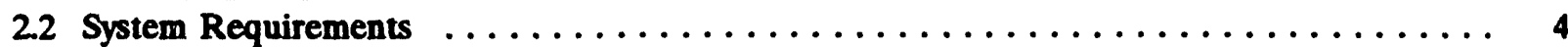

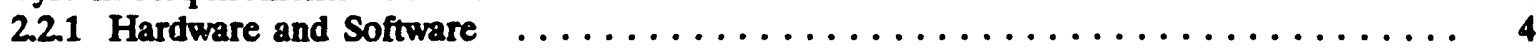

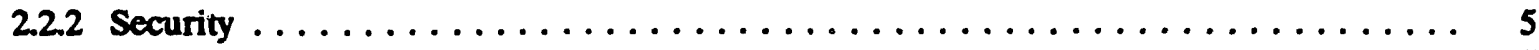

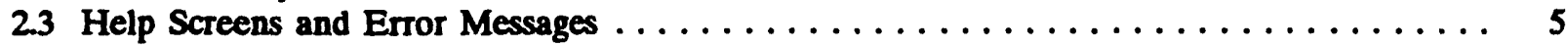

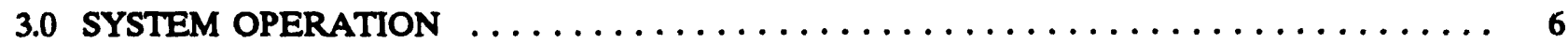

3.1 Conventions in System Commands and Keys $\ldots \ldots \ldots \ldots \ldots \ldots \ldots \ldots \ldots$

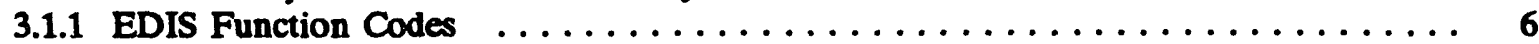

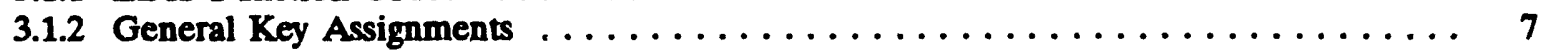

3.1.3 Special Screen Processing Features $\ldots \ldots \ldots \ldots \ldots \ldots \ldots \ldots \ldots \ldots \ldots \ldots \ldots \ldots$

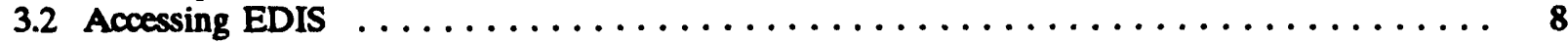

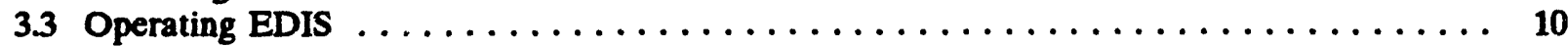

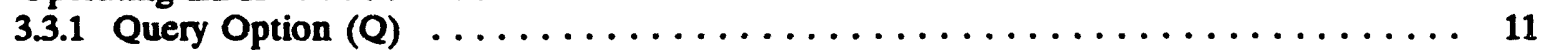

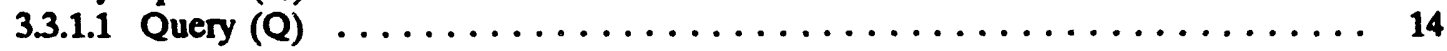

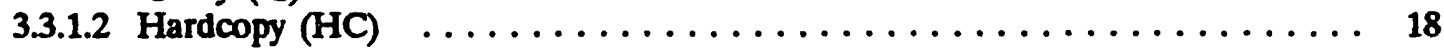

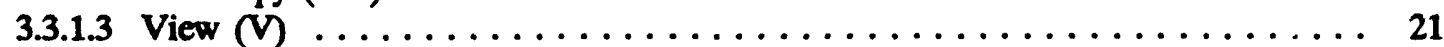

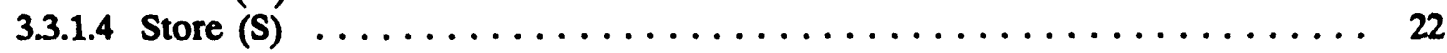

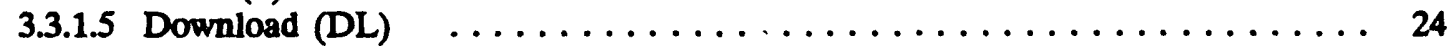

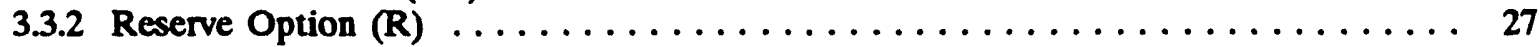

3.3.2.1 Reserve Document Numbers (Option 1) . . . . . . . . . . . . . 28

3.3.2.2 Reserve Revisions for Existing Documents (Option 2) . . . . . . . . . . . . 32

3.3.2.3 Select Reserved Documents/Revisions (Option 3) . . . . . . . . . . . 34

3.3.2.4 Reserve Engineering Job Numbers for Special Projects (Option 4) . . . . . . 38

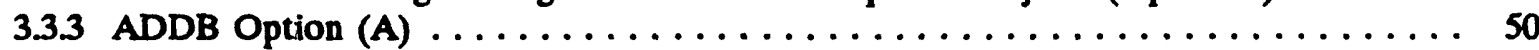

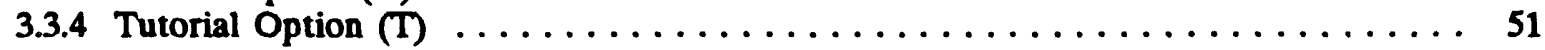

APPENDIX A: SPECIAL REQUIREMENTS FOR VIEWING

APPENDIX B: SOFT MASTER

APPENDIX C: SPECIAL REQUIREMENTS FOR STORE AND DOWNLOAD

APPENDIX D: HELP AND ERROR SCREENS

APPENDIX E: EDIS DATA DICTIONARY 


\subsection{INTRODUCTION}

This manual is a guide to the use of the Engineering Design Information System (EDIS). The system runs on the Martin Marietta Energy Systems, Inc., IBM 3084 unclassified computer. EDIS is in the second phase of implementation, which provides an index, storage, and retrieval system for engineering documents produced at various plants and laboratories operated by Energy Systems for the Department of Energy (DOE). The second phase also provides additional hard copy request functionality.

Section 2.0 of this manual presents an overview of EDIS, describing the system's purpose; the functions it performs; hardware, software, and security requirements; and help and error functions.

Section 3.0 describes how to access EDIS and how to operate system functions using Database 2 (DB2), Time Sharing Option (TSO), Interactive System Productivity Facility (ISPF), Soft Master viewing, and FT/Express file transfer features employed by this system.

Appendix $A$ lists the special hardware and software requirements that must be met to run the View function.

Appendix B contains a description of the Soft Master viewing capabilities provided through the EDIS View function.

Appendix $C$ contains a list of special hardware and software requirements for the Store and Download functions of EDIS.

Appendix D provides examples of the system error screens and help screens for valid codes used for screen entry.

Appendix E contains a dictionary of data elements and descriptions. 


\subsection{SYSTEM OVERVIEW}

\section{SYSTEM DESCRIPTION}

The Engineering Design Information System (EDIS) provides a means for reserving unique design document numbers (Reserve), locating released engineering design documents (Query), storing electronic document images in the EDIS repository (Store), downloading selected electronic formats of documents from the EDIS repository to an attached personal computer (PC) storage medium (Download), plotting (Hardcopy) or electronically viewing those stored in CADAM electronic format (View), and requesting hard copies of those released by the Information Services Division (ISD) Design Centers (Hardcopy). EDIS provides the ability to query the index on various document attributes. These system functions are summarized below.

The Reserve function of EDIS is used primarily to reserve unique design document numbers and revision codes. This function is required for all document types to establish initial identification in EDIS for document control and security. In the current Phase II development of EDIS, the Reserve function is used to standardize the alphanumerical identification of Design Drawing, Bill of Material, Equipment Specification, Equipment Data Sheet, and Design Analysis and Calculation documents. Ultimately, all Engineering design documents throughout the DOE plants and laboratories operated by Energy Systems will be included in this system. This is an attempt to eliminate duplicate, invalid, and unofficial document numbers, as well as to prevent the uncontrolled simultaneous revision of released documents.

The Query function of EDIS is used to obtain a list of documents meeting a desired selection criteria or to obtain detailed information about a specific document. To obtain this information, a user enters values for one or more selection fields. Documents contained in the EDIS database that have values matching those entered are displayed in the form of a table. Each of the documents shown in the table can be selected and queried to obtain additional detailed information about the document.

The EDIS View function is used to request a graphical display of those documents that have a graphical image stored in the EDIS repository. Currently, the ability to view documents is limited to design drawings that have an associated CADAM format stored in the EDIS repository.

The EDIS Hardcopy function is used to request copies of documents indexed into the EDIS database. Currently, the Hardcopy function is limited to requests for (1) copies of documents stored and maintained by the ISD Design Centers and (2) plots of documents stored in CADAM format.

The EDIS Store function is used to transfer electronic copies of selected documents from an attached PC storage medium to the EDIS repository. The store function is currently limited to documents that have been indexed into the system by ISD.

The EDIS Download function is used to transfer electronic copies of selected documents from the EDIS repository to an attached $\mathrm{PC}$ storage medium. 


\subsection{EDIS Database}

The basic information that is stored for each document in the EDIS Index and displayed on the system screens is defined by the following data elements:

Access Date
Anticipated Release Date
Block 48
Block 1
Block 50
Block 49
Building
Change Date
Change Control Number
Classification
Classification Date
Classifier ID
Company
Company Description
Configuration Control Number
Cost Center
Design Date
Designer
Disposition
Document Title
Document Type

Document Number
Draft Date
Draftsman
Drawing Size
EJN
ESO
Floor
Format Code
Function Code
Index Date
Initial Store Date
Issue Date
Last Store Date
Number of Sheets
Number of Models
Original Format
Originator Discipline
Originator ID
Originator's Company
Plant
Project Number

Reserve Date
Reserver ID
Responsible ID
Responsible Discipline
Revision Code
Revision Date
Send to EFM
Sequence Letter
Sequence Number
Sequence Letter Title
Sheet Number
Software Version
Special Project Title
Status Date
Status Code
Storage Location
Storage Date
Subject Code
Type of Package
Vendor Code
Workorder

A complete dictionary defining data elements retained by the system is presented in Appendix $E$.

\subsection{EDIS Subsistems}

EDIS functions are accessed through a Primary Option Menu that lists the Reserve, Query, ADDB, and Tutorial subsystems available in EDIS. Section 3.0 describes the screens and user actions for each of the EDIS subsystem functions. The following sections describe these major subsystems.

\subsection{Reserve}

The Reserve subsystem provides you with the capability to initiate the entry of new document information into the system. The Reserve main menu offers a variety of functions that govern the entry of and access to this initial document information. The following functions may be selected from the Reserve Menu:

1. Reserve one or more new document numbers.

2. Reserve revisions for any existing drawings.

3. Select a specific document:

a. To Query information about the document.

b. To Modify existing information about the document.

c. To Unreserve and return the number.

4. Reserve Engineering Job Numbers (EJNs) for Special Projects and query and modify EJN information.

The operation of these functions is described in Sect. 3.3.2 of this user's manual. 


\subsection{Query}

This subsystem allows you to display index information for documents that exist in the EDIS Index based on data element values you enter into a query screen. Once you loc te a document index record(s), you may select to do further query, to make a hard copy request, to store the document, to download the document, or to view a graphical display of the document. The operation of these functions is described in Sect. 3.3.1 of this user's manual.

\subsection{Active Design Database (ADDB)}

The ADDB provides the capability to perform query functions on active CADAM models or on those models that currently reside in user subgroups. This capability allows for the sharing of design information, provides identification of duplicate design activity, and assists in detection of the use of duplicate revision codes for a drawing. This capability can also be used in clean-up efforts to identify models that have not been updated since a specified date.

\subsection{Tutorial}

This feature is only provided with the Reserve subsystem of the Phase II implementation of EDIS. The Reserve subsystem tutorial can be viewed in its entirety or in segments that describe the procedures to follow for each individual Reserve subsystem screen. Refer to Sect. 3.3.4 for a description of the Tutorial feature.

\section{SYSTEM REQUTREMIENTS}

\section{Hardware and Software}

EDIS is located on the IBM 3084 unclassified processor located at the Oak Ridge K-25 Site. EDIS is accessed via asynchronous communication over the unclassified DCA network using VT-100-type terminals or microcomputers equipped with VT-100 emulation software as follows:

1. An ASCII terminal connection to the IBM 7171 (System Select 47) through the unclassified DCA network for the 3084 unclassified system or a microcomputer with communications software (e.g., SmarTerm).

2. An IBM 3270-type terminal or a microcomputer equipped with 3270 emulation, such as IRMA, connected through coaxial cable or an IBM token ring network.

PL/ is the primary programming language used for EDIS. The following vendor software packages are used:

1. ISPF Dialog Manager - User interface screens

2. DB2 relational database - Repository for EDIS data

3. Soft Master - Viewing capability

4. FT/Express - Store and Download capabilities.

All vendor software packages currently reside on the IBM 3084 . 


\section{Security}

To access the system, you must have a user ID, a computer password, and an authorized TSO account on the IBM 3084 computer at K-25. You also must be given specific access to EDIS by the Engineering Data Resource Administrator (DRA). Security is enforced through user identification at the time of logon and through authorization tables that exist within EDIS to define the functions that are permitted to be performed by each user of the system.

Each EDIS user is given access to EDIS and specific access to documents for specific plants by the Engineering DRA. This requires that an EDIS Access application be submitted to the Engineering DRA by each user's supervisor. User access control information is obtained from the Engineering Management Information System (EMIS). Engineering information, including EMIS user IDs, is written to a DB2 table that is used to control access to the EDIS data.

\section{HEIP SCREENS AND ERROR MESSAGES}

Help screens are available throughout the system to prompt you with valid codes for buildings, engineering personnel, document formats, plotter IDs, companies, classifications, plants, document types, etc. These screens may be accessed by placing a "?" in the code field and pressing <ENTER>. The help screens are displayed in Appendix D of this user's manual.

A help screen of valid EDIS command and selection codes to be used in operating the interactive system screens can be obtained by typing "?" in the COMMAND line of any screen and pressing <ENTER>. Refer to Appendix D for this help screen. When this screen is displayed, only the valid codes appropriate fo: the current screen will be shown.

Help is also available for the Reserve subsystem in the form of an online tutorial that can be accessed from any screen by typing HELP or $H$ in the COMM the Tutorial option fom the Primary Option Menu (see Sect. 3.3.4).

Error screens for certain special cases are also displayed in Appendix D.

Error messages are displayed to you on the system screens just below the COMMAND line whenever an invalid command or invalid information is entered. Messages that confirm the system's execution of functions you have requested are also displayed on the screen just below the COMMAND line. 


\subsection{SYSTEM OPERATION}

\subsection{CONVENTIONS IN SYSTEM COMMANDS AND KEYS}

System operations are performed using a series of data display, selection, and/or entry screens. The system performs the tasks you request by guiding you from one screen to the next based upon your responses to the prompts. You can make selections from a displayed menu by entering requested data and pressing the <ENTER> key or by entering one of the EDIS function command codes (shown below) in the indicated command field and pressing the <ENTER> key. Section 3.1.1 lists the EDIS function codes and their associated system responses. Section 3.1.2 lists the general key assignments and their associated functions.

\subsubsection{EDIS Punction Codes}

The system screens are operated from a COMMAND line, which is the second line of each screen. The commands that may be entered on this line are listed below. Command keys are enclosed in angle brackets (e.g., <ENTER >) that indicate you should press a single key to perform the action.

\begin{tabular}{|c|c|c|c|}
\hline \multicolumn{3}{|c|}{ Command or Code and Press } & Action \\
\hline END & $\mathbf{E}$ & <ENTER> & $\begin{array}{l}\text { Terminates the present screen or function and returns to the } \\
\text { previous screen or function accessed. }\end{array}$ \\
\hline UP & UP & $<$ ENTER > & 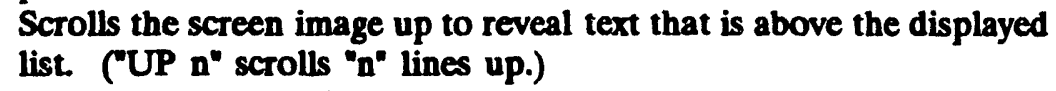 \\
\hline DOWN & DN & <ENTER> & $\begin{array}{l}\text { Scrolls the screen image down to reveal text that is below the } \\
\text { displayed list. ("DOWN } n \text { " scrolls " } n \text { " lines down.) }\end{array}$ \\
\hline $\begin{array}{l}\text { EXIT } \\
\text { HELP }\end{array}$ & $\begin{array}{l}\mathbf{X} \\
\mathbf{H}\end{array}$ & $\begin{array}{l}<\text { ENTER> } \\
\text { <ENTER> }\end{array}$ & $\begin{array}{l}\text { Returns to the Primary Option Menu from any other system screen. } \\
\text { Calls the EDIS on-line tutorial. (Only available in Phase II for the } \\
\text { Reserve subsystem.) }\end{array}$ \\
\hline
\end{tabular}

The following function codes are used in the Select field of screens that display document listings. These functions will be performed for the documents selected from the screen. (The commands can be entered on the COMMAND line if an $\mathrm{X}$ is placed in the Select field.)

\begin{tabular}{|c|c|c|c|}
\hline Command or & Ode & and Press & Action \\
\hline MODIFY & $\mathbf{M}$ & $\langle$ ENTER $>$ & Modifies an existing document or project information. \\
\hline QUERY & $\mathbf{Q}$ & $\langle$ ENTER> & Displays document information. \\
\hline HARDCOPY & HC & <ENTER> & Requests a hard copy of the selected document. \\
\hline VIEW & $\mathbf{v}$ & <ENTER> & Displays electronically stored documents. \\
\hline STORE & $\mathbf{s}$ & <ENTER> & $\begin{array}{l}\text { Transfers an electronic copy of a ducument from an attached PC } \\
\text { storage medium and stores the copy in the EDIS repository. }\end{array}$ \\
\hline DOWNLOAD & DL & <ENTER> & $\begin{array}{l}\text { Downloads an electronic copy of a document to an attached PC } \\
\text { storage medium. }\end{array}$ \\
\hline UNRES & $\mathbf{U}$ & $<$ ENTER > & $\begin{array}{l}\text { Unreserves a previously reserved number. (Used in the Reserve } \\
\text { subsystem only.) }\end{array}$ \\
\hline
\end{tabular}




\subsubsection{General Key Assienments}

Command keys and their functions to operate cursor movement on the screen are listed below:

\begin{tabular}{|c|c|}
\hline Command Key & Function \\
\hline <ARROW-DOWN $\rangle$ & Moves cursor down one line directly below the current cursor position. \\
\hline <ARROW-LEFT > & Moves cursor one space to the left of the current cursor position. \\
\hline <ARROW-RIGHT> & Moves cursor one space to the right of the current cursor position. \\
\hline <ARROW-UP> & Moves cursor up one line directly above the current cursor position. \\
\hline <BACKSPACE> & Moves cursor one space to the left of the current cursor position. \\
\hline <DELETE> & $\begin{array}{l}\text { Deletes character on which the cursor currently rests and moves all characters } \\
\text { on the right of the cursor one space to the left. }\end{array}$ \\
\hline$<$ ENTER > & Executes the system command that was entered. \\
\hline <RESET > & $\begin{array}{l}\text { Unlocks keyboard when the system displays the locked symbol in the lower-left } \\
\text { corner of the screen. (Applies to connections using IRMA.) }\end{array}$ \\
\hline $\begin{array}{l}<\text { SHIFT }><\text { TAB }> \\
<\text { TAB }>\end{array}$ & Moves cursor back to the previous sequential field on the screen. \\
\hline
\end{tabular}

\subsubsection{Special Screen Processing Features}

\section{Search Screens}

For the entry of partial search criteria on search screens, a "\%" sign can be used as a wild-card to represent unknown characters located before, after, or in the middle of a known string of characters. The system will search all records that contain the search string in the indicated position.

When using Code Help screens (see Appendix D) to find valid codes to use for search entries while using one of the system's search screens, do not select directly from the code listing screen if you have not completed entering search criteria on the search screen. Return to the search screen using the END command, and then, type the chosen value directly on the search screen. If the code and $<$ ENTER $>$ are entered on the help screen, the search will be executed with only the search criteria existing at that time.

\section{System Code Help Screens}

You may enter "?" in some of the input fields of the system screens to receive a help screen listing valid input options for that field. These fields include document type, plant, building, classification, block 48, block 49, block 50, etc. See Appendix D for examples of these screens. In most cases, you may select from the list in one of two ways: either by placing an $\mathrm{X}$ beside the desired option or by entering the indicated response code. The system will return you to the original screen, and the data for the input option selected will be placed in the original screen's input field just as if you had entered the characters directly into the field manually. If you press $<E N T E R>$ while one of these list screens is displayed without having made a selection, the system will display a message requesting a selection. If you enter END in the command field of any of these list screens, the system will redisplay the screen where the "?" was originally entered, place the cursor at that field, and continue processing as required.

\section{EMIS ID Help Screens}

For input fields that require EMIS IDs to be entered, you may enter "?" and press <ENTER> to receive the Engineering Personnel Help screen. This screen allows you to enter search criteria consisting of a portion of a person's name and to receive a second screen listing the EMIS IDs and the associated names that meet the search criteria you entered. You may then select an entry from this list for the needed EMIS ID. 


\subsection{ACCESSING EDIS}

To access EDIS, you must have a user ID, a computer password, and an authorized TSO account on the IBM 3084 machine.

Several types of terminal connections may be ussd to access the 3084, as described in Sect. 2.2.1. To $\log$ on the K-25 IBM 3084 unclassified system using one of these terminal connections, follow one of the procedures described below. Responses enclosed in parentheses ( ) indicate that you should fill in the appropriate variable information.

NOTE: Whenever the system displays *** at the bottom of tuxt, you must press <ENTER> to continue.

1. For the 7171 connection to the K-25 system, answer the following prompts with the indicated responses:

\section{Prompt}

Which System (1 thru 55)?

enter terminal type:

THIS TERMINAL IS ATTACHED TO ...

\section{Response}

$47<$ ENTER> $<$ ENTER $>$

(type) $<$ ENTER >*

TSOK <ENTER>

-The (type) response for this terminal type is almost aiways VT100.

2. For the 3270-type terminal with coaxial or token ring connection, respond to the prompt as shown below:

\section{Prompt}

THIS TERMINAL IS ATTACHED TO THE ...

\section{Response}

TSOK <ENTER>

After entering the TSOK command for each of these log-on sequences, you will receive prompts for user ID and password:

\section{Prompt}

ACF82003 ACF2, ENTER LOGON ID

ACF82004 ACF2, ENTER PASSWORD

ACFo2012 ACF2, ENTER ACCOUNT

(Displayed if no default account

has been set up.)

\section{Response}

(user ID) <ENTER>

(user password)

<ENTER>

(account number)

<ENTER> 
If the log-on session is successful, you will receive TSO log-on messages followed by the TSO prompt:

\section{READY}

To access EDIS, type

EDIS <ENTER>

The EDIS Primary Option Menu shown on the next page will be displayed if you have been given proper access to EDIS by the Engineering DRA. 


\section{OPERATING EDIS}

When you have gained access to EDIS, the following menu will be displayed, from which you may select the system functions.

\section{PRIMARY OPTION MENU}

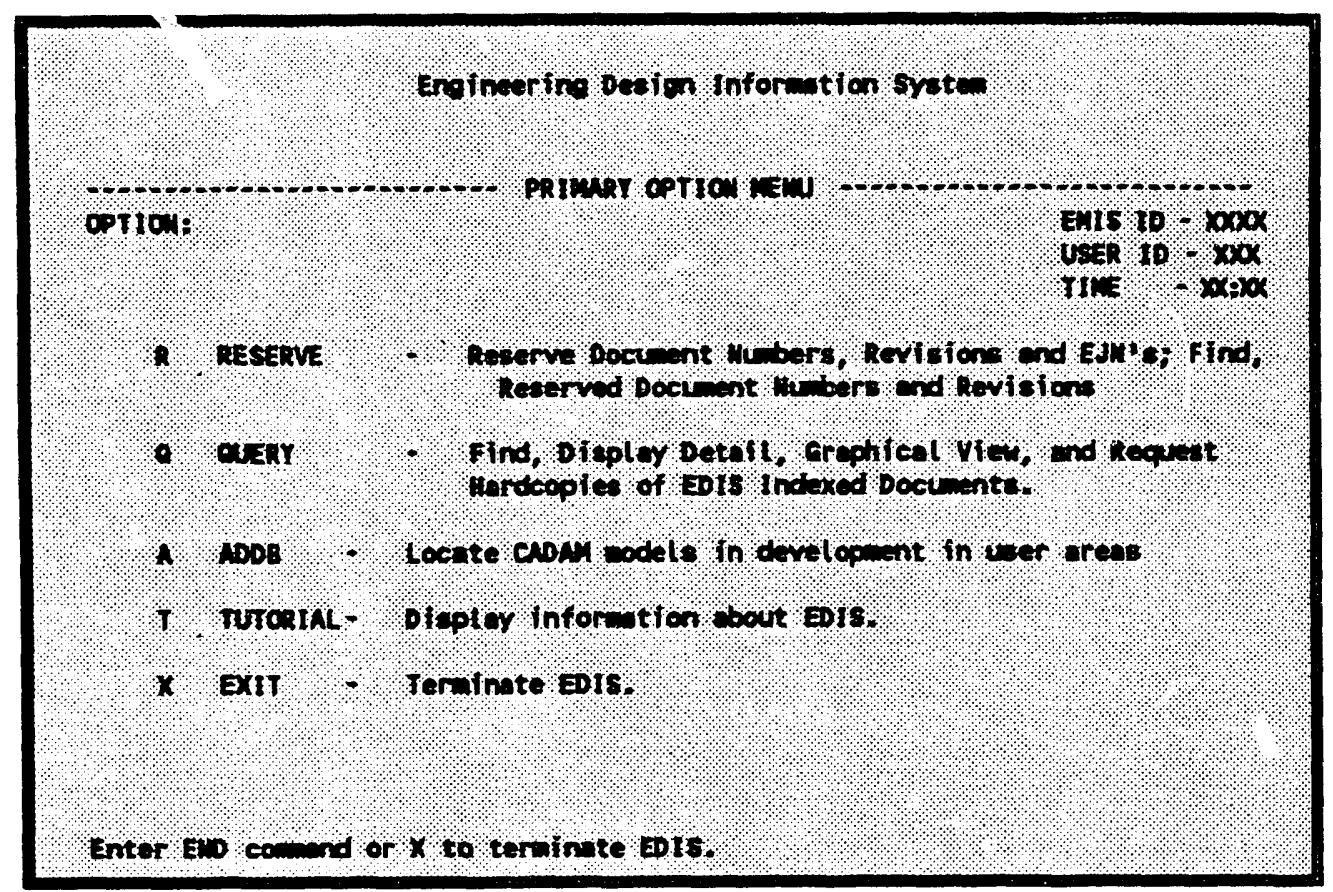

You can indicate the function to be performed by typing the option character $(R, Q, A, T$, or $X)$ on the OPTION line and pressing <ENTER>. The following sections of this manual describe the operation of the Primary Option Menu options. Refer to the table below to find the manual section that covers each option.

\section{Option}

$\mathbf{R}$

$\mathbf{Q}$

A

T

\section{Action}

RESERVE (see Sect. 3.3.2).

QUERY (see Sect. 3.3.1).

ADDB (see Sect. 3.3.3).

TUTORIAL (see Sect. 3.3.4). (This option is only available for the Reserve subsystem.)

Entering option X or the command END and pressing <ENTER > will exit EDIS and return you to the system READY prompt. From the READY prompt, type "LOGOFF" to exit TSO. 


\subsubsection{Qvery Option (Q)}

The Query option on the EDIS Primary Menu allows you to find and display index information for documents that exist in the EDIS Index based on data element values you enter into a query screen. Once you locate a document index record(s), you may select to do further query, store, or download an electronic copy of the document, request a hard copy, or view a graphical display of the document.

When you select option $Q$ from the EDIS Primary Menu, the following screen will be displayed to allow you to enter search criteria:

\section{QUERY SCREEN}

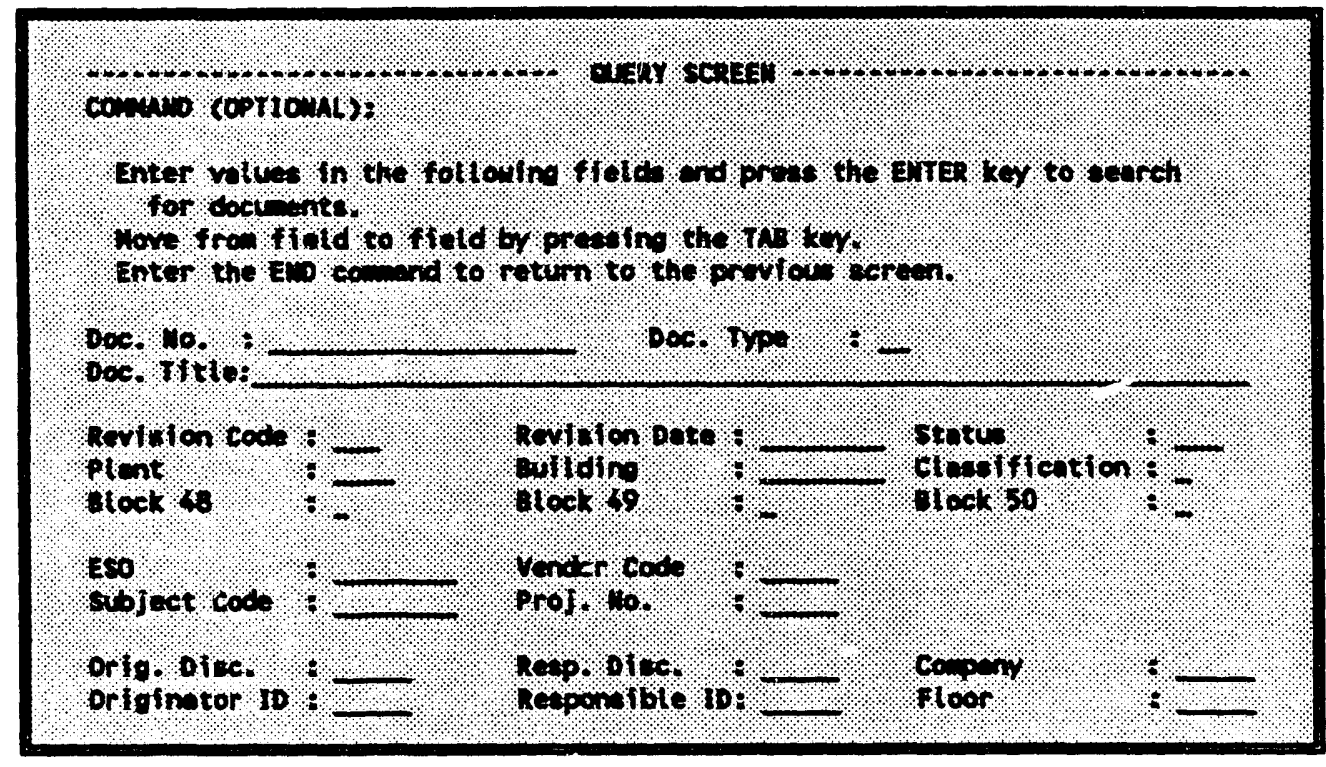

Use the $<\mathrm{TAB}>$ and $<\mathrm{SHIFT}><\mathrm{TAB}>$ keys to move between the blank fields on the screen to enter search values into the fields. When all values have been entered, press <ENTER> to begin the search. It is not necessary to enter information in every field. You should, however, enter enough information to obtain the desired result. In general, entering more information will produce a narrower search, and the resulting list of documents will be shorter and more specific. Valid values entered in the Doc. No., Doc. Type, and Revision Code fields uniquely identify a document; therefore, any information entered in addition to the document type and document number is unnecessary if the goal of the query is to locate a particular revision of a document. However, if the goal of the query is to locate all of the latest revisions of all design drawings related to a particular building, you should enter "DD" in the Doc. Type field and the building number in the Building field and press <ENTER>.

Seven fields on this screen will accept partial entries if the whole value is not known: Doc. No., Doc. Title, Building, ESO, Vendor Code, Subject Codc, and Proj. No. A "\%" sign can be used as a wild-card to represent unknowi characters located before, after, or in the miudle of a known string of characters. Using a "\%" symbol to terminate a partial Building field entry will allow a search of a group of buildings starting with the same characters.

The system will search the database for any released documents that fulfill the values you enter and either show you the document information (Detail Document Information Screen) or a list of the documents that are found (Abbreviated Document Information Screen). (These screens are described in the following 
text.) If you do not specify a revision number in the revision code field, only the latest revision of documents meeting the entered search criteria will be displayed. If you enter an asterisk (") in the revision code field, all revisions of each document meeting the entered search criteria will be shown.

If no documents are found that match the entered values, the Query Screen will be redisplayed with a message stating that no documents meet the search criteria. If you press <ENTER> without entering values in any of the input fields, the screen will be redisplayed with a message requesting entry of search fields. Enter END in the command field and press <ENTER> if you wish to cancel this function and return to the Primary Option Menu.

When more than one document satisfies the search criteria you enter, the system will display the partial index information for the documents on the following Abbreviated Document Information Screen, in order by document number and revision.

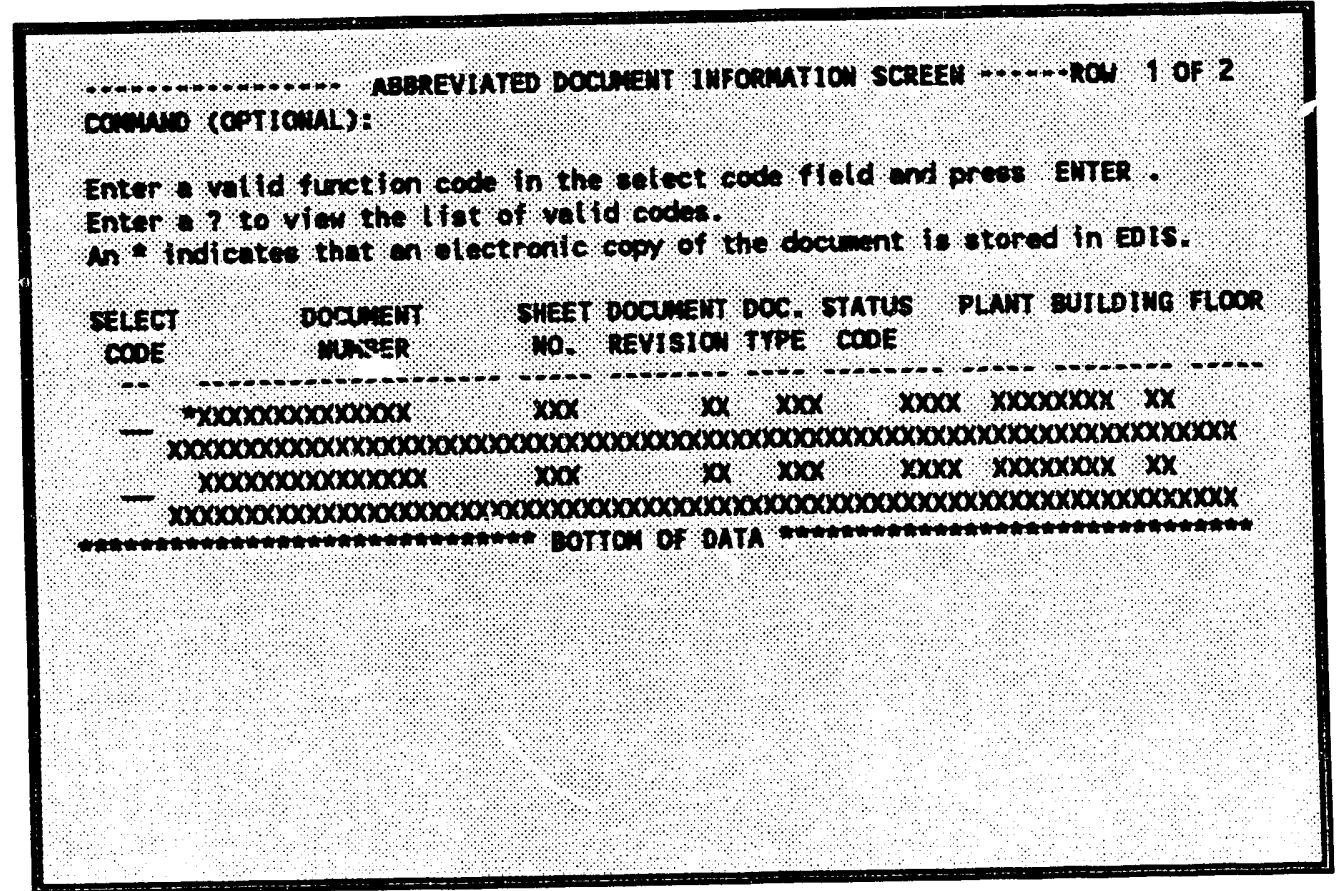

If more documents are listed than can be viewed on one screen, enter UP or DOWN on the COMMAND line and press <ENTER > to scroll the rest of the list onto the screen. The prompt "ROW OF -" in the upper right corner of the screen tells you how many rows are included on the list. If more than $2 \overline{40}$ documents satisfy the search criteria you enter, the system will display the partial index information for the first 240 documents found on the Abbreviated Document Information Screen with a message requesting additional search criteria to help narrow the search. The END command will end the Abbreviated Document listing and return you to the Query Screen.

You may select one or more of the listed documents for further query, harisisy request, or graphical display by entering one of the following codes in the SELECT CODE field directly beside the ducument(s) and pressing <ENTER>. [A help screen of these and other EDIS codes will be displayed if you type "?" in the COMMAND line and press <ENTER> (see Appendix D).] 


\section{Function}

Q

Query - Displays a screen of more detailed index information (see Sect. 3.3.1.1).

HC

Hardcopy - Sends a requast to the ISD Document Center for a hard copy of the drawing or plots a copy of a CADAM drawing at a user-specified remote plotter (see Sect. 3.3.1.2).

$\mathbf{V}$

View - Permits a Soft Master graphical display of the drawing if it exists in EDIS (as noted by "* just to the left of the document number) (see Sect. 3.3.1.3 and Appendix B).

$\mathbf{S}$

Store - Transfers an electronic copy of a document from an attached PC storage medium to the EDIS repository (see Sect. 3.3.1.4).

DL Download - Transfers an electronic copy of a document from the EDIS repository to an attached PC storage medium. (see Sect. 3.3.1.5).

NOTE: You may also select one or more documents from the list using an $X$ instead of a letter in the SELECT CODE field. Then, enter the $Q, H C, S, D L$, or $V$ command on the COMMAND line and press <ENTER>. Doing so will apply the $Q, H C, S, D L$, or $V$ command to all those documents marked with an $X$.

If multiple documents are selected from this list, the system will process them, one by one, in the order in which they are listed and then retur you to the Abbreviated Document Information Screen when finished.

If you have not been given proper authority to access any of the documents listed, the titles of those documents will not be displayed. If you request a hard copy, attempt to store or download, or request to view any of these documents, an error message will be displayed, and your request will be denied.

Additional restrictions apply to the use of the View function. Please refer to Sect. 3.3.1.3 for an explanation of these restrictions.

The Query, Hardcopy, View, Store, and Download functions are presented in Section 3.3.1.1, 3.3.1.2, 3.3.1.3, 3.3.1.4, and 3.3.1.5, respectively, along with the screens that are displayed for each function. 


\subsubsection{Opery (0)}

When a search from the Query Screen finds only one document or when you enter the $Q$ function code for a specific document on the Abbreviated Document Information Screen, the following screen is displayed containing detailed index information for the selected document:

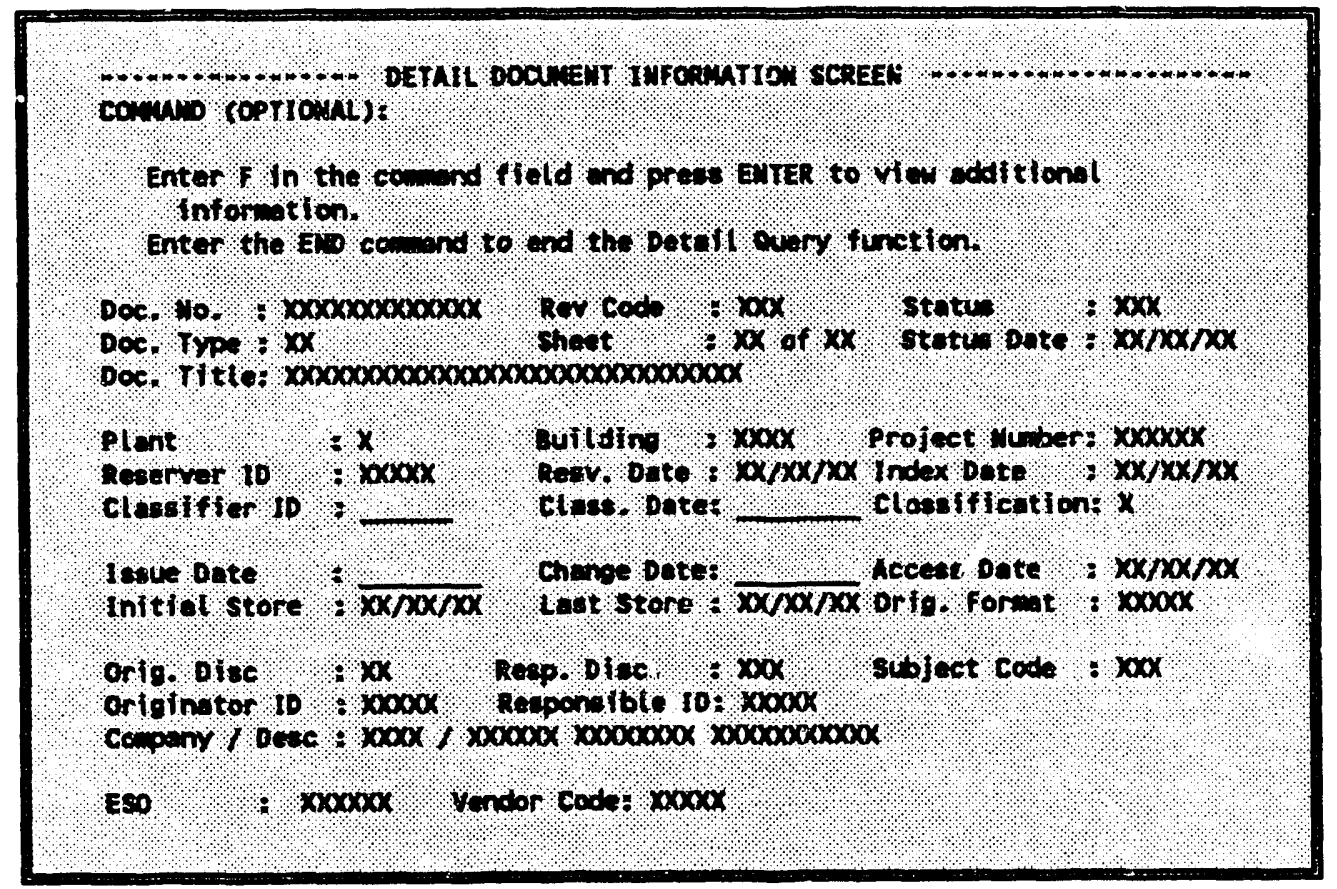

The information supplied on this screen is standard for all document types in the EDIS Index and is provided for display only. If you have not been given proper authority to access this document, the title and project number will not be shown. No changes can be made to the displayed information using this function. To exit the Detail Query function, enter END and <ENTER > on the COMMAND line, and you will be returned to the previous screen (Abbreviated Document Information Screen or the Document Query Screen).

The HC, V, S, and DL codes can be entered on the COMMAND line of this screen to obtain a hard copy of this document, view a graphical display of the drawing, and store or download an electronic copy of the document. These functions are described in detail in Sects. 3.3.1.2, 3.3.1.3, 3.3.1.4, and 3.3.1.5, respectively. If you have not been given proper authority to store, download, view, or receive a hard copy of this document, a message indicating this fact will be displayed if you enter either the HC, V, S, or DL codes. Additional restrictions apply to the use of the View function (refer to Sect. 3.3.1.3).

If the displayed document is a design drawing, you can type $F$ and $<$ ENTER $>$ to receive additional screens of information containing (1) more design information and (2) a list of formats associated with the document. These two additional screens are described below as numbered. 
1. If you type $F$ to request additional information for a design drawing, the system will display the additional index information for this document on the Detail Document Information Screen 2.

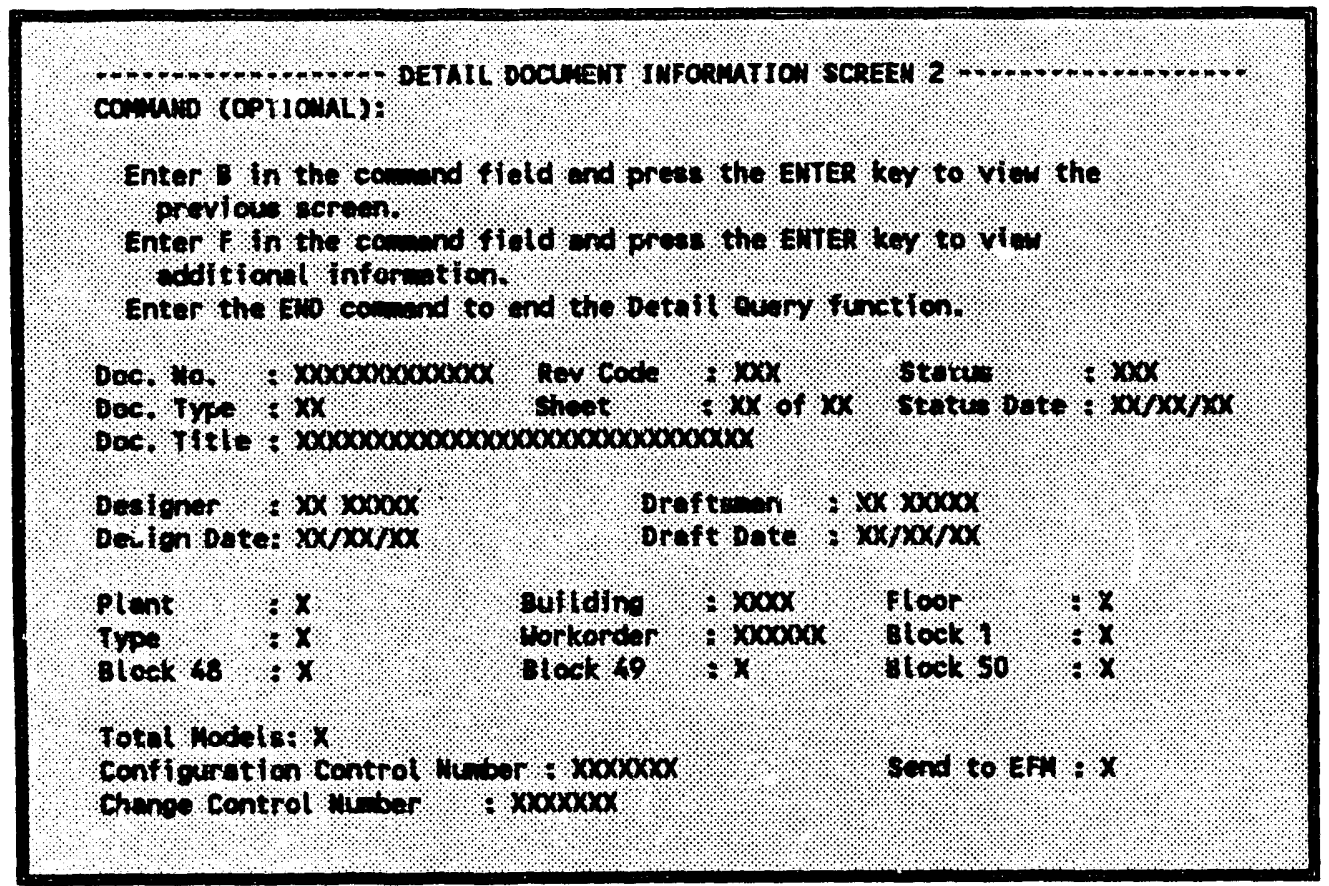

This information is provided for display only and cannot be changed. The END command will end the Detail Query function and return you to either the Abbreviated Document Information Screen or the Document Query Screen from which the function was requested. If you have not been given proper authority to access this document, the title will not be shown.

The HC, V, S, and DL codes can be entered on the COMMAND line of this screen to obtain a hard copy of this document, view a graphical display of the drawing, and store or download an electronic copy of the document. These functions are described in detail in Sects. 3.3.1.2, 3.3.1.3, 3.3.1.4, and 3.3.1.5, respectively. If you have not been given proper authority to storc, download, view, or receive a hard copy of this document, a message indicating this fact will be displayed if you enter the $\mathrm{S}, \mathrm{DL}, \mathrm{HC}$, or $\mathrm{V}$ codes. Additional restrictions apply to the use of the View function (refer to Sect. 3.3.1.3).

Enter the B or F codes in the COMMAND line and press <ENTER> to either back up to the prior screen of information for this drawing or continue forward to the Document Format Listing screen described in (2) below. 
2. The Query Function - Document Format Listing Screen displays a listing of all the formats in which this document is stored and their associated storage locations. It is displayed when you enter an $F$ in the COMMAND line of either of the two previous Detail Document Information screens, depending upon the document type.

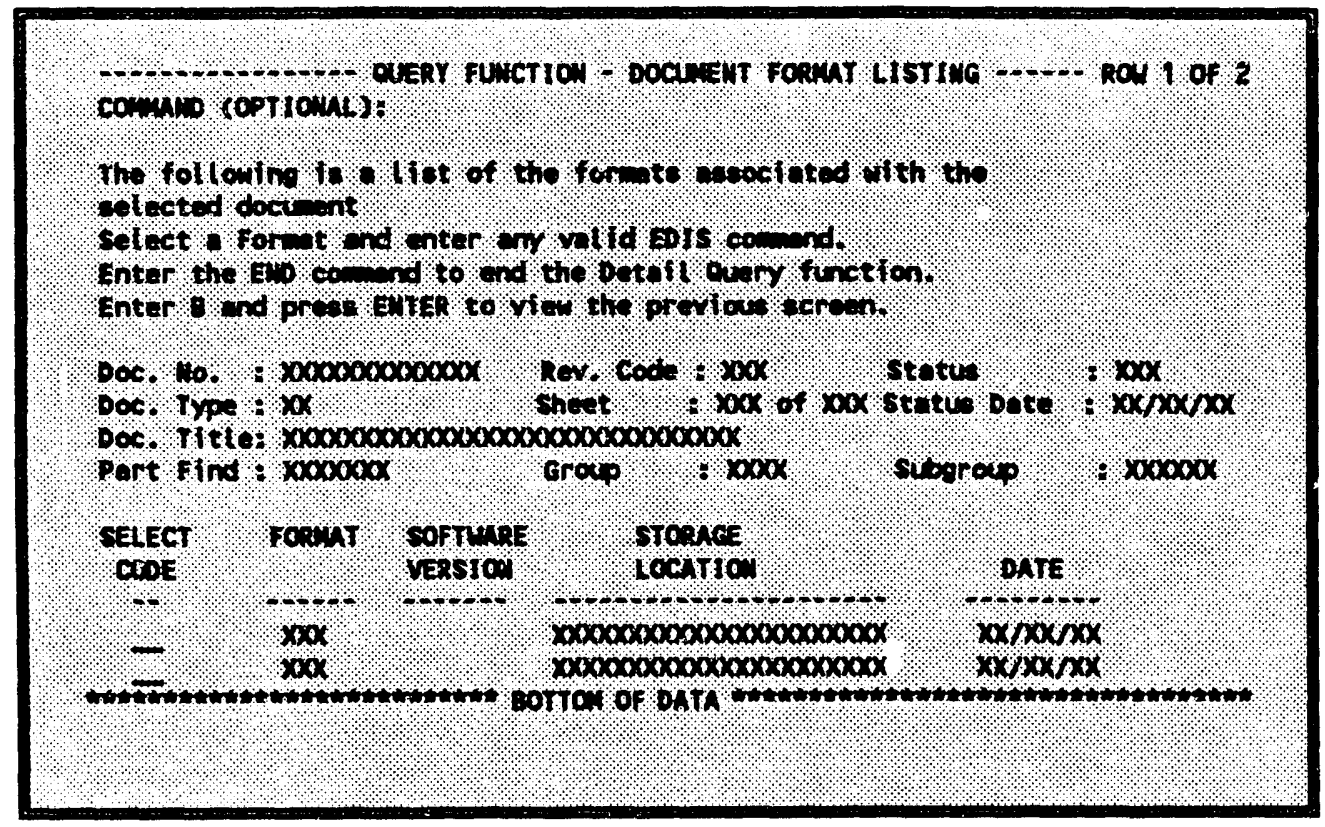

If the selected document is a CADAM drawing stored in the EDIS repository, the part find number, group, and subgroup will be displayed. Otherwise, this information will not be shown.

If more formats are listed than can be viewed on one screen, enter UP or DOWN on the COMMAND line and press <ENTER > to scroll the rest of the list onto the screen. The prompt "ROW _ OF _" in the upper right corner of the screen tells you how many rows are included on the list. Enter B and <ENTER> in the COMMAND line of the screen if you wish to redisplay the prior screen of information for this document.

The END command will end the Detail Query function and return you to the Abbreviated Document Information Screen.

You may select one of the listed formats for further graphical display, store, download, or hardcopy request by entering either the View (V), Store (S), Download (DL), or Hardcopy (HC) function codes in the SELECT CODE field directly beside the format and pressing <ENTER>. The HC command either sends an electronic request to the ISD Document Center for a hard copy or initiates a remote plot of the drawing selected. The $\mathrm{V}$ command permits a Soft Master Graphical display of the documen' if it exists in EDIS. The S command permits you to transfer an electronic copy of the indexed document from an attached PC storage medium to the EDIS repository. The DL cornmand allows you to transfer an electronic copy of an indexed document from the EDIS repository to an attached PC storage medium. (You may also perform the same operation by entering the function code in the COMMAND line and indicating the desired format by entering an " $\mathrm{X}$ " in the SELECT CODE field directly beside the format and pressing $<$ ENTER $>$ ). 
A help screen of the above valid EDIS codes will be displayed if you type "?" in the COMMAND line or SELECT CODE field and press <ENTER>.

If you have not been given the proper authority to access the selected document, you will not be allowed to store, download, view the graphical display, or request a hard copy of the document. If you attempt to do so, an error message will be displayed indicativg that you lack the necessary authority. Additional restrictions apply to the use of the View function (refer to Sect. 3.3.1.3). 


\subsubsection{Hardoopy (HC)}

The Hardcopy command provides the ability to request either (1) a copy of an ISD Design Center document stored in a MANUAL or FILM format or (2) a plot of a selected document that has been stored in EDIS in a CADAM format. The Hardcopy function can be requested for a selected document from the Format Listing Screen, the Abbreviated Document Listing Screen, or either of the Detailed Document Information Screens. If a hard copy is requested for a document that is not available in a CADAM, MANUAL, or FILM format, the screen from which the Hardcopy function was requested will be redisplayed with an error message.

If the document selected from one of the above screens is available in only one of the three formats, either the ISD Copy Request Screen or the Plot Request Screen is displayed to allow you to define your request (see the following two pages of this manual). If the selected document has several formats, the following Hardcopy Options Screen is displayed to allow you to choose the format for your request. This screen is also displayed from the Format Listing Screen if the format you selected for hard copy is not a valid hard copy format: this screen will tell you which hard copy formats are available for that document.

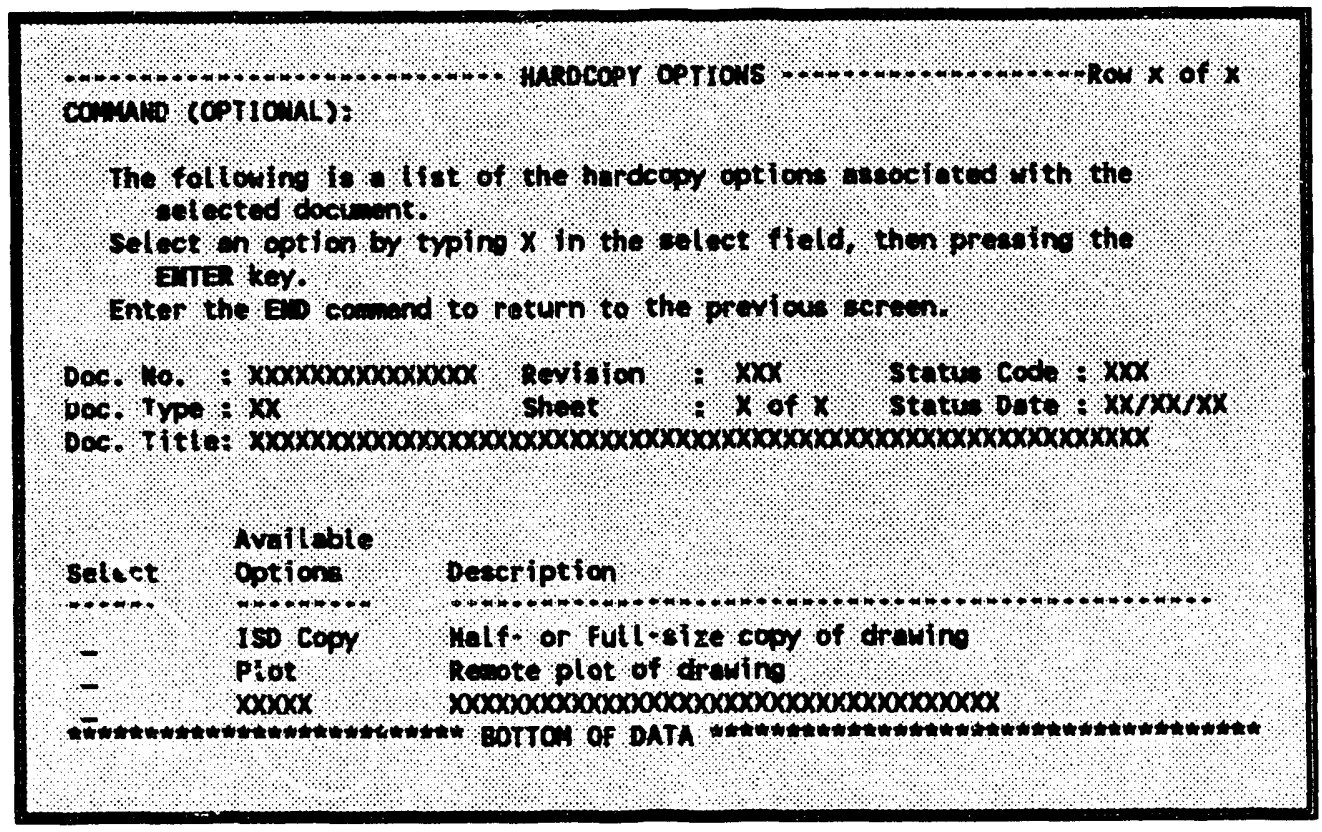

You may select one of the Available Options by entering an " $\mathrm{X}$ " in the Select field beside the desired option and pressing <ENTER>. One of the two following screens will be displayed as appropriate. (To cancel your request at this point and return to the previous listing screen, enter END and <ENTER $>$ on the COMMAND line.) 


\section{ISD Copy Request}

When a Haricopy is requested for a MANUAL or FILM format copy of a document then the following ISD Copy Request screen will be displayed with summary information for the selected document at the top of the screen.

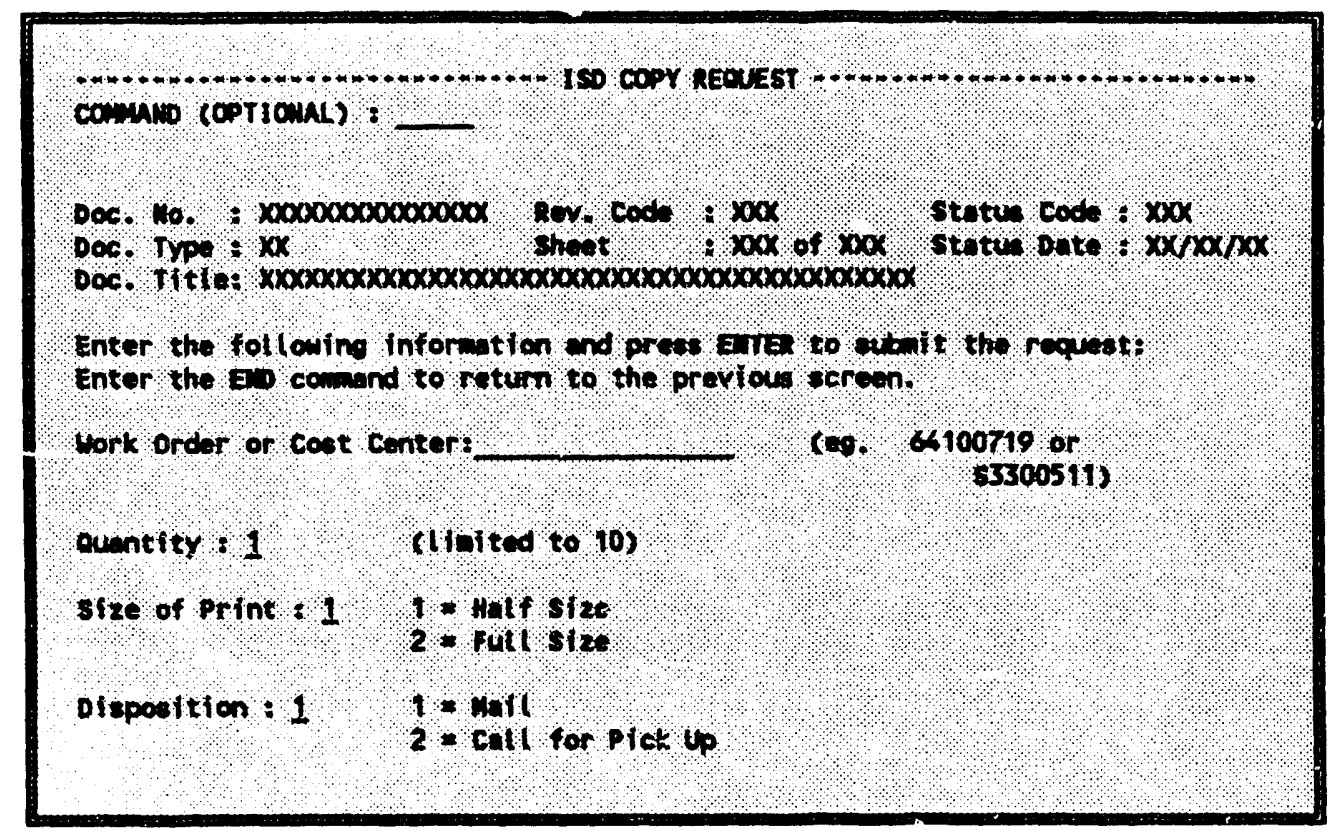

Use the $<\mathrm{TAB}>$ and $<\mathrm{SHIFT}><\mathrm{TAB}>$ keys to move the cursor between data fields on the bottom of the screen to enter your request. You must enter a charge number to request a hard copy of a document. You are allowed to modify the displayed default values for the following data items:

\section{Field}

Quantity Description

Size of Print Enter number of paper copies desired. This is limited to 10 copies per request.

Disposition Specify whether the document is to be printed in (1) Half- or (2) Full-Size form. Specify whether (1) the output is to be mailed to your address or (2) you wish to be called to pick up the output.

When all data are complete on the screen, press <ENTER > to validate the data. If there are invalid data on the screen, an error message will be displayed, and you will be prompted to correct the data. If all input is valid, your request will be processed and you will be returned to the previous screen from which this screen was accessed. 


\section{Plot Request}

When a Hardcopy is requested for a CADAM format copy of a document, the following Plot Request screen is displayed with summary information for the selected document at the top of the screen. The charge number you used for your last plot request will be displayed as the initial charge number for this request. The last plotter ID you selected will be displayed as the plotter for this request. If you have never requested a plot, your default TSO account number will be presented as the initial charge number for plotting and the plotter ID will be blank.

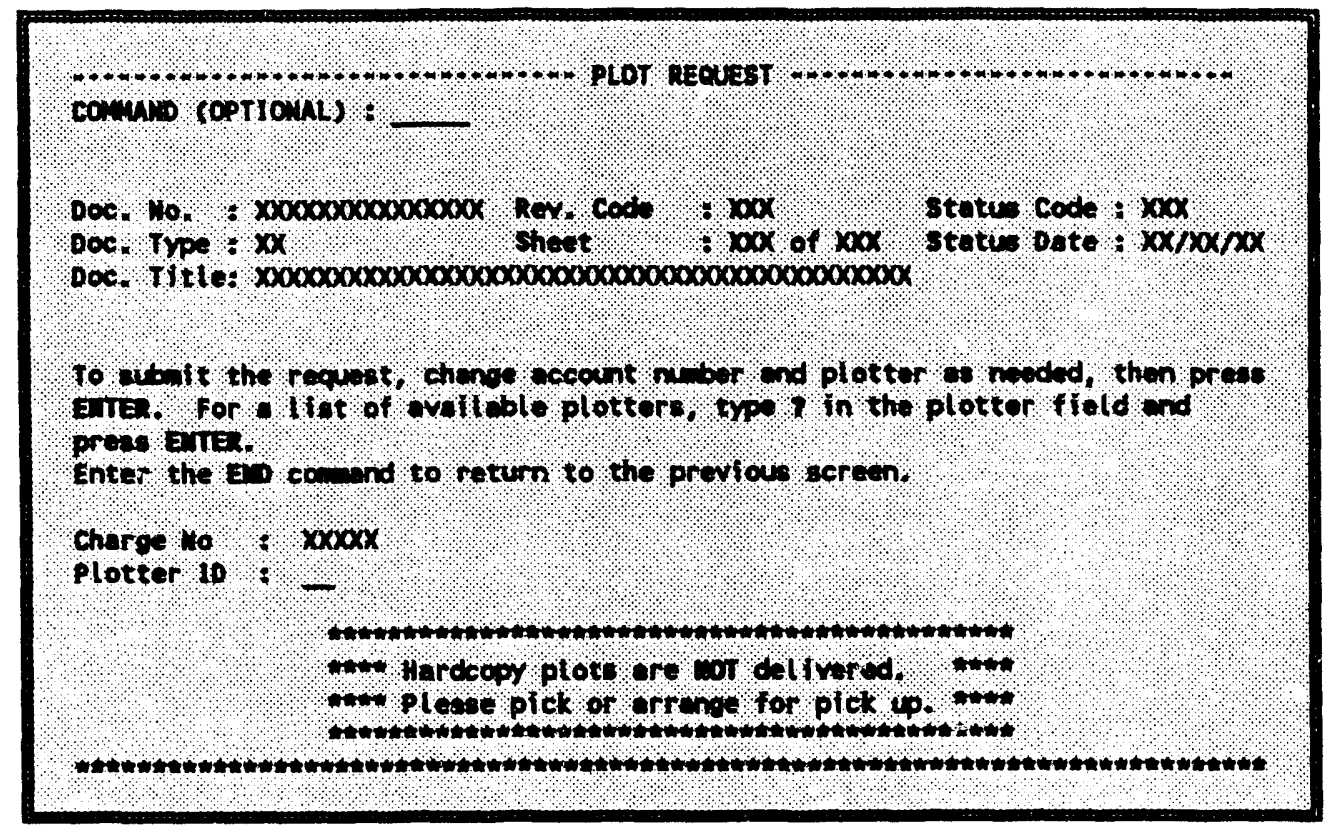

Use the $<\mathrm{TAB}>$ and $<\mathrm{SHIFT}><\mathrm{TAB}>$ keys to move the cursor between the two data entry fielc's on the bottom of the screen. A charge number and valid Plotter ID must be present in the respective fields to request a plot copy of a document. You are allowed to modify the displayed default values for the following data items:

\section{Field \\ Charge Number \\ Plotter ID}

Description

Enter a valid TSO computer account number.

Specify the plotter at which the requested hardcopy will be printed.

If you enter "?" in the Plotter ID field and press <ENTER>. the Select Plotter ID help screen will be displayed (see Appendix D). Select the desired plotter by entering an " $X$ " in the Select field beside the desired plotter and press <ENTER>. The selected plotter ID will be transferred to the Plot Request screen.

When all data are complete on the screen, press <ENTER > to validate the data. If there are invalid data on the screen, an error message will be displayed, and you will be prompted to correct the data. If all input is valid, your request will be processed and you will be returned to the previous screen from which this screen was accessed.

NOTE: Hardcopy Plots will not be delivered to your plant address. You must pick them up or arrange for them to be picked up at the physical location of the plotter to which your request was routed. 


\subsubsection{View (V)}

NOTE: There are special requirements regarding the ability to view graphical images using Soft Master. Please refer to Appendix A of this manual.

When the function code $\mathrm{V}$ is antered from the Abbreviated Document Listing Screen, the Format Listing Screen or either of the Detailed Document Information Screens, the Soft Master Graphical Viewing process will be initiated by EDIS. Refer to Appendix B for a description of using Soft Master to view the selected document. If you invoke the View function and have not logged on properly, continue pressing <ENTER> after each display of "***" and you will return to the EDIS menus.

To exit the Soft Master program and return to the EDIS screen from which the View function was initiated, press the $\langle\mathrm{PF} 13\rangle$, $\langle\mathrm{PF} 13\rangle$, $\langle\mathrm{PF} 24\rangle$ function keys as separate keystrokes.

Currently, viewing is only available for documents stored in the EDIS repository in CADAM format. If the View command is issued for a document not stored in CADAM format, the screen from which the View command was invoked will be redisplayed with an error message. 


\subsubsection{Store (S)}

NOTE: There are special hardware and software requirements regarding the ability to store documents in the EDIS Repository. Please refer to Appendix C of this manual.

When the code $S$ is entered from the Abbreviated Document Listing Screen, the Format Listing Screen, or either of the Detailed Document Information Screens, and the document is not classified, the following Store Document Screen will be displayed. The EDIS Store function is limited to those documents that are unclassified, including nonsensitive, business sensitive, and UCNI. If an attempt is made to perform the Store function on a document that has a classification other than unclassified nonsensitive, business sensitive, or UCNI, the screen from which the function was invoked will be redisplayed with an error message.

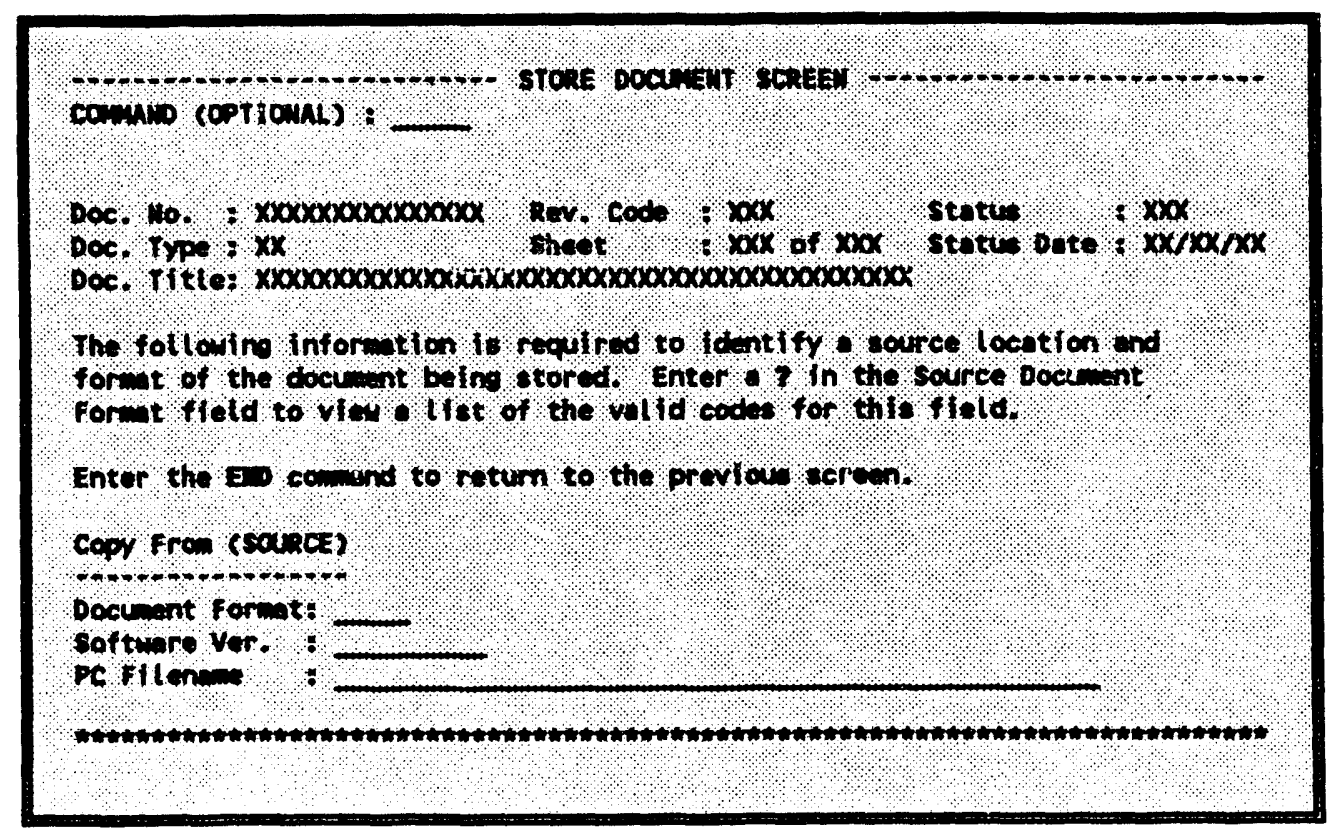

Use the $<\mathrm{TAB}>$ and $<\mathrm{SHIFT}><\mathrm{TAB}>$ keys to move the cursor between data fields on the bottom of the screen. You must enter values for the following data items:

Field

Description

Document Format Enter a valid electronic storage format.

Software Version Enter the version of the software used to create the document being stored.

PC Filename Enter the full directory path and filename of the document on your PC (e.g., C:LMCADMPCFILESITEST.CAD).

When these three data fields are completed on the screen, press <ENTER > to validate the data. If there are invalid data values on the screen, an error message will be displayed, and you will be prompted to correct the data. If all input is valid, your store request will be processed, and if no problems are encountered during file transfer, you will be returned to the previous screen from which this screen was accessed. 
Several problems may occur during the store process that might include but are not limited to the following:

1. The PC filename is not in existence.

2. FT/Express software errors.

3. Defective storage medium on the PC.

4. Problems encountered in the storage of file in the EDis repository.

5. Improper software and hardware configurations.

If any errors occur during this process, attempt to correct the error. If you are not successful, contact your system administrator. 


\subsubsection{Download (DL)}

NOTE: There are special hardware and software requirements regarding the ability to download documents from the EDIS Repository. Please refer to Appendix C of this manual.

The Download function can be requested from the Format Listing Screen, Abbreviated Document Listing Screen, or either of the Detailed Document Information Screens.

If the selected document is stored in multiple formats, the system will display the following Download Function - Document Format Listing Screen, listing all electronic formats of the document that are eligible for transfer. This screen allows you to select the format of the document you wish to download. If only one format is available or if you have already chosen the format from the Format Listing Screen, you will not receive this screen but will proceed immediately to the Download Document Screen on the following page.

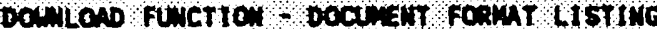

conenos (oprtoust):

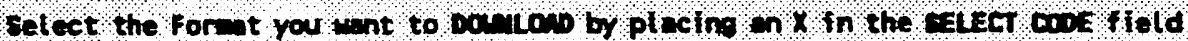
and presoling Eme.

Enter the Ewo canend to end the pamion furction.

$000.10 ., \div \times 0000000 \times 000000$

Rev code: $\mathbf{0 0 x}$

strtus

$+\infty 00$

Doc. Type. $\mathbf{x x}$

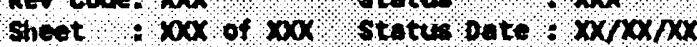

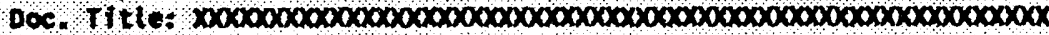

\begin{tabular}{|c|c|c|c|c|}
\hline $\begin{array}{l}\text { SELECT } \\
\text { coot }\end{array}$ & FOANT & $\begin{array}{l}\text { SOFTunRE } \\
\text { Verston }\end{array}$ & $\begin{array}{l}\text { stophes } \\
\text { cochtiol }\end{array}$ & DATE: \\
\hline & $\mathbf{p} \times \mathbf{x x}$ & xoxoxxx & 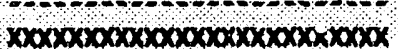 & $x \times / x \times x / x x$ \\
\hline & $\mathbf{x} \times \mathbf{x x x}$ & $\mathbf{x} \times \mathbf{x \times x \times}$ & $\times \times \times \times \times \times \times \times \times \times \times \times>0 \times \times \times \times \times \times \times \times \times \times \times \times x$ & $x \times / x \times / x x$ \\
\hline & $x \times x \times x$ & $x \times x \times x \times x$ & 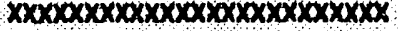 & $x \times / \times \times / \times x$ \\
\hline
\end{tabular}

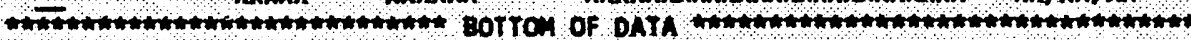

Select the format to download by entering an " $\mathrm{X}$ " in the SELECT CODE field beside the desired format. After a format has been selected, the system will display the Download Document Screen shown on the next page. 


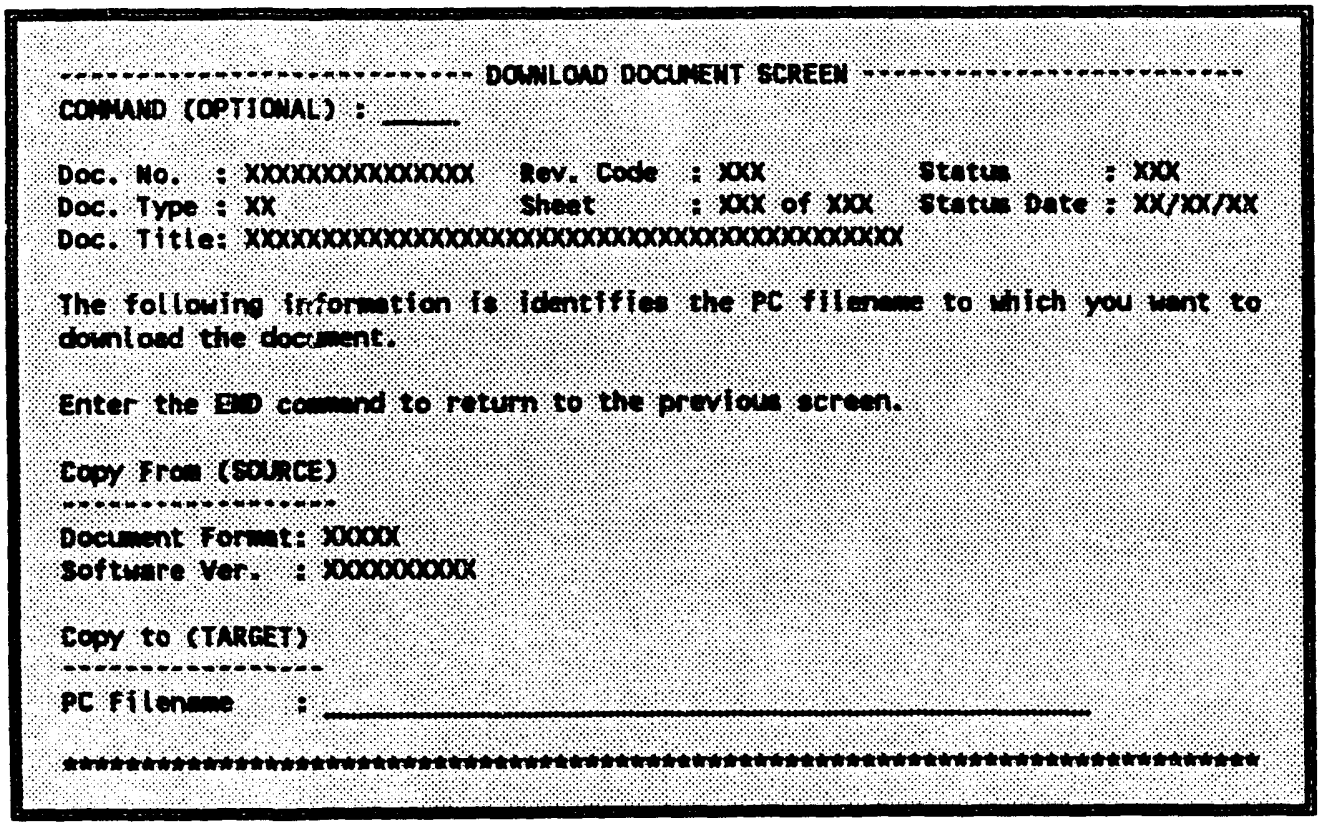

This screen contains identification of the document, format, and software version that you have selected from previous screens. At the bottom of the screen you are prompted to enter the full PC directory path and filename to which the document is to be copied. After entering this information and pressing $<$ ENTER>, the system will attempt to initiate the Download process. If no problems are encountered during the file transfer, your request will be processed and you will be returned to the previous screen from which this screen was accessed.

Once the transfer process has been initiated, several problems may be encountered. Some of the problems might include but are not limited to the following:

1. Invalid directory path in PC filename.

2. FT/Express software errors.

3. Defective storage medium on the PC.

4. Problems encountered in the retrieval of the file from the EDIS repository.

5. Improper software and hardware configurations.

6. Insufficient storage space.

If any errors occur during this process, attempt to correct the error. If you are not successful, contact your system administrator.

If the document you have selected has a classification of Sensitive (either Business Sensitive or UCNI), the system will display the Sensitive Document Warning Screen shown on the next page. 
The Sensitive Document Warning Screen indicates that the document you have selected for download has been marked as Unclassified Sensitive.

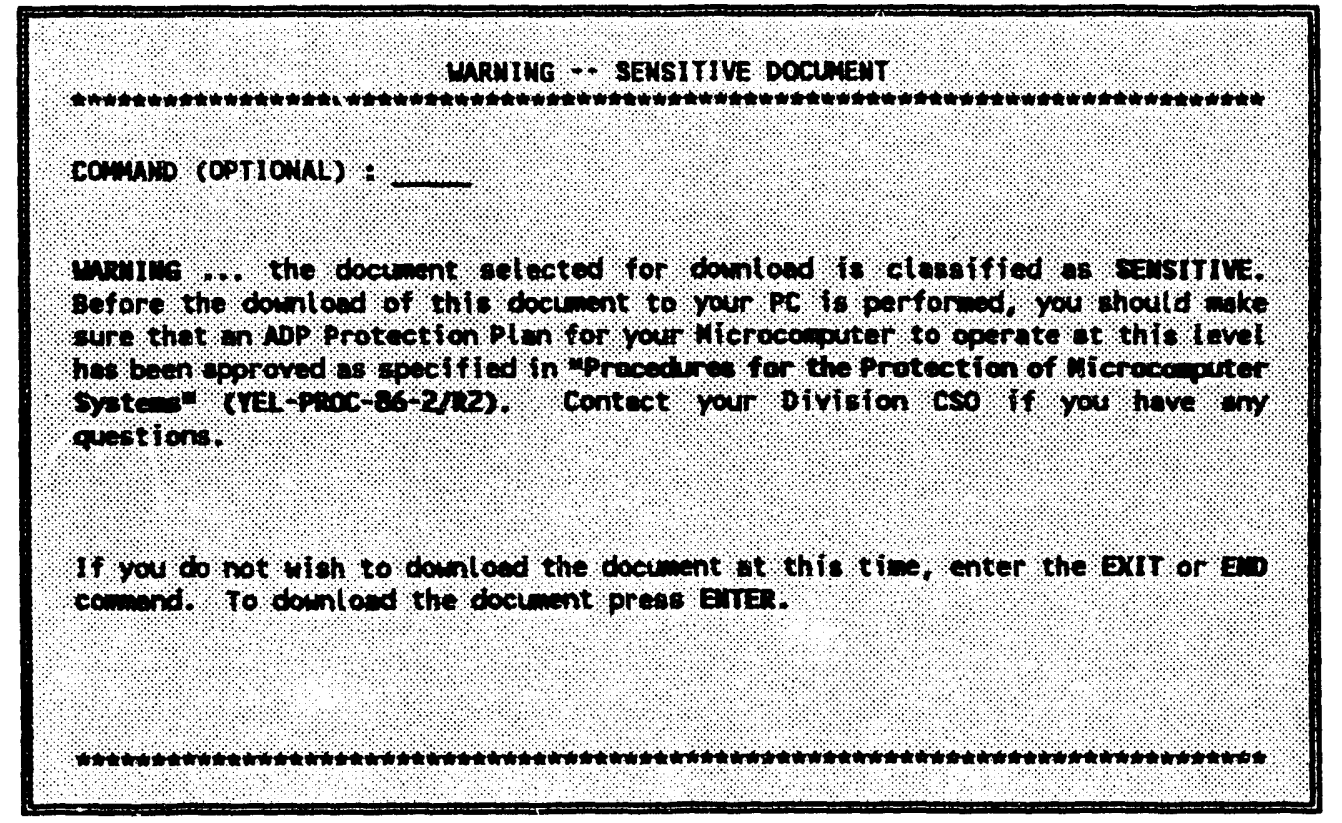

Before downioading a Sensitive document, you are asked to confirm that your PC has an ADP Protection Plan certifying its use at this level of classification by pressing the $<E N T E R>$ key. Doing so will initiate the download process.

If your PC has not been approved to operate at a Sensitive level or you are unsure of its status, you should enter either the END or EXIT command to cancel this download process. For further information, contact you Division CSO. 


\subsubsection{Reserve Option (R)}

When you have selected Reserve from the EDIS Primary Option Menu, the following menu will be displayed, from which the Reserve functions may be selected.

\section{RESERVATION MENU}

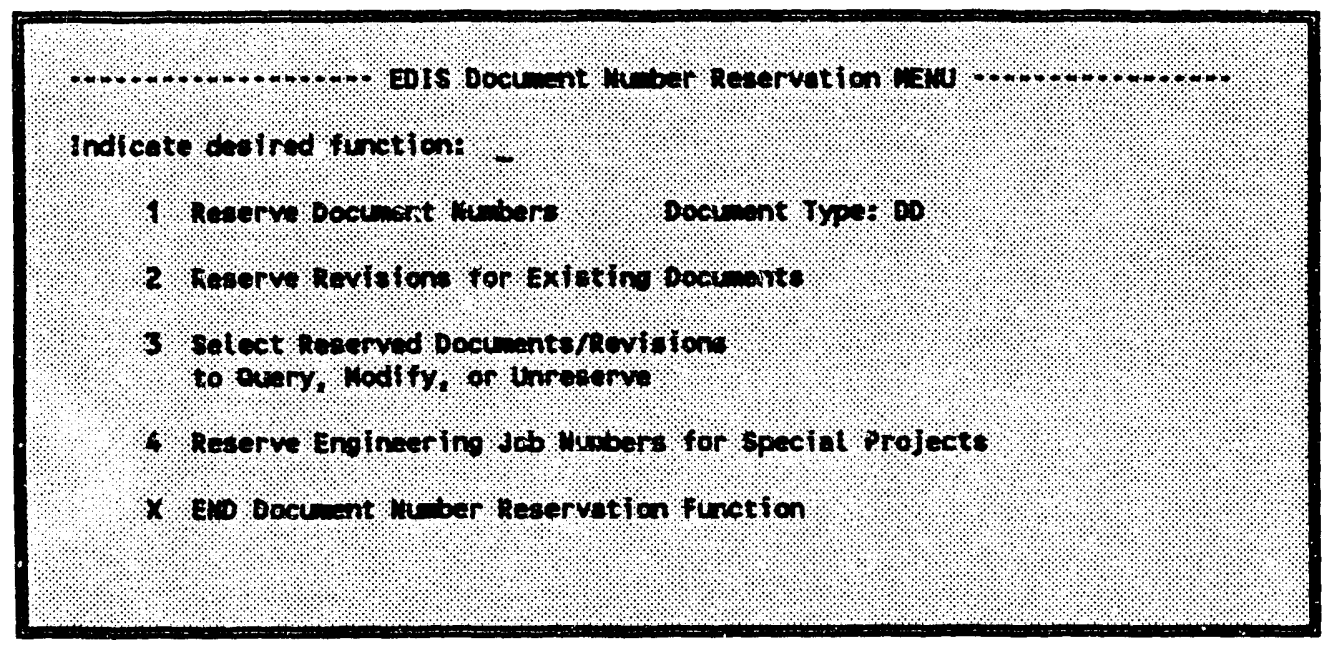

You can indicate the subfunction to be performed by typing the option number in the "Indicate desired function" field and pressing <ENTER>. A Document Type must be entered to reserve a document number (Option 1). The default code DD, which stands for design drawings, is entered by the system in the Document Type field. You may $<\mathrm{TAB}>$ to this field to enter another document type code. If an invalid document type is entered (or if you enter a "?" for help in this field and press <ENTER>), a list of valid document types will be displayed on the screen (see Appendix D).

The following sections of this manual describe the operation of the Reservation Menu options. Refer to the table below to find the manual section that covers each option.

Option $\quad$ Action

1 Reserve one or more new document numbers (see Sect. 3.3.2.1).

$2 \quad$ Reserve a revision for an existing drawing (see Sect. 3.3.2.2).

3 Select a specific document number for the purpose of performing a Query, Modify, or Unreserve action (see Sect. 3.3.2.3).

NOTE: This command on the Reservation Menu only displays reserved document numbers (not released or issued documents). To query released or issued documents, use the Query option on the EDIS Primary Option Menu (see Section 3.3.1).

4 Reserve Engineering Job Numbers (EJNs) for Special Projects or query and modify EJN information (see Sect. 3.3.2.4).

Option X will exit the Reserve function and return you to the EDIS Primary Option Menu. 


\subsubsection{Reserve Document Numbers (Option 1)}

One of two separate screens are displayed to perform this function depending upon whether (1) you entered DD as a document type on the menu screen or (2) you entered BM, JS, DS, or DC as a document type. These two screens are discussed below.

1. When DD is selected as the document type on the Reserve Menu, you will receive the following screen to reserve numbers for design drawings.

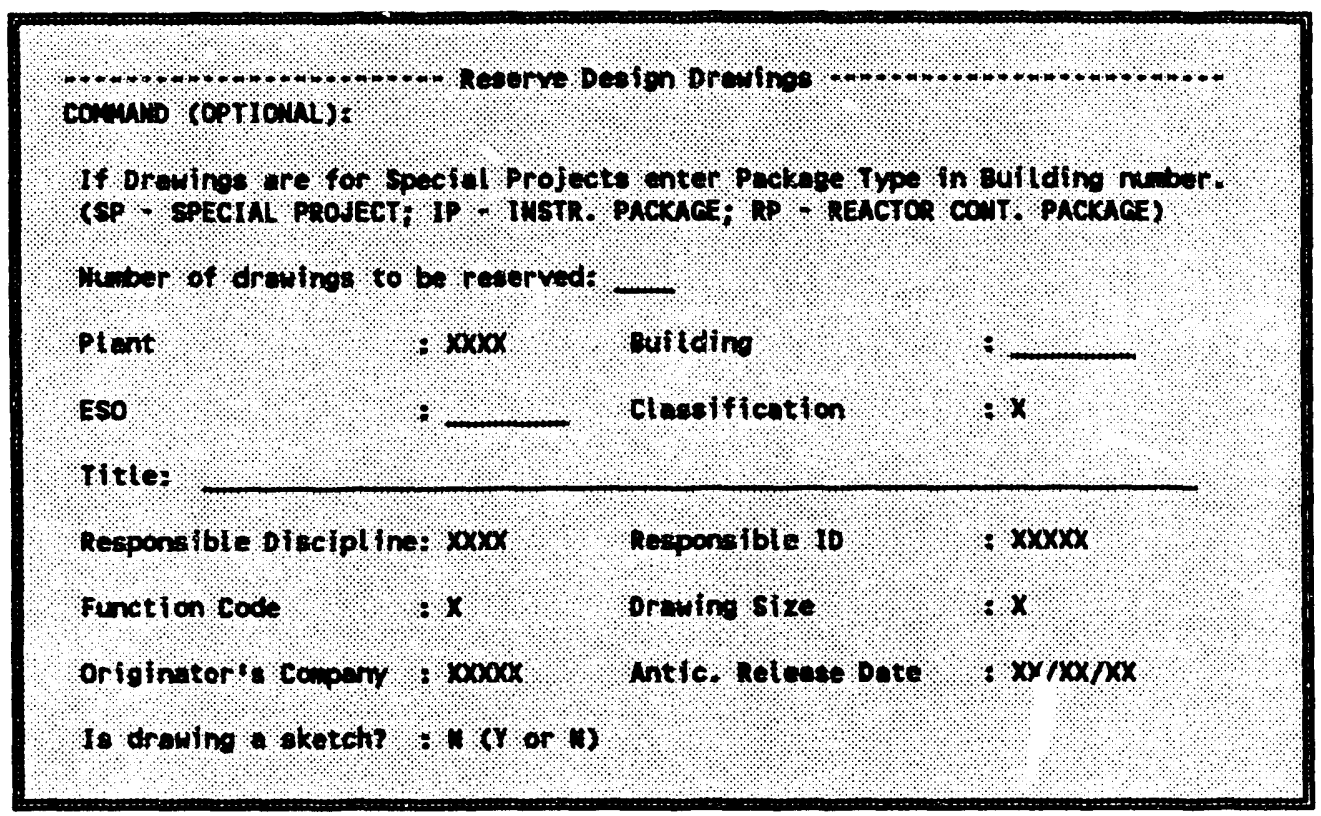

2. When BM (Bill of Material), JS (Equipment Specification), DS (Equipment Data Sheets), or DC (Design Analysis and Calculations) is selected as the document type on the Reservation Menu, you will receive the following screen to reserve numbers for the selected document type.

Comino (COTInAH)

If documents are for specibl projects enter Packege Type in Building nuber. (SP - SPECIAL PROJECT, IP - IUSTR, PACKAEE, AP - REACTOR COUT, PACKACE)

Muber of documents to be reserved:

Plant

. $\mathbf{x x x x}$

ESO

$+$

Title:
Buftiding liuber

Ctassiftication
$+$

. $x$

Responsible bisctpline: $\mathbf{x x x x x}$ Respone Ible EMIS ID, XXXXX

originator's company,$x \times x x x$ Ariticip, Relesese bate , $\mathrm{xX} / \mathrm{XX} / \mathrm{XX}$ 
Use the $<\mathrm{TAB}>$ and $<\mathrm{SHIFT}><\mathrm{TAB}>$ keys to move the cursor forward and backward between input fields on either of the above screens to enter data or change field values. Typing END and <ENTER $>$ in the COMMAND line will cancel this function without generating new numbers and cause the Document Numiber Reservation Menu to be displayed.

These screens will have data supplied by the system in the following fields:

Field

Value

Plant

Classification

Responsible Discipline

Responsible ID

Function Code

Drawing Size

Originator's Company

Anticip. Release Date

Sketches

User's plant

U

User's discipline (will be blank if your discipline is AS, SP, ISD, KPJ, XPJ, or YPJ)

User's EMIS ID

Code for user's discipline (will be blank if your discipline is AS, SP, ISD, KPJ, XPJ, or YPJ) (for DD documents only)

$E$ (for DD documents only)

MMES (for Martin Marietta Energy Systems)

Current date +12 months

$\mathrm{N}$ (for DD documents only)

These data are system defaults or are obtained from your logon information, but they may be changed. You are required to fill in all remaining fields on the screen.

If any field is not completed or if any codes you have entered are not valid, when you press <ENTER > to submit the screen information to the system, screens of valid codes for any field that is in error will be displayed on the screen. These screens are available for the following fields and are displayed in Appendix $D$.

Building

Responsible Discipline

Responsible ID

Function Code
Originator's Company (Participant Code)

Classification

Plant (where constructed or funded)

These code screens are also available to you from this screen if you type a "?" and <ENTER> in an empty code field. Select a valid code from the help screen list and press <ENTER > to return to the Reserve Design Drawings screen, and the code you selected will be displayed in the code field from which you requested help.

The specific requirements of several fields are described below:

- All weapons drawings are assigned an EJN of 800440 . These drawings do not require entry of ESO and Building Number; these values are set to blank in the database.

o If SP, RP, or IP is entered for Building Number, the Charge ESO will be used to obtain the appropriate special project EJN. If an EJN has not been assigned to the Charge ESO that is entered and if you have proper authority, you must exit to the Document Number Reservation Menu and select the Reserve EJNs for Special Projects option (Option 4) to create an EJN for this project (see Sect. 3.3.2.4 for information on using this function). An error message will be displayed if you do not have authority to assign an EJN. This message will tell you whom to contact to have the EJN established. 
o If SP, RP, or IP is entered for Building Number and the EJN for this project has sequence letters assigned to it, the following screen will be displayed to allow you to select the sequence letter for which this document number should be generated:

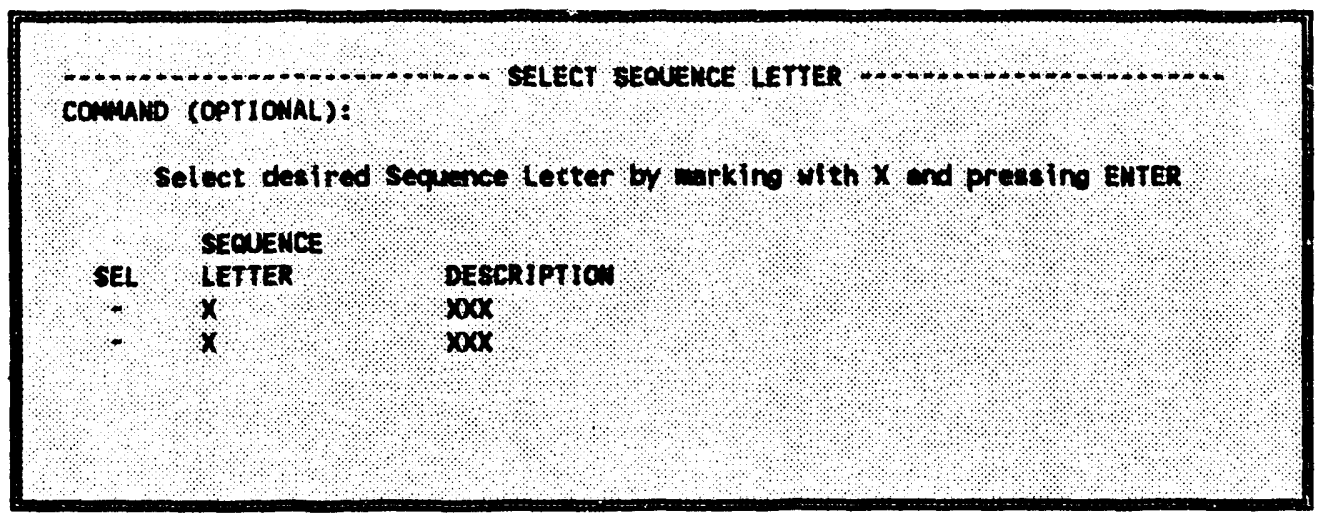

- OAS, SP, ISD, XPJ, KPJ, and YPJ cannot be entered as the Responsible Discipline for the document.

- A message will be displayed if either the Function Code field or the Responsible Discipline field is changed and the function code and discipline do not match. The system will require a valid function code to be entered for each responsible discipline.

o If you enter anything other than $U$ for Classification, the Title Classification Verification panel (see Appendix D) is displayed to remind you not to enter a title containing classified information.

- The Title field may reflect a general project title for the group of drawings requested and may be modified later for the individual drawings. Titles for classified drawings must be unclassified. When the document is actually issued and placed in the EDIS index of released documents, this title will be replaced by the title appearing on the document.

- If documents are not released within $\mathbf{1 2}$ months after the anticipated release date, the document initiator will be contacted for approval to unreserve the document numbers. 
When all fields of either of the Reserve Document Numbers screens (screen 1 or 2 shown on page 28) are completed and <ENTER> is pressed, the Document Reservation Confirmation screen is displayed to show you the range of numbers to be reserved:

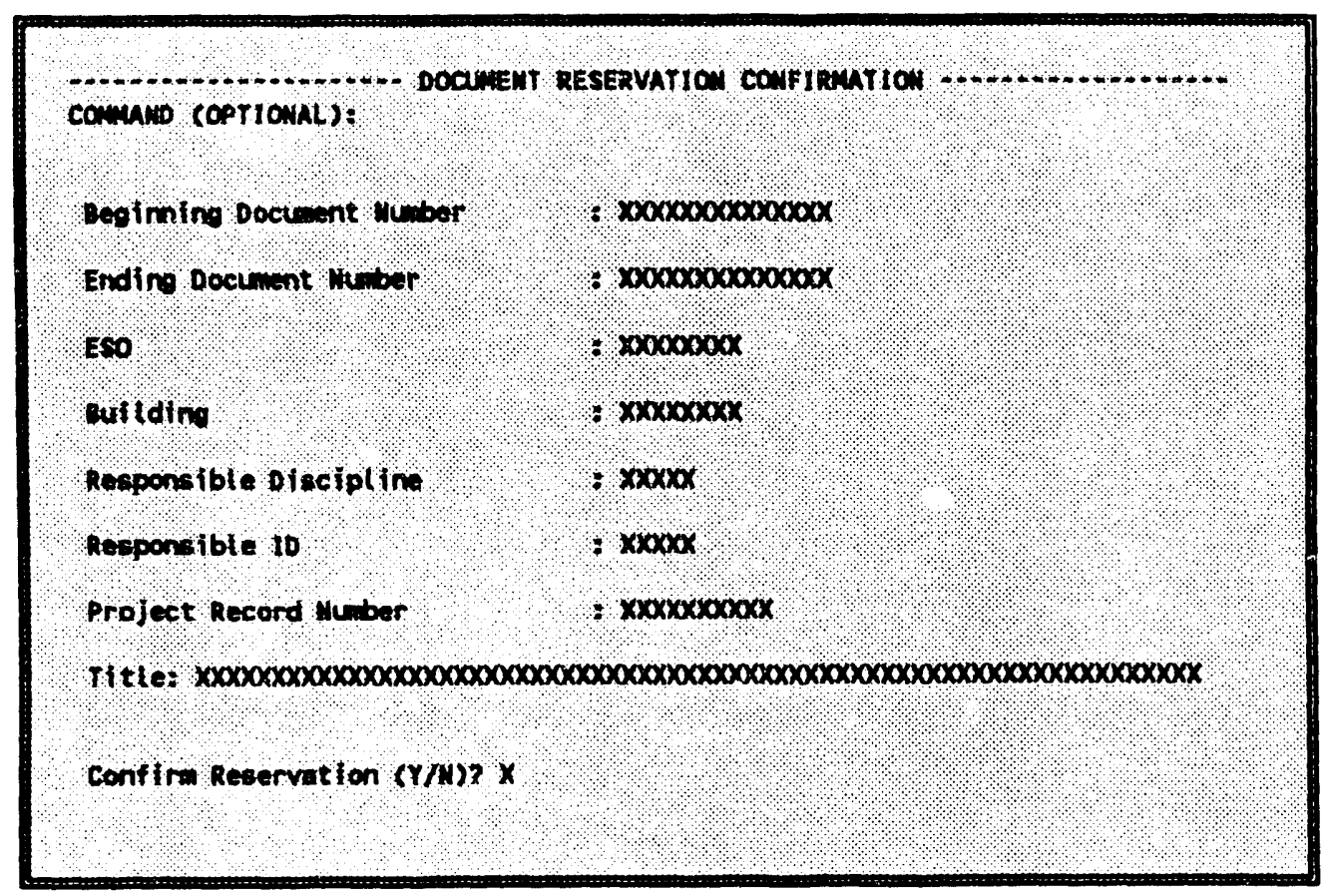

You may confirm or cancel the reservation by entering $Y$ or $N$ at the screen prompt. Entering $N$ will cancel generation of these numbers and return you to the previous screen.

Entering $\mathrm{Y}$ will cause the requested quantity of document numbers to be generated and displayed to you on the Reserved Document List screen (see Sect. 3.3.2.3). The same query, modify, and delete functions are available to you from this List screen as are accessed through Option 3 of the Reservation Menu and described in Sect. 3.3.2.3.

NOTE: When constructing the actual physical drawing (document), the exact character representation of the document number displayed on this screen should be placed on the face of the drawiig (document). 


\subsubsection{Reserve Revisions for Eristing Documents (Option 2)}

When option 2 is selected from the Reservation Menu, you will receive the following screen to reserve revisions for existing or reserved drawings. Revisions may only be obtained for Design Drawings (DD).

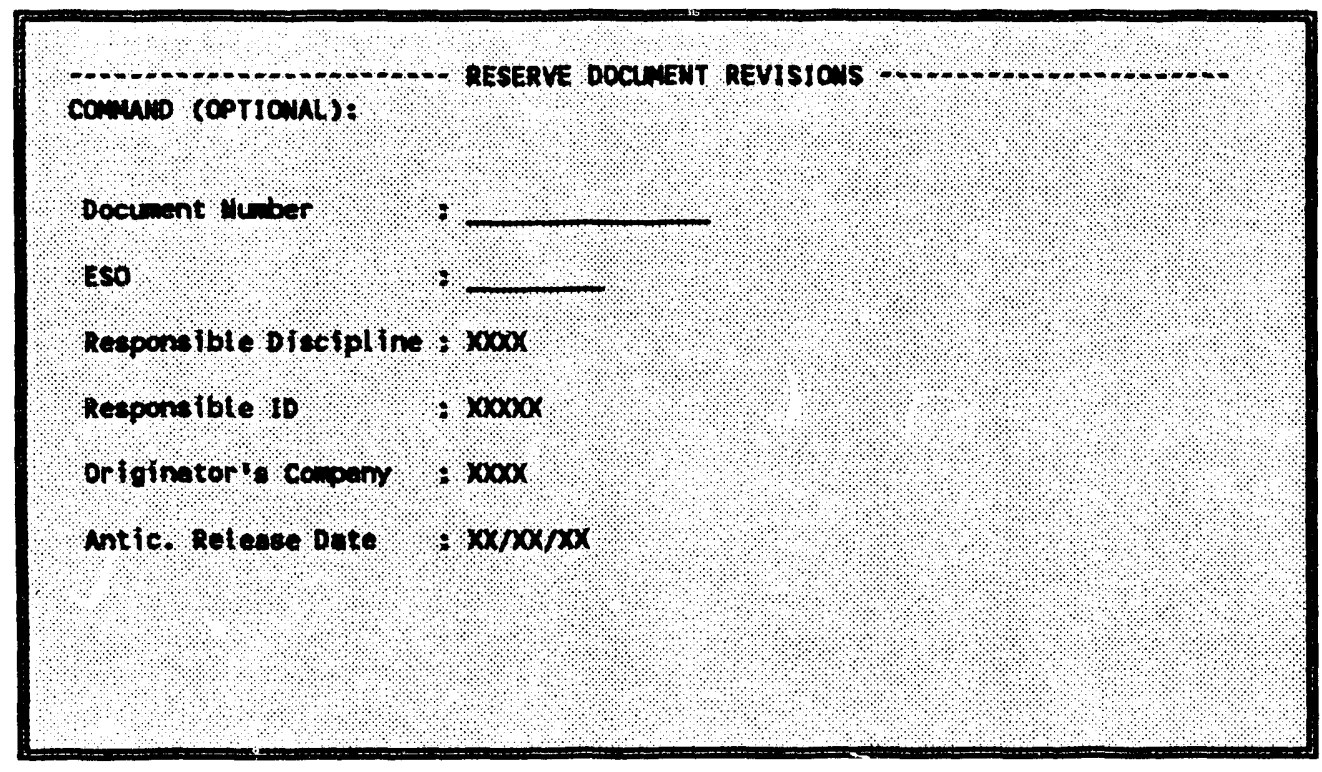

Use the $<\mathrm{TAB}>$ and $<\mathrm{SHIFT}><\mathrm{TAB}>$ keys to move the cursor forward and backward between fields to enter the Document Number and ESO values or type over the displayed field values. Typing END and $<E N T E R>$ or $\mathrm{X}$ and <ENTER> in the COMMAND line will cancel the operation of this function and return you to the Document Number Reservation Menu. Pressing <ENTER> without an entry in the COMMAND line will process the request.

This screen will have data supplied by the system in the following fields:

Field

Responsible Discipline

Responsible ID

Originator's Company

Anticipated Release Date
Value

User's discipline (will be blank if your discipline is AS, SP, ISD, KPJ, XPJ, or YPJ)

User's EMIS ID

User's company code

Current date +12 months

These data are system defaults or are obtained from your logon information, but they may be changed. You are required to fill in all remaining fields on the screen.

Help screens are available for this screen to prompt you with valid codes if you type a "?" and <ENTER > in a code field or if the data you enter in these fields are not valid. Help screens are available for the following fields and are displayed in Appendix D.

Responsible Discipline

Responsible ID

Originator's Company 
The specific requirements cf several fields are described below:

o AS, SP, ISD, XPJ, KPJ, and YPJ cannot be entered as the Responsible Discipline for the document.

o An ESO value is not required for a weapons drawing. If a value is entered, it is ignored and stored as a blank.

o The initial revision assigned for Energy Systems weapons drawings will be "A" instead of "0."

When all fields are completed and <ENTER> is pressed, the following Document Revision List screen will be displayed:

\section{conavid:}

Docunint REVISIOU LIST

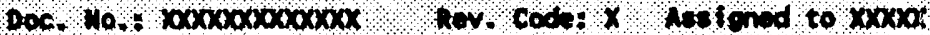

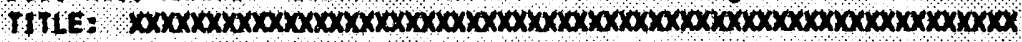
Conf Ira Reservation (Y/W) ? 1

Uoe UP and boul conends, If neceseary, to view entire 11 et of current revistend for the document. Use ENo commend to exit.

DoCAMEVT, REVISIOA , STATUS, RESP. ID

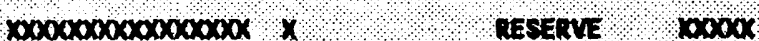

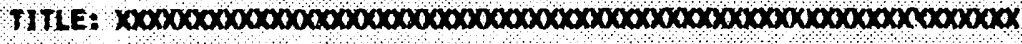

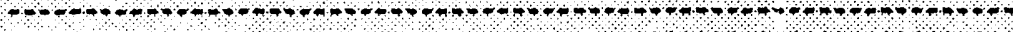

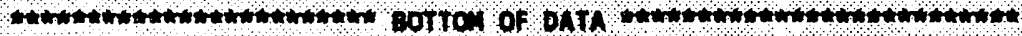

This screen displays a newly assigned document revision code and lists all revisions that have already been reserved or released for this document, the status of each revision, and the responsible person who requested the revision number, if available. If the "ROW _ OF _" prompt in the upper right-hand corner of the screen indicates there are more revisions than appear on this screen, type DOWN or UP and $<$ ENTER > on the COMMAND line to scroll to the rest of the document revisions. ("DOWN $n$ " and "UP $n$ " can be userl to scroll " $n$ " number of rows that you specify.) You are asked to confirm the reservation of this revision after reviewing the screen information by typing $Y$ and <ENTER> by the "Confirm Reservation $(x / \mathbb{N})$ ?" prompt.

If you confirm the revision and press <ENTER>, the revision information will be added to the Reserved database. If you enter anything except $Y$ to confirm reservation, the revision will not be assigned, and the Reserve Document Revisions screen will be shown. Typing END and <ENTER> will return you to the Reserve Document Revisions screen; typing $X$ and <ENTER> will return you to the Document Number Reservation Menu. 


\subsubsection{Select Reserved Documents/Revisions (Option 3)}

The Reserve database information may be queried, modified, or unreserved (deleted) using option 3 on the Document Number Reservation Menu. To perform these functions, you must first enter criteria by which to select documents from the database and then indicate what action is to be performed on these documents. You can select the desired document or document revision using the following search screen:

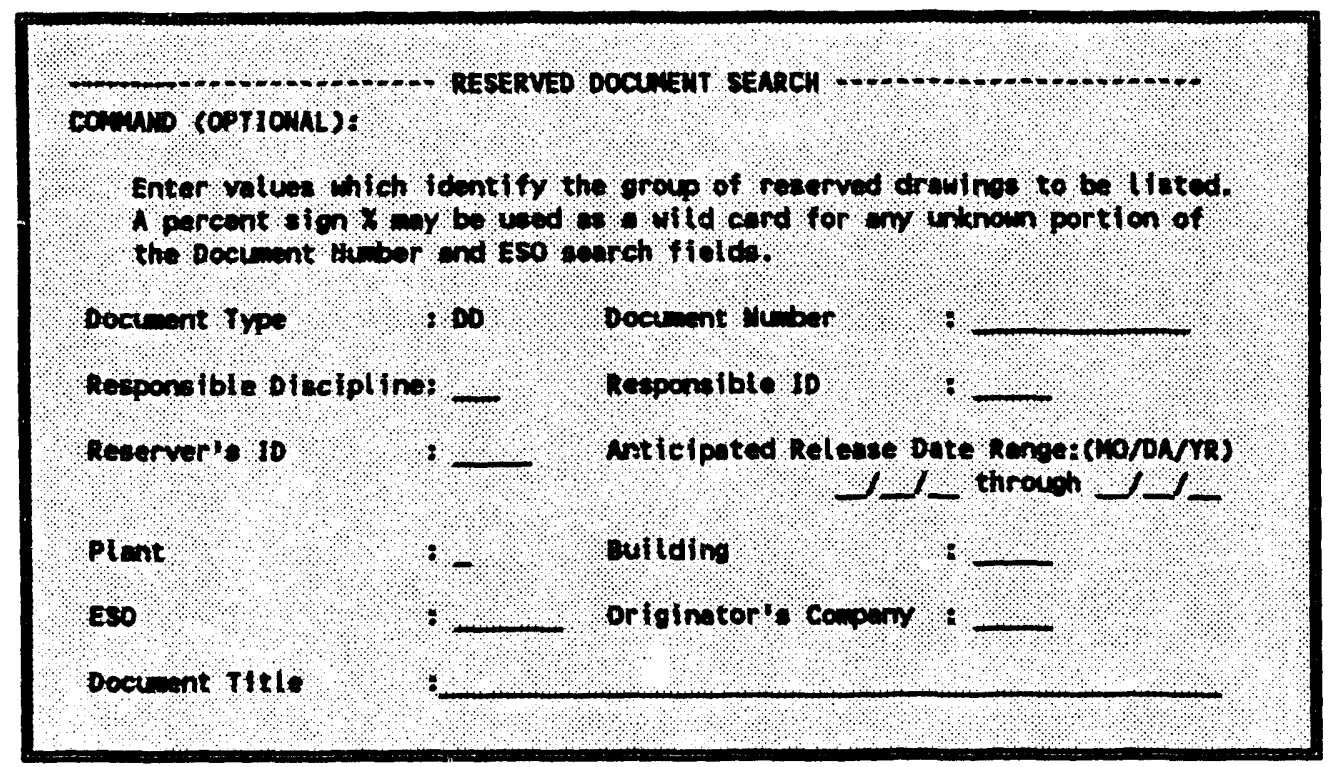

Use the $<\mathrm{TAB}>$ and $<$ SHIFT $><\mathrm{TAB}>$ keys to move the cursor forward and backward between input fields. Values need not be entered for all fields, but you should enter as many search criteria as needed for the desired query and press <ENTER>. In general, entering more information will produce a narrower search, and the resulting list of documents will be shorter and more specific. Valid values entered in the Document Type and Document Number fields uniquely identify a document; therefore, any information t ntered in addition to the document type and document number is unnecessary if the goal of the query is to locate a particular document. Partial document and ESO numbers can be entered using a \% sign for unknown portions of the numbers, and a range of dates may be found using the Anticipated Release Date Range. The END command may be entered to cancel the search function and return to the Document Number Reservation Menu.

Help screens are available to prompt you with valid codes if you type a "?" and <ENTER > in a code field or if the data entered in these fields are not valid. These screens are available for the following fields and are displayed in Appendix D.

$\begin{array}{ll}\text { Responsible Discipline } & \text { Plant } \\ \text { Responsible ID } & \text { Originator's Company } \\ \text { Reserver's ID } & \end{array}$

Do not select directly from these help screens if you have not completed entering search criteria on the search screen, but return to the search screen to enter the code. If the code and <ENTER> are entered on the help screen, the search will be executed with only the search criteria existing at that time. Exit the help screen by typing END and <ENTER > on the COMMAND line of the help screen and then type the code over the "?" in the field from which the help screen was requested. 
When the search criteria are completed and <ENTER> is pressed, all documents in the database matching the search criteria will be displayed to you on the Reserved Document List screen shown next. From this screen you can elect to perform one of the displayed functions for a particular document.

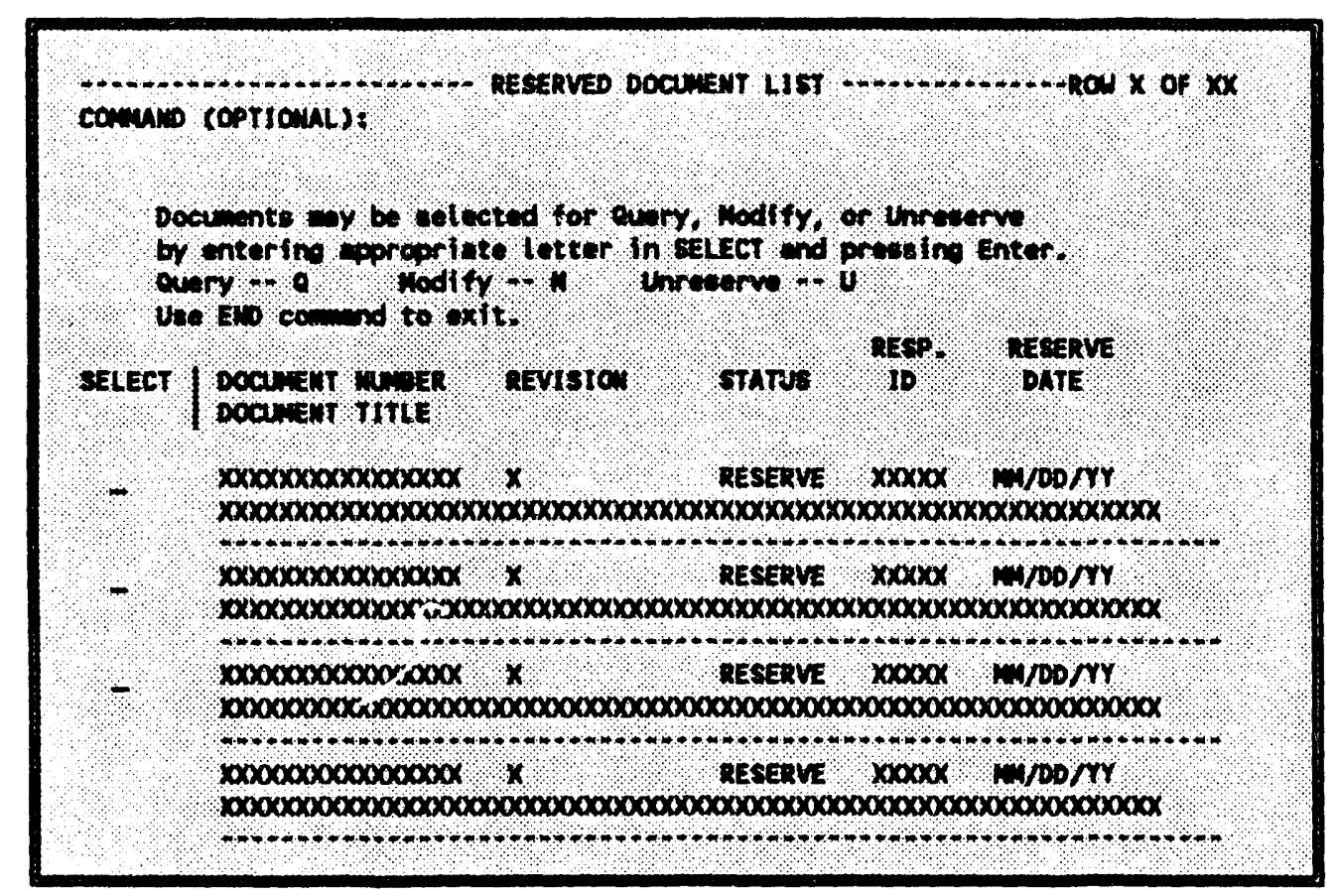

Use the $\angle T A B>$ keys to move the cursor between the SELECT input fields. Typing DOWN and $<$ ENTER > or UP and <ENTER > on the COMMAND line will display additional documents on the list if the "ROW _ OF _." prompt on the upper right-hand corner of the screen indicates that there are more documents on the list than are displayed on the screen. ("UP $n$ " or "DOWN $n$ " will scroll " $n$ " number of lines at a time.) The END command will return you to the Reserved Document Search screen.

You can select documents for query, modification, or unreserve by entering ont of the following codes beside a document number in the SELECT field:

Code Action

Q Display more complete information about the selected document on the Reserved Document Query screen (see Query section on the following pages).

M Execute the Reserved Document Modification screen if you have authority to modify (see Modify section on the following pages).

U Unreserve or remove the document from the Reserved Document Number table. The Status field will be changed to UNRESERVE. If the document is a design drawing with a Revision Code of 0 and no higher revisions exist for the drawing, the sequence number and sequence letter will be made available for re-use. You must have delete authority to perform Unreserve (see Unreserve section on the following pages). 
A $Q, M$, or $U$ code may be entered beside more than one document at a time. When $<E N T E R>$ is pressed, the documents will be displayed one after the other before you are returned to the Reserved Document List screen. These codes can also be executed by typing an $X$ in the SELECT field beside the selected document(s) and then typing a code (either $Q, M$, or $U$ ) and <ENTER> on the COMMAND line.

\section{Query (Q)}

The Reserve Document Query screen displays information about a document selected by the $Q$ code on the Reserved Document List screen.

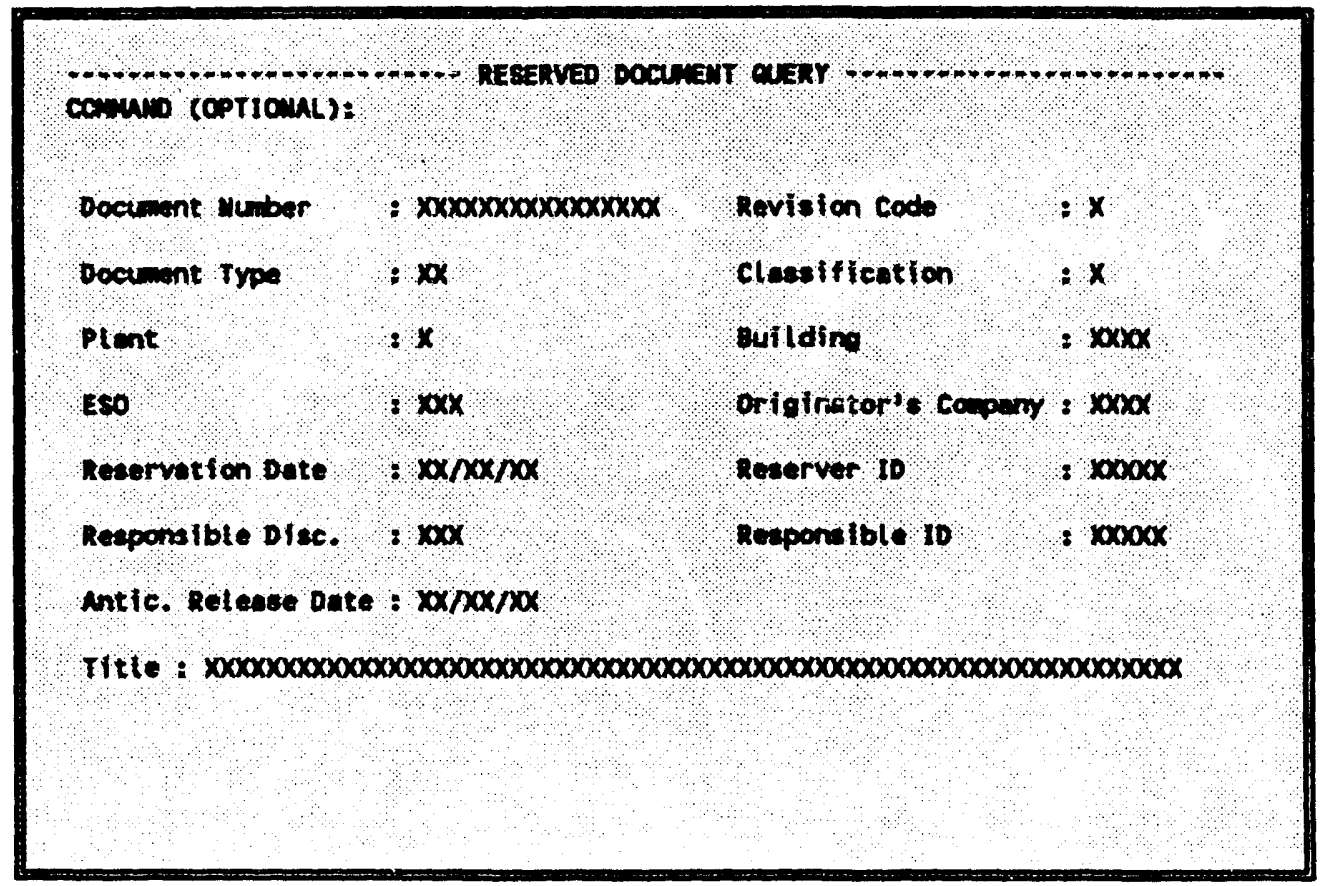

This information is displayed for query only and cannot be changed. If more than one document was selected, press <ENTER> to see the next selected document. The END command will return you to the Reserved Document List screen. 


\section{Modify (M)}

When the code $M$ is enterec beside a document number on the Reserved Document List screen, the following modification screen will be displayed with the existing data for the selected document:

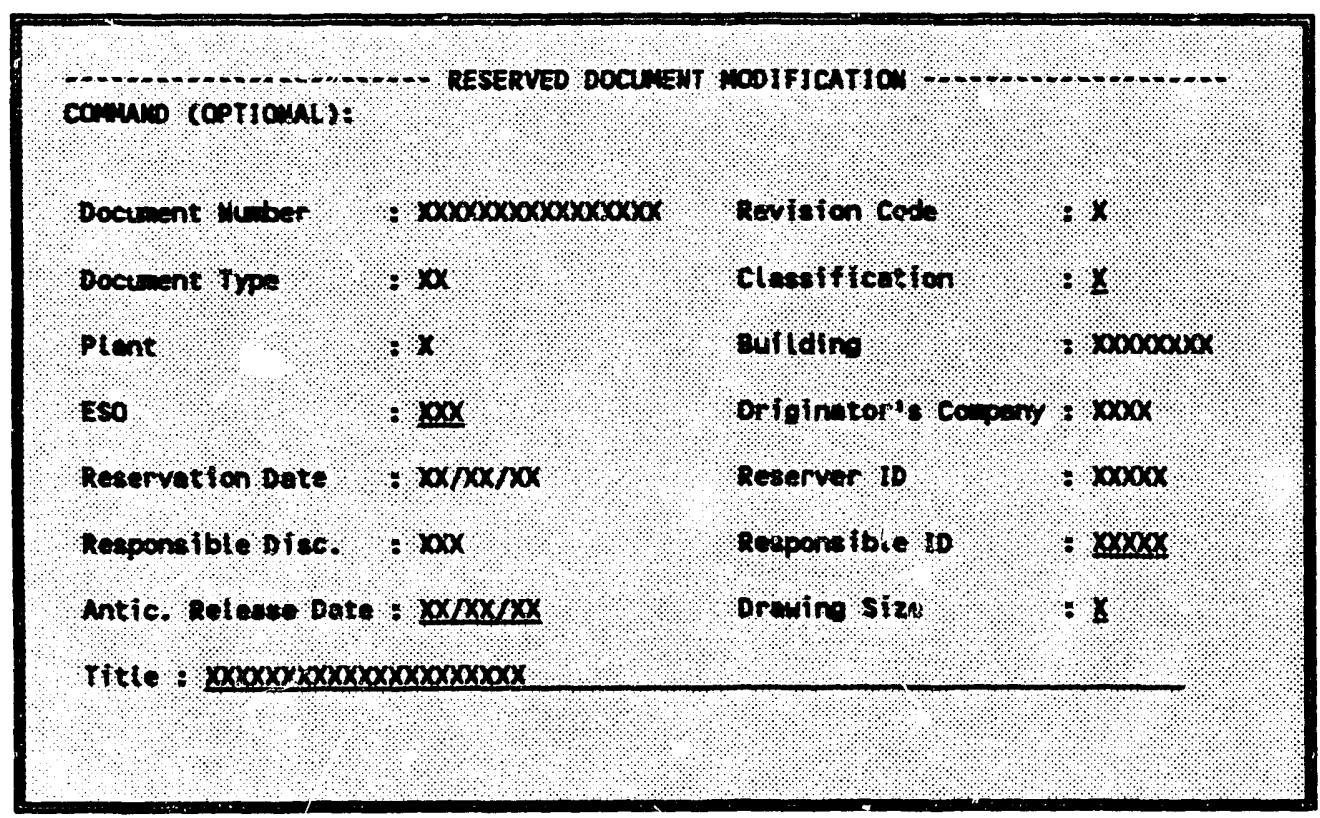
of $\mathrm{DD}$.

The Revision Code and Drawing Size fields will be displayed only for records with a Document Type

Use the $<\mathrm{TAB}>$ and $<\mathrm{SHIFT}><\mathrm{TAB}>$ keys to move the cursor between data fields. You are allowed to modify the foilowing data items:

Responsible ID

Anticipated Release Date

Title

Classification
ESO

Drawing Size (if document type $=\mathrm{DD}$ and no revisions have been received)

Drawing size may be changed only on the initial issue of the drawing and only prior to release into ISD. If Classification is other than $U$ and the title is changed, the Title Classification Verification panel is displayed to warn you not to enter classified information in the title (see Appendix D).

When all changes are complete, press <ENTER> to save the changes and return to the Reserved Document Lisi scicen. Typing END and <ENTER> will cancel the function and return you to the Reserved Document List screen without saving the changes.

\section{Unreserve (U)}

If a $U$ is typed in the SELECT field of a document on the Reserved Document List screen (see Sect. 3.3.2.3), the selected document number will be returned to the system and can be reassigned. This Unreserve function can also be operated from the list by typing an $\mathrm{X}$ in the SELECT column beside a document number and UNRESERVE and <ENTER> on the COMMAND line. 


\subsubsection{Reserve Engineering Job Numbers for Special Projects (Option 4)}

EJNs may be reserved or queried by choosing Option 4 on the Document Number Reservation Menu. The following Special Project Menu will be displayed:

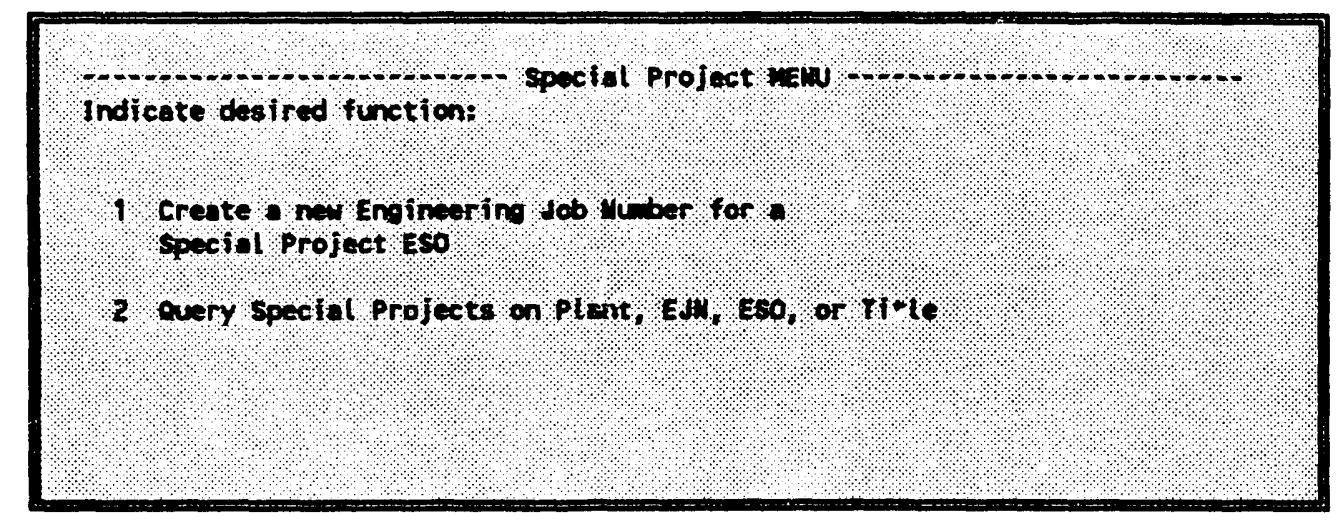

This menu allows you to either create a new EJN and sequence letters (option 1) or query, add, or modify information on an EJN that exists in the database (option 2). Choose one of these functions and press <ENTER>. These two options are described in the following two sections.

\section{Create a New EJN (1)}

When you select option 1 from the Special Project Menu, one of the following screens will be displayed, depending upon the division to which you belong. If you are in the Instrumentation and Controls Division, the following screen will be displayed:

- - - - - - - - - - - - - ASSIEA SPECIAL PROJECT EJ

comand (OPTIONAL):

Enter special Project Information. Use Exo comand to exit screen.

Plant $: x$

Eso

3

Type of Packoge:

(SP - SPECIAL PROJECT; IP - IMSTR, PACKAGE; RP - REACTOR COHT, PACKACE)

specisl Profect

Title:

Do you wish to specify an ot pho sequence $?$ I $(r$ or $n)$

Do you wish to add additional ESOs ? : M (Y or W) 
If you are from either the Chemical Technology Division or the Engineering Division, the following screen will be displayed:

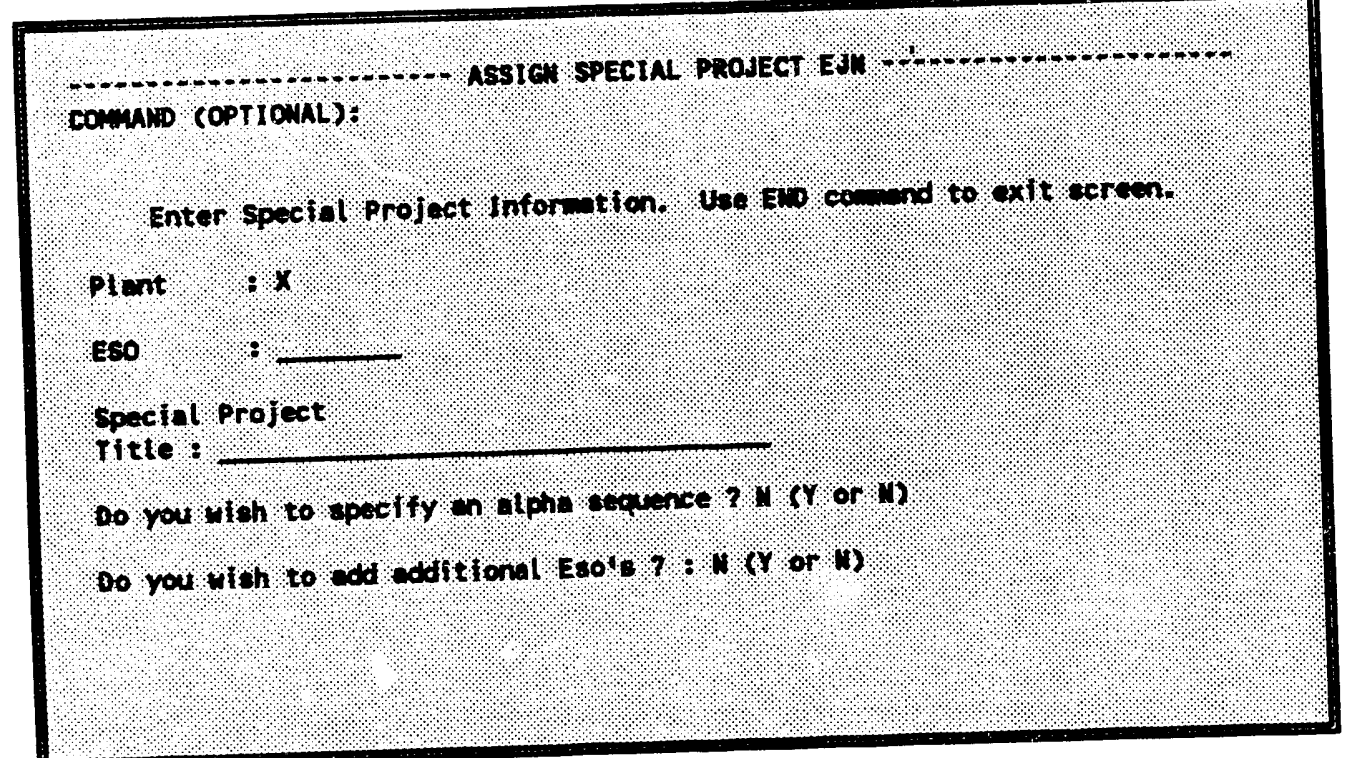

On these screens, the Plant field is initialized to your plant and may not be changed unless you have authority for more than one plant. You must enter values for all of the remaining fields. Use the $<\mathrm{TAB}>$ keys to move the cursor between input fields to enter data. Only one EJN can be assigned for each ESO/Workorder. The END command will cancel this function and return you to the Document Number Reservation Menu.

If you wish to specify an alpha sequence to be used on document numbers for this EJN you must $Y$ to the declared now. When reserving new document numbers using this EJN, you will be prompted for the alpha sequence to be used only if this prompt has been answered Y (as described in Sect. 3.3.2.1). Specifying an alpha sequence for document numbers provides a means to further organize work. For example, all documents ending with A001 through A999 could be assigned to component 1, B001 through B999 could be assigned to component 2 , etc.

If you wish to add additional ESOs at this time, answer $Y$ to the last prompt. Additional ESOs can be added at a later time if desired (using option 2 of the Special Projects Menu; see Query Special Projects section on the following pages).

When all fields and prompts have been completed, press <ENTER $>$. The next numerically sequential EJN will be assigned and stored for the ESO entered, and you will receive a message below the COMMAND line saying "EJN XXXXXX WAS CREATED FOR ESO XXXXXXXX." If you selected to add (1) alpha sequence letters or (2) additional ESOs, one or both of the following screens will be displayed to accept these data, as described below. 
1. Sequence Letter Addition Screen. When you choose to add an alpha sequence to an EJN, the following screen is displayed for entry of the sequence letter(s) and title(s):

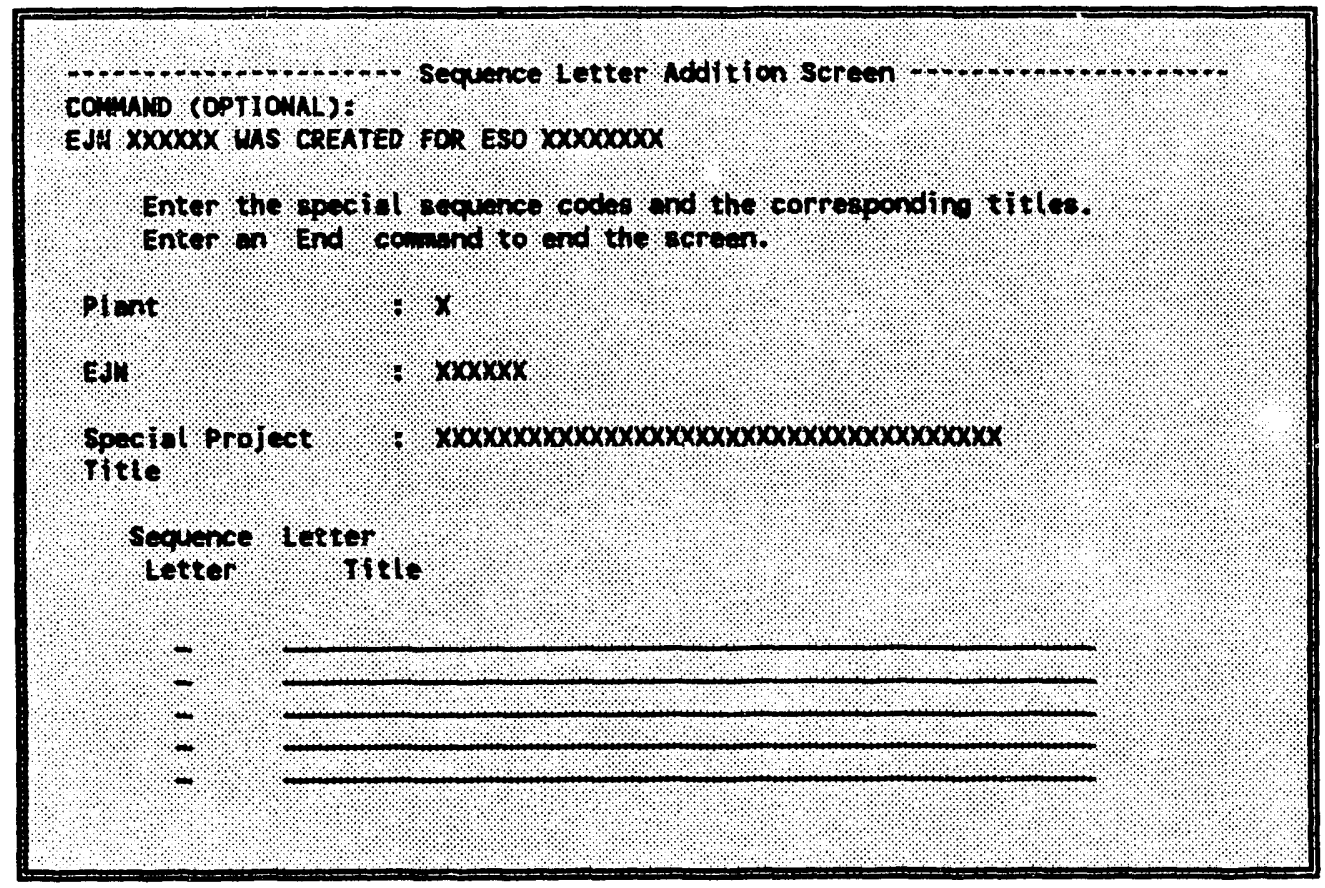

A message "EJN XXXXXX WAS CREATED FOR ESO XXXXXXXX" will be displayed on the second line of the screen to inform you that the EJN you just requested has been reserved.

Use the $<\mathrm{TAB}>$ and $<\mathrm{SHIFT}><\mathrm{TAB}>$ keys to move the cursor forward and backward to the input fields. Typing END and <ENTER > on the COMMAND line will exit this screen without saving the data and display the next screen to process; typing $X$ and $<E N T E R>$ returns you to the Document Number Reservation Menu. If you exit from this screen without entering a sequence letter, it will result in the cancellation of the sequence letter assignment function, and no future assignments will be allowed for this EJN.

More than five sequence letters can be added on this screen by filling all five of these lines and pressing <ENTER>. A message will appear under the COMMAND line to tell you the sequence letters entered were added to the $\mathrm{ENN}$, and then five more blank lines will be displayed to accept more sequence letters. Repeat this process until all desired entries have been made.

When you have entered the sequence letters and pressed <ENTER>, you will be returned to the Assign Special Project EJN screen unless you selected to add additional ESOs at the time you reserved the EJN. In this case, you will receive the Special Project ESO Addition screen displayed below. 
2. Special Project ESO Addition Screen. When you select to add additional ESOs to the EJN you just reserved, the following screen will be displayed:

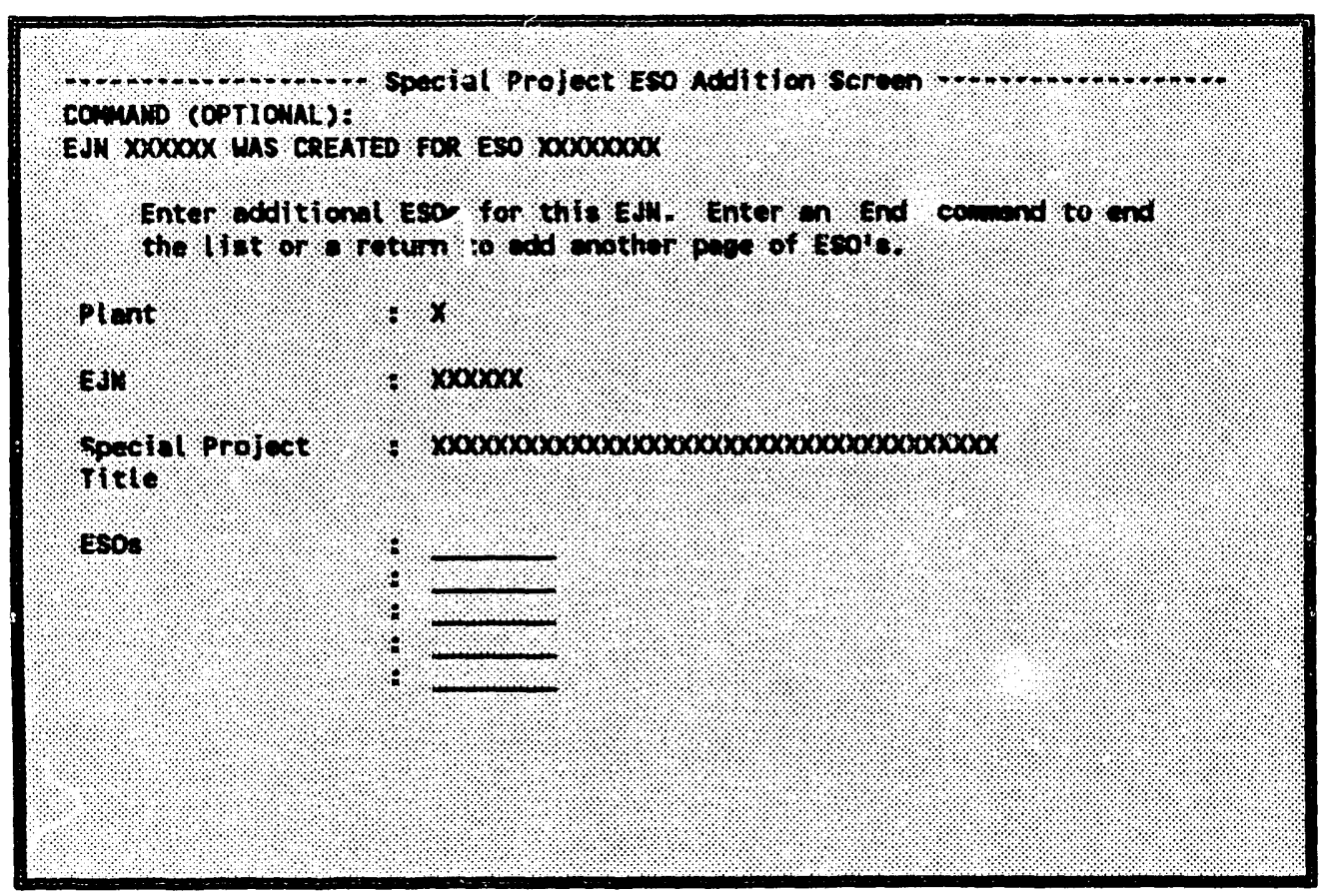

The message "EJN XXXXXX WAS CREATED FOR ESO XXXXXXXX" may be displayed on the second line of this screen if you access it directly after requesting an EJN without first selecting sequence numbers. Use the $\langle\mathrm{TAB}>$ and $<$ SHIFT $><\mathrm{TAB}>$ keys to move the cursor between input fields for entry of ESOs. END and <ENTER> may be typed on the COMMAND line to cancel this screen.

More than five ESO numbers can be added on this screen by filling all five of these fields and pressing <ENTER>. A message will appear under the COMMAND line to tell you the ESOs entered were added to the EJN, and then five more blank lines will be displayed to accept more ESO numbers. Repeat this process until all desired entries have been made. When all ESOs are entered, press <ENTER> to save these entries and return to the Assign Special Project EJN screen. 


\section{Query Special Projects (2)}

Query, adaition, or modification of existing EJN information can be performed using option 2 of the Special Project Menu screen. The following Search screen will be displayed for you to identify the EJN group you wish to access:

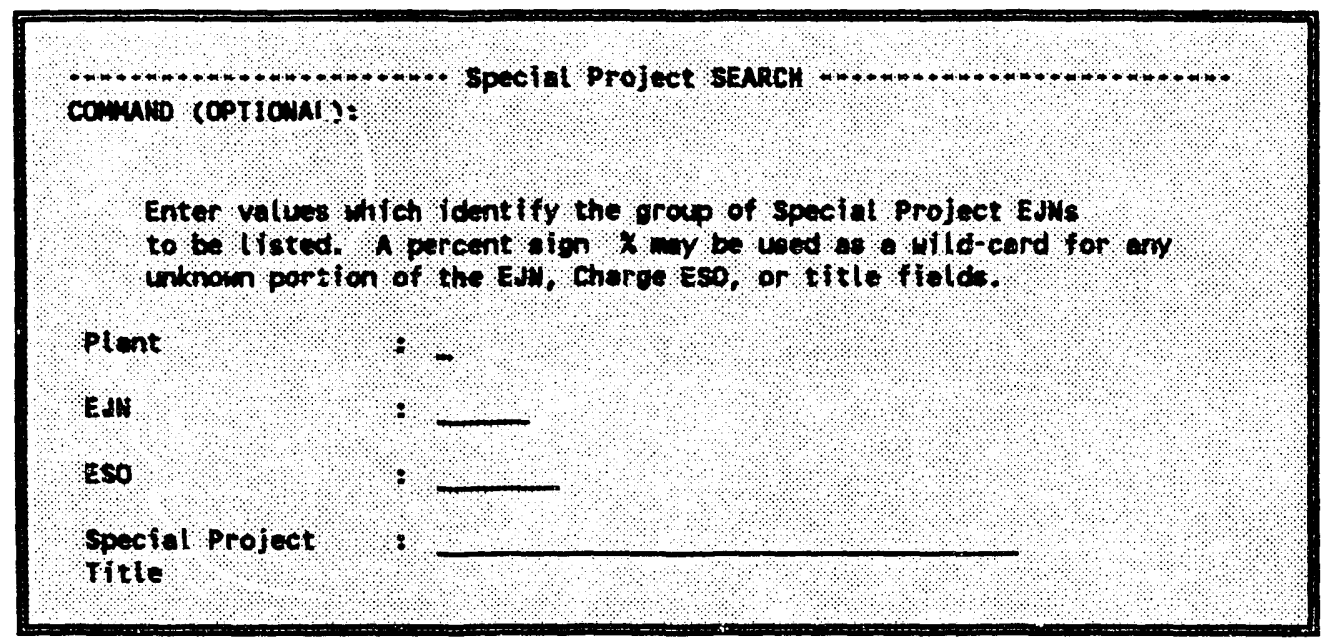

Use $\langle\mathrm{TAB}>$ and $<\mathrm{SHIFT}><\mathrm{TAB}>$ to move the cursor between input fields. The END command will cancel the search and return you to the Special Project Menu screen. Enter as many search criteria as possible, using the percent sign (\%) for any portion of the EJN, ESO, or title that is not known.

When the search criteria are entered and <ENTER $>$ is pressed, all records meeting the search criteria will be located and displayed on the ENN List screen shown below:

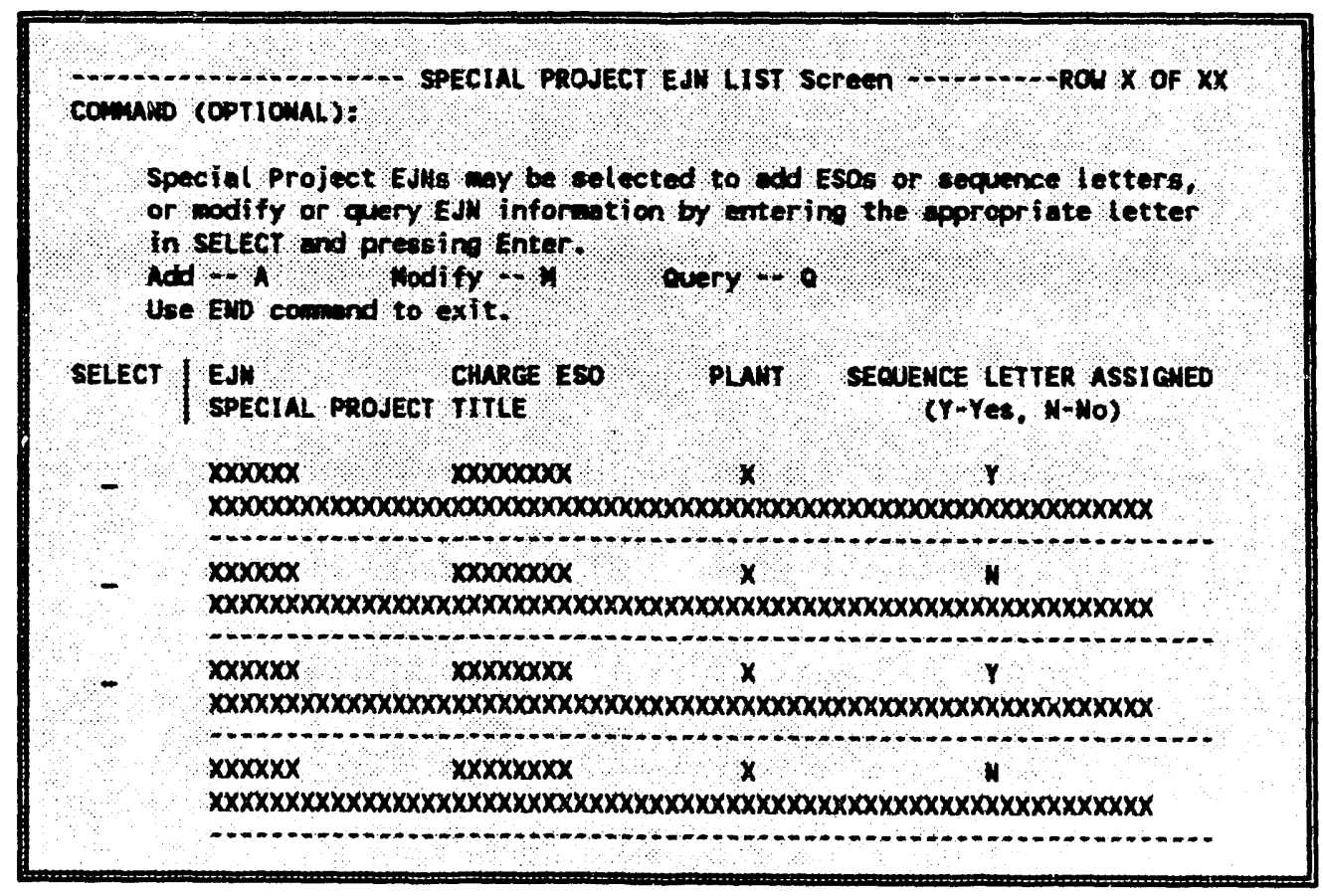


Use the $<T A B>$ and $<$ SHIFT $><T A B>$ keys to move the cursor to the SELECT column input fields to select an EJN for query, title modification, or addition of sequence letters and ESOS. One of the following codes can be entered in the SELECT field to perform these actions:

Code

A

$\mathbf{M}$

$\mathbf{Q}$
Action

Add ESOs to the ENN. If Sequence Letters Assigned column on the above screen is Yes, this function also will allow new sequence letters to be assigned.

Modify the EJN title. If Sequence Letters Assigned column on the above screen is Yes, this function also will allow existing sequence letter titles to be modified.

Query the EJN Title. If Sequence Letters Assigned column on the above screen is Yes, this function also will allow existing sequence letter titles to be queried.

The steps required to perform each of these functions are described below.

\section{Add}

If sequence letters are assigned to the EJN selected from the EJN List screen, the Special Project Addition Menu shown below will be displayed for you to indicate whether you want to add an ESO or a sequence letter to the EJN. If the sequence letter option is not available for this EJN, you will go directly to the ESO Addition screen (the second screen displayed below).

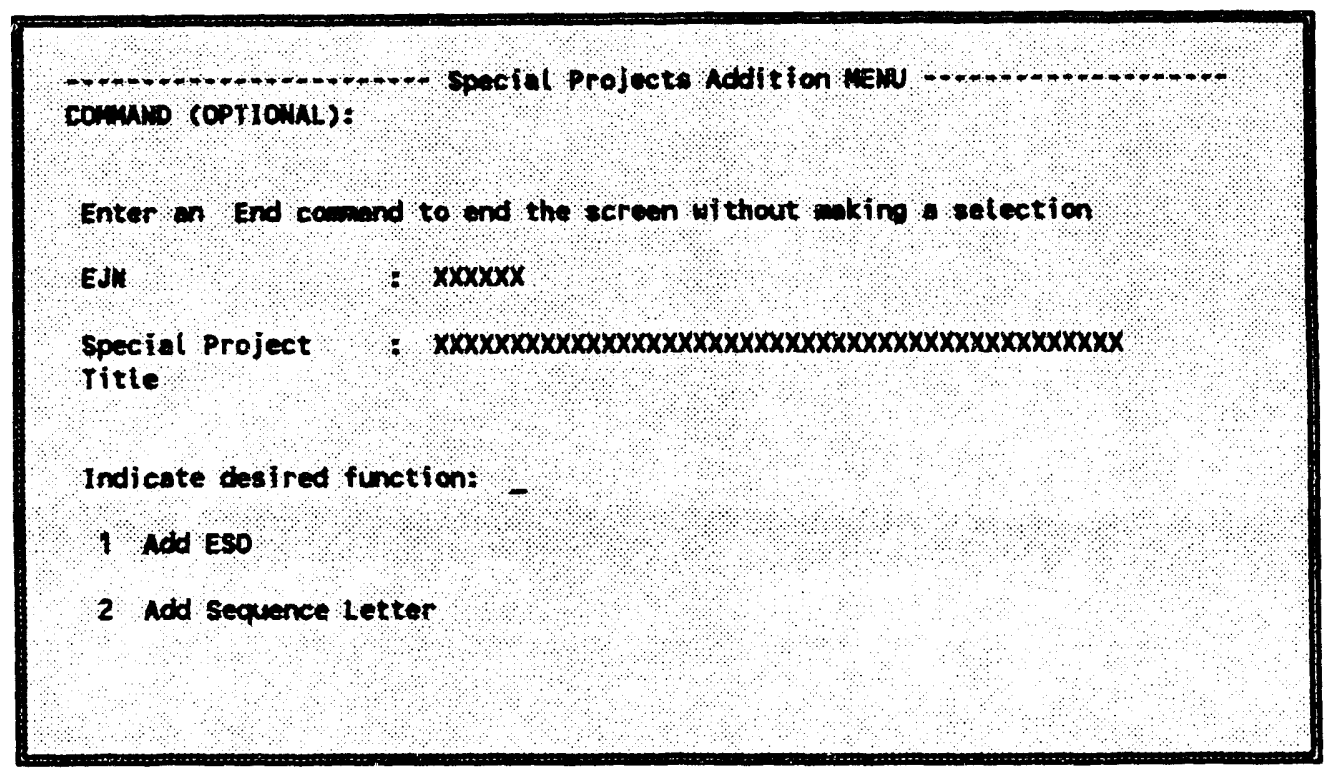

Enter either 1 or 2 by the "Indicate desired function:" prompt and press <ENTER>. These options will be performed as described below: 
1. Add ESO. If 1 is entered on the above menu, the ESO Addition screen will be displayed to accept input of additional ESO numbers:

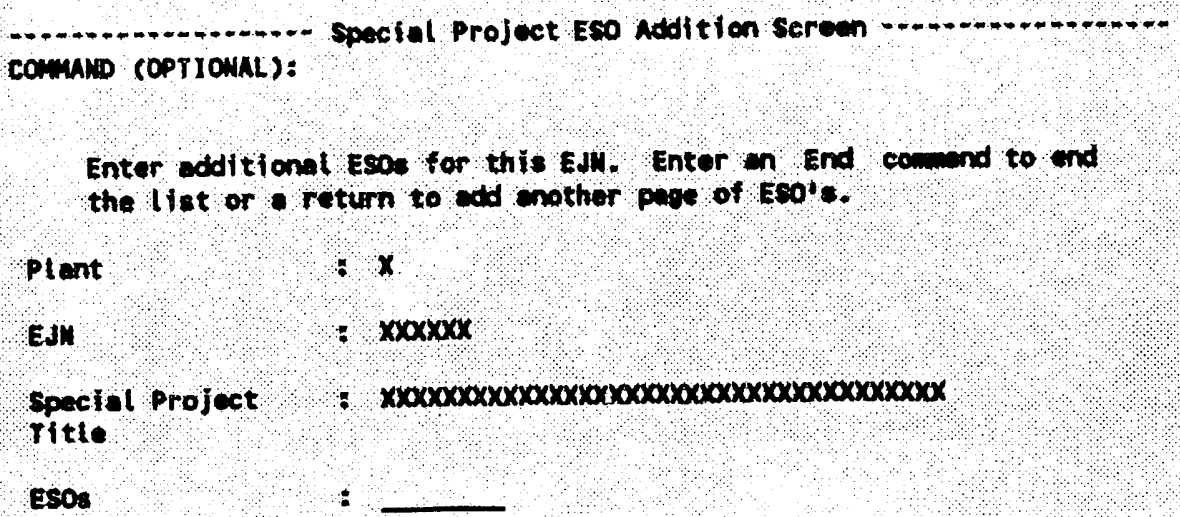

Use the $\angle \mathrm{TAB}>$ and $<\mathrm{SHIFT}><\mathrm{TAB}>$ keys to move the cursor to the input fields to enter ESO numbers. The END command will exit this screen without adding any ESOs and return you to the EJN List screen.

More than five ESO numbers can be added on this screen by filling all five of these fields and pressing <ENTER>. A message will appear under the COMMAND line to tell you the ESOs entered were added to the EJN, and then five more blank lines will be displayed to accept more ESO numbers. Repeat this process until all desired entries have been made.

Press <ENTER> when all ESOs are entered, and you will be returned to the EJN List screen, where the ESOs just added will be included on the list. 
2. Add Sequ ince Letter. Option 2 on the Addition Menu allows you to add additional sequence letters and titles to an EJN using the following screen:

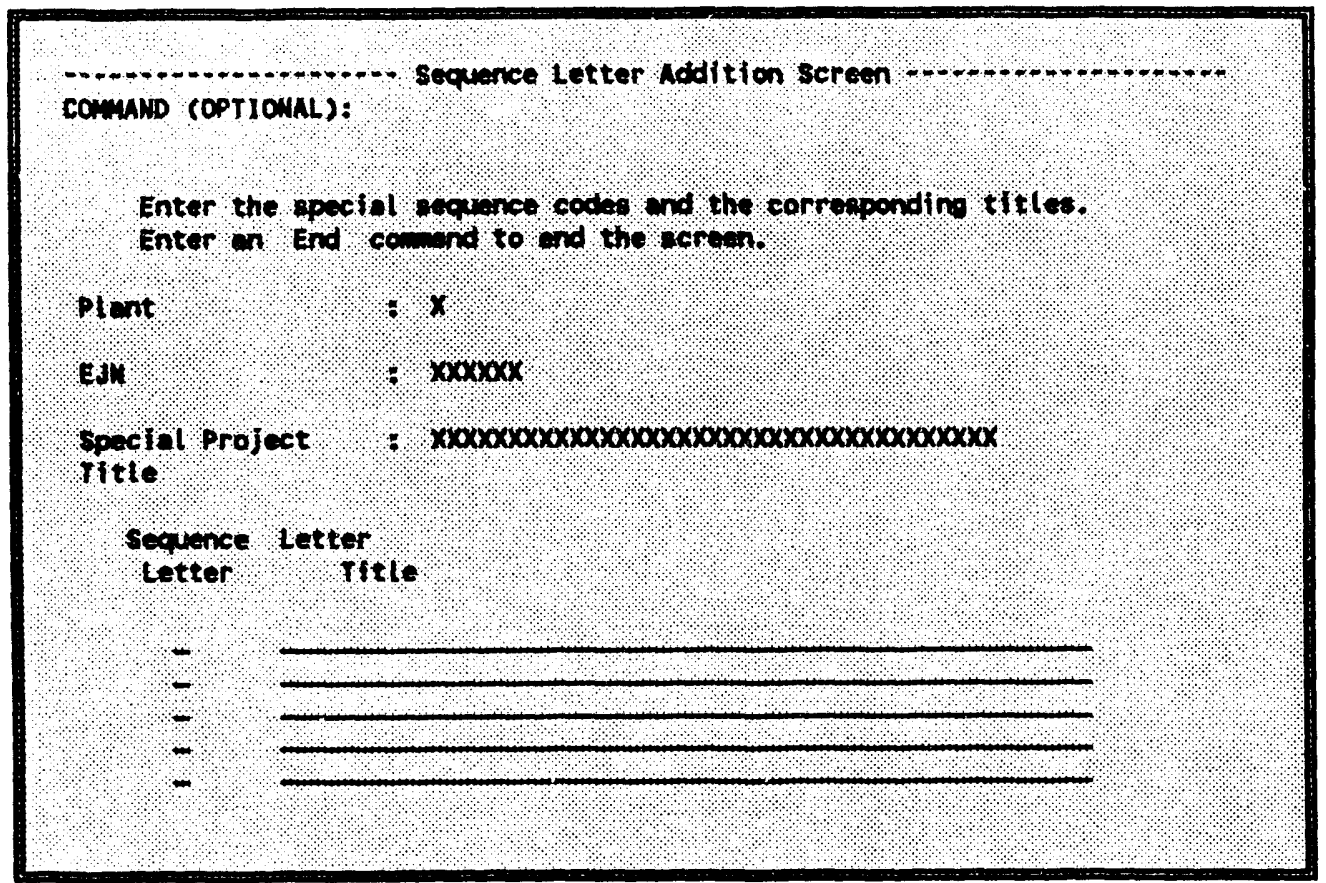

Use the $<\mathrm{TAB}>$ and $<\mathrm{SHIFT}><\mathrm{TAB}>$ keys to move the cursor to the input fields to enter sequence letters and titles. The END command will exit this screen without adding any sequence letters and return you to the EJN List screen.

More than five sequence letters can be added on this screen by filling all five of these lines and pressing <ENTER>. A message will appear under the COMMAND line to tell you the sequence letters entered were added to the ENN, and then five more blank lines will be displayed to accept more sequence letters. Repeat this process until all desired entries have been made.

Press <ENTER> when all sequence letters are entered, and you will be returned to the EJN List screen to END or select another function. 


\section{Modify}

If the M command is entered for an EJN on the EJN List screen, and that EJN has sequence letters assigned, the following Special Projects Modification Menu will be displayed. If no sequence letters are assigned to the selected EJN, you will go directly to the Title Modification screen (the second screen displayed below).

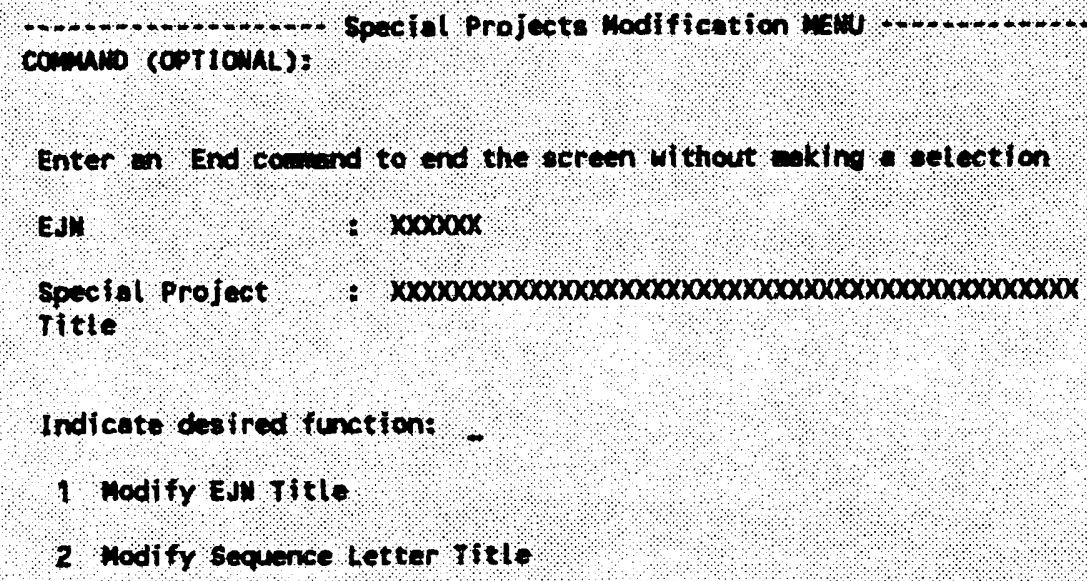

Enter either 1 or 2 by the "Indicate desired function:" prompt and press $<E N T E R>$. These options will be performed as described below:

1. Modify EJN Title. If $\mathbf{1}$ is entered on the above menu, the following Title Modification screen will be displayed:

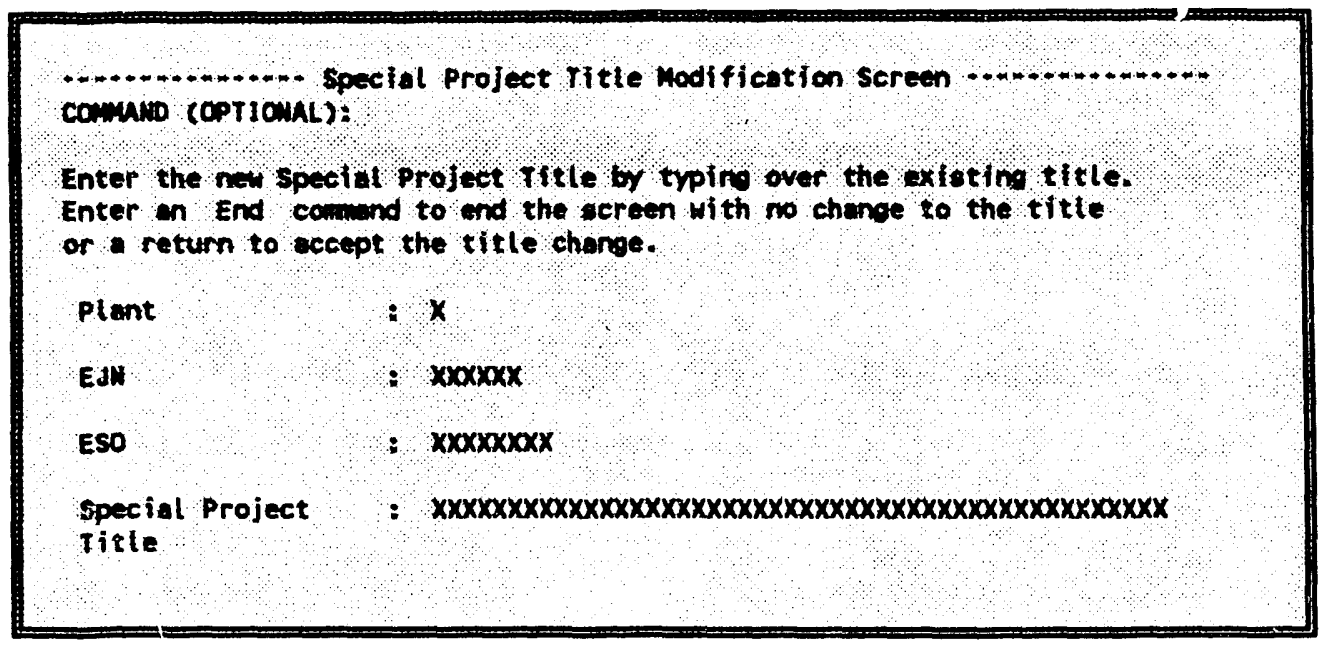

The only data that can be modified on this screen is the EJN title. Overtype the existing title and press <ENTER > to save the new title. You will be returned to the EJN List screen. 
2. Modify Sequence Letter Title. If you entered option 2 at the Modification Menu prompt, the following Sequence Letter Modification screen will be displayed listing all of the sequence letters and titles for the selected EJN, allowing title modification:

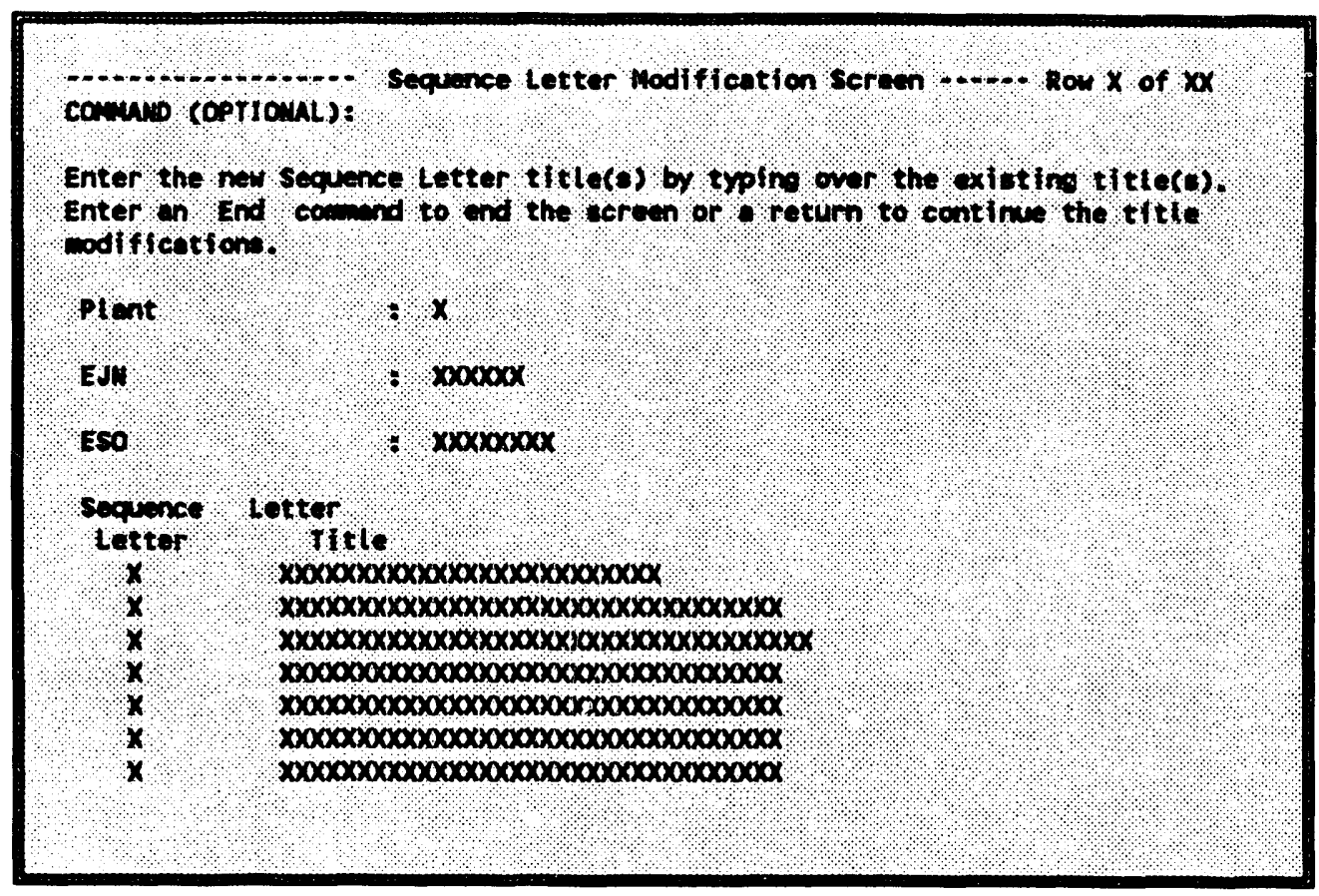

Use the $<\mathrm{TAB}>$ and $<\mathrm{SHIFT}><\mathrm{TAB}>$ keys to move the cursor to the titles you wish to change. If more sequence letters exist for this EJN than are shown on the screen, the message "ROW _ OF _" in the upper right-hand corner of the screen will indicate how many rows exist and the number of the first row that is displayed on the screen. Enter either UP or DOWN and <ENTER> on the COMMAND line to scroll the additional sequence letters onto the screen. W'hen the screen is scrolled, any title changes you have made on the first list displayed will be saved, and you will receive a message below the COMMAND line confirming THE TITLE(S) HAVE BEEN UPJATED FOR EJN XXXXXX."

When all modifications have been made, press <ENTER > to save the current changes. To exit this screen and return to the EJN List screen, type END and <ENTER> on the COMMAND line. If you give the END command without first pressing <ENTER> to save the current screen's changes, the system will exit this screen without saving the changes. 
Query

If you entered the $Q$ command on the Special Project EJN List screen to query a selected EJN, the If you entered the $Q$ command on the Special Project EJN List screen
Special Projects Query Menu shown below will be displayed if the EJN has sequence letters assigned. If
sequence letters do not exist for the select EJN, you will go directly to the EJN Query screen (the second screen displayed below).

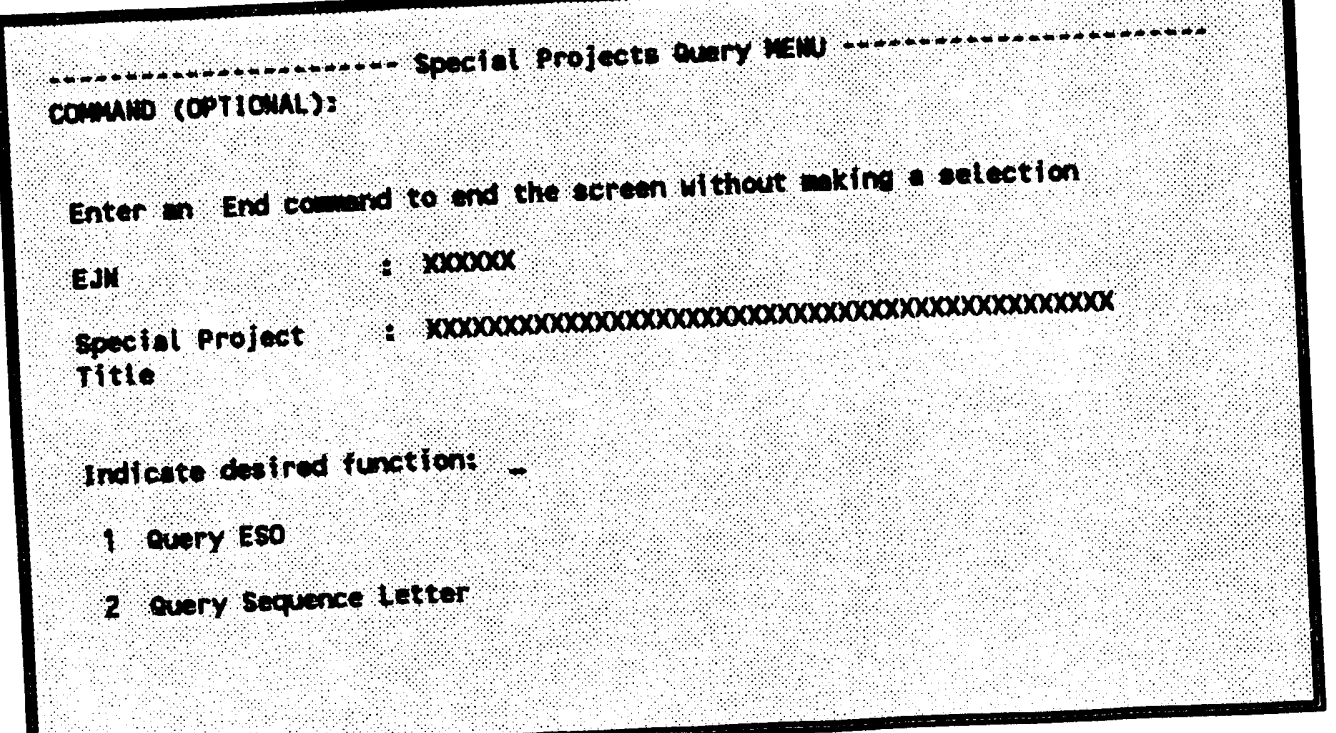

Enter either 1 or 2 by the "Indicate desired function:" prompt and press <ENTER>. Either one of the following steps will be performed:

1. Query ESO. If 1 is selected from the above menu, the EJN Query screen will be displayed:

special Projects EJW Query screen

COWUND (OPTIOUAL):
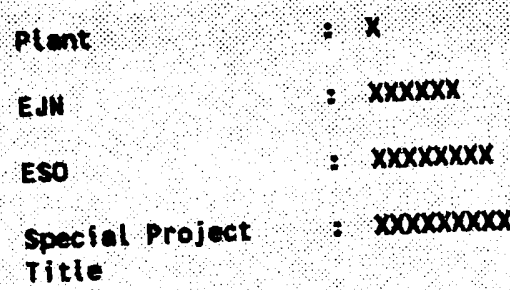

This screen is for display only and may not be modified. To exit the screen, enter END and $<$ ENTER > on the COMMAND line, and you will be returned to the EJN List screen. 
2. Query Sequence Letter. If option 2 is entered on the Query Menu screen, the Sequence Letter Query screen will be displayed:

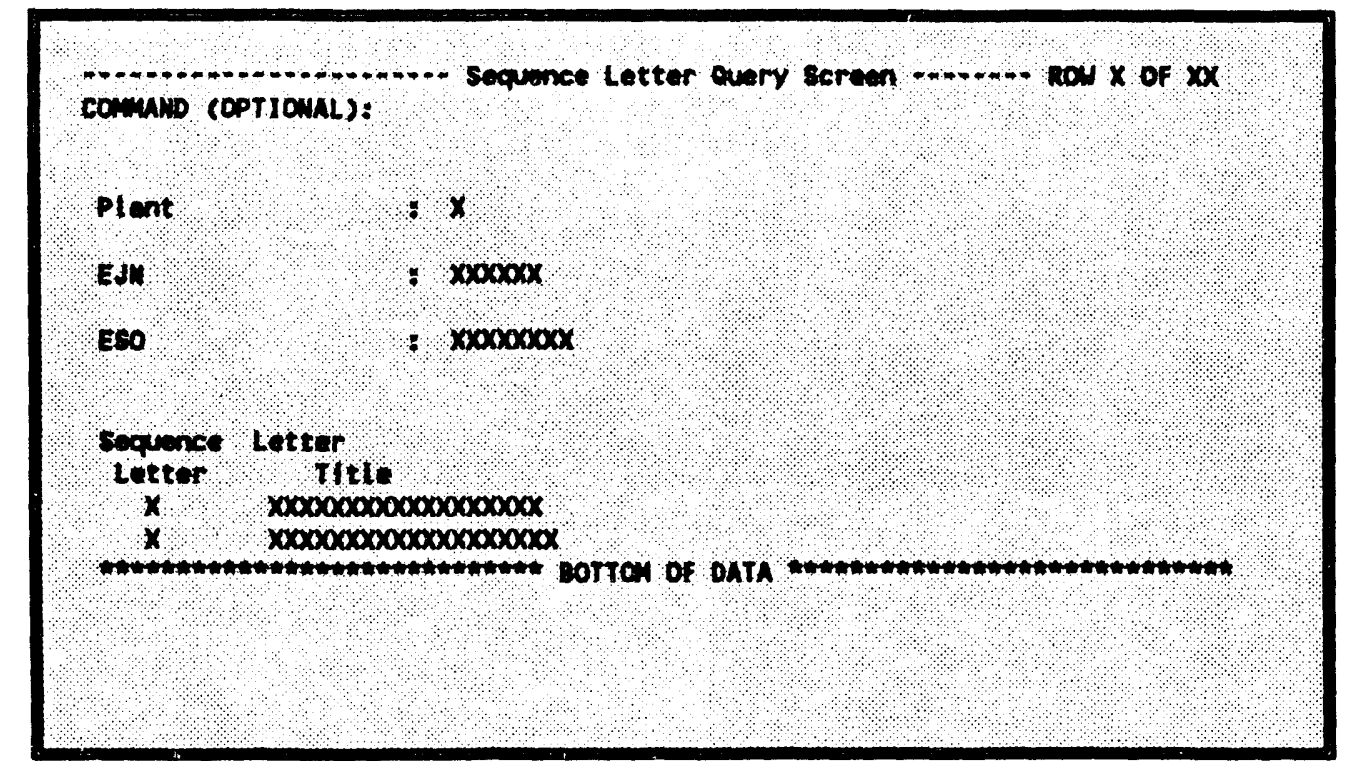

This screen displays all of the sequence letters and titles for the seiected EJN. If the "ROW - OF _- message on the upper right-hand corner of the screen indicates that more rows of data exist than are displayed on the screen, enter UP or DOWN and <ENTER> on the COMMAND line to scroll the additional information onto the screen for viewing. This data is for display only and canicot be modified. To return to the EJN List screen, enter END and <ENTER > on the COMMAND line. 


\subsection{ADDB Option (A)}

The ADDB provides the capability to perform query functions on active CADAM models or on those models that currently reside in user subgroups. This capability allows for the sharing of design information, provides identification of duplicate design activity, and assists in detection of the use of duplicate revision codes for a drawing. This capability can also be used in clean-up efforts to identify models that have not been updated since a specified date.

Instructions for using the ADDB have not been included as part of this document but have been published as a separate document. Please refer to Active Design Database (ADDB) User's Manual (K/CSD/TM-97) for further information concerning the ADDB subsystem. 


\subsubsection{Tutorial Option (I)}

When the tutorial option is selected from the Primary Option Menu, the following Tutorial Select Menu is displayed to allow you to select the tutorial information you wish to view.

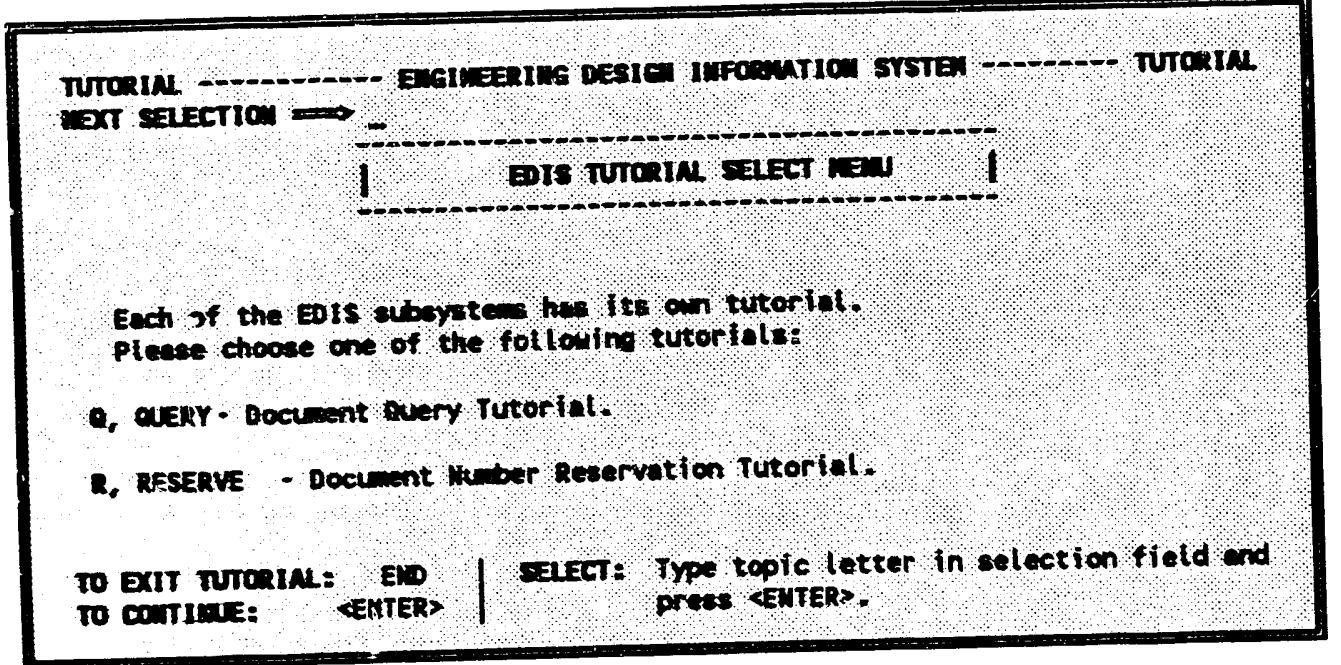

This option is currently available only for the Reserve subsystem of EDIS (option R on the Primary Option Menu). When the Reserve tutorial option is selected from the Tutorial Select Menu, the first screen of the Reserve Tutorial will be displayed on your terminal screen, as shown below.

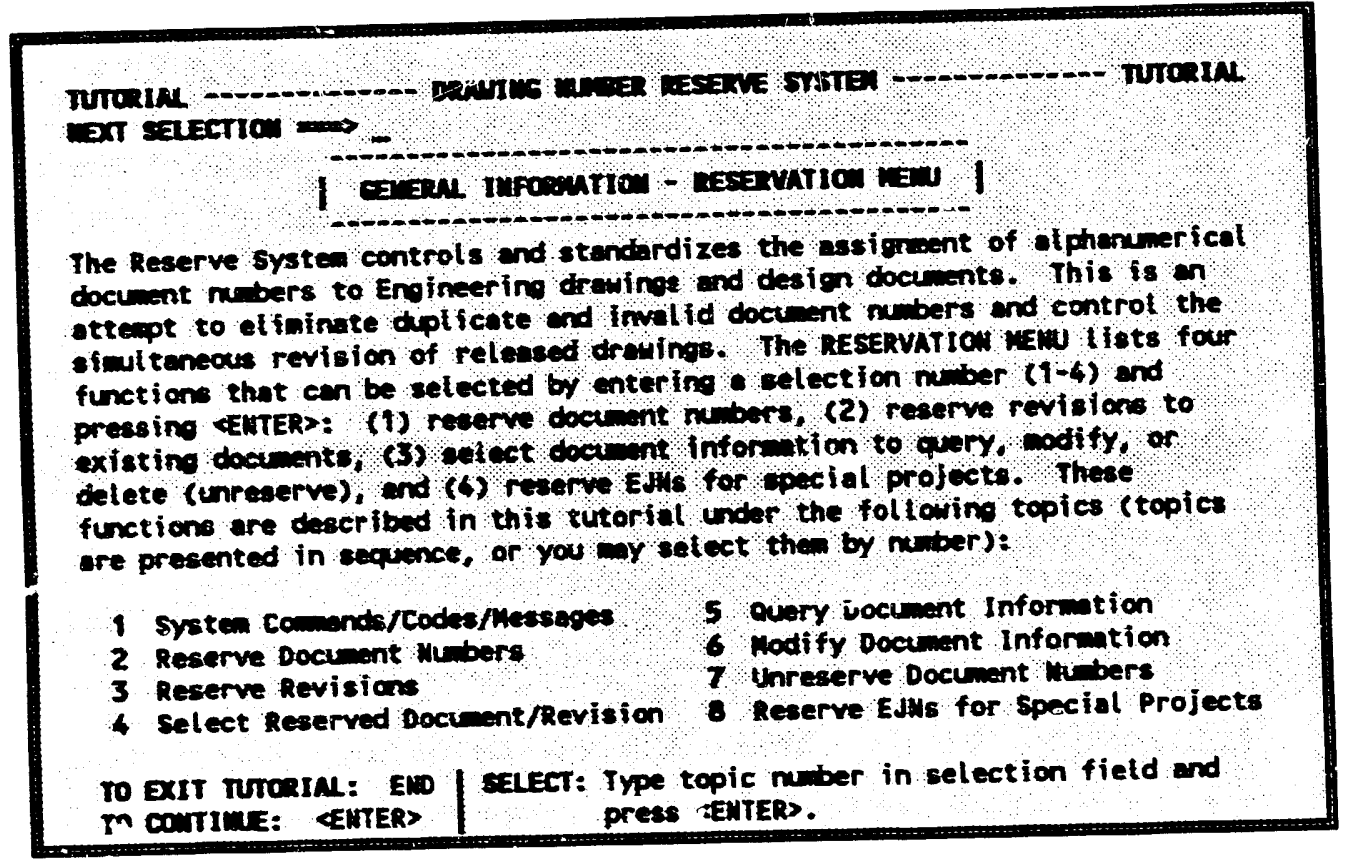

The tutorial can be viewed in its entirety by pressing <ENTER> to page through each successive screen. It can also be viewed in segments that describe the procedures to follow for each individual Reserve subsystem screen. Options 1 to 8 listed on the tutorial menu describe the separate functions and screens for the Reserve subsystem. Enter the option you wish to view at the NEXT SELECTION prompt at the 
top of the screen and press <ENTER>. Options to allow you to move about in the tutorial screens are displayed at the bottom of each screen. When you have completed viewing the tutorial, type END and <ENTER > at the NEXT SELFCTION prompt, and you will be returned to the EDIS Primary Option Menu.

The tutorial car also be accessed from any Reserve subsystem screen by typing HELP or $\mathrm{H}$ in the COMMAND line and pressing <ENTER>. If accessed by this method, upon typing END and <ENTER> to exit the tutorial, you will be returned to the subsystem screen from which the tutorial was accessed.

Tutorial information for the Query and ADDB subfunctions of EDIS will be provided at a later date. 

be met.

To perform the View function of EDIS, the following hardware and software requirements must first

1. Viewing requires the use of an IBM 3270-type terminal or a microcomputer equipped with 3270 emulation that supports the display of Graphical Data Display Manager (GDDM) graphics (such as IRMA) connected through coaxial cable or an IBM token ring network.

2. Your TSO account must be set up to allow the request of a larger region size than normally allowed.

3. Special logon requirements apply to the viewing function.

Please contact your Engineering User Representative, Karen Shaw, at 4-7869 for more information regarding the View function. 


\section{APPENDIX B: SOFT MASTER}

Soft Master is a computer program that allows a you to view a CADAM drawing on a low-cost graphics terminal without the need for expertise in the use of CADAM. You can perform viewing and query on an actively displayed drawing. Other features such as drawing mark-up and plotting are available in Soft Master but are not active in the EDIS Phase II environment.

The information presented in this appendix is adapted from the manual Soft Master Release 3.0, A Dynamic Viewing Analysis, and Mark-Up System for the CADAM Database with permission from IGS Corporation.

Soft Master uses the IBM Graphical Data Display Manager (GDDM) software to display the graphics on the terminal screen. To view a drawing, your terminal or terminal emulation software must support GDDM graphics. Because both the ASCIISeries 1 and the IBM 7171 terminal emulators do not support GDDM, users accessing EDIS via the DCA will be unable to perform the Soft Master viewing capabilities.

\section{B.1 OBTAINING ACCESS TO SOFT MASTER VIEWING}

Soft Master can be executed from the EDIS Detailed Document Information Screen, Format Listing Screen, or either of the Abbreviated Document Listing screens by placing a $V$ in the drawing Select field or COMMAND line of the screen and pressing <ENTER>. The model(s) associated with the selected drawing will then be displayed by Soft Mas er. When more than one model is associated with the drawing, each model will be displayed in a separate color. Instructions for viewing are presented in Sect. B.4. Pressing the <PF13>, <PF13>, <PF24> function keys in separate keystrokes will exit the Soft Master program and return you to the EDIS system screen from which the View request was initiated.

\section{B.2 SOFT MASTER SCREENS}

There are two screens used by the Soft Master program: the Command screen and the Graphic screen. You can toggle between these two screens by pressing the <PF9> key.

\section{B.21 Graphic Scraen}

The Graphic screen is used for the display and selection of CADAM drawing geometry. Using the Window function, you can perform pan, zoom, and full display of an active drawing. Using the Analysis function, you can select geometry, such as a circle, and afterwards be provided specific data about the element, such as coordinate location, diameter, etc.

\section{B.22 Command Screen}

The Command Screen shown below depicts the Soft Master menus/commands that are available to you. The listing of CADAM drawings, subgroups, and Soft Master prompts and error messages are also presented on this screen. 


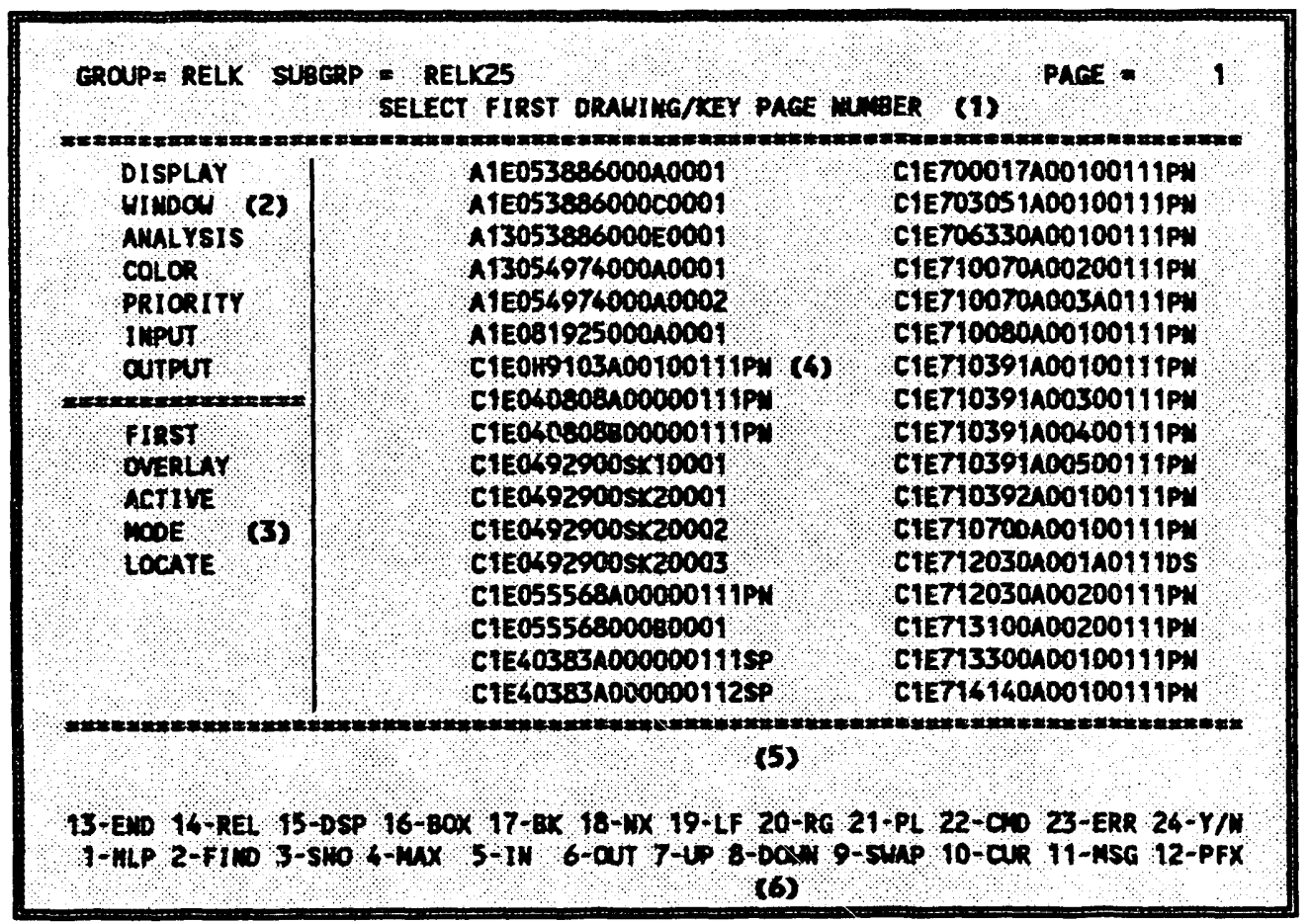

Sections of the screen (1-6) that manage these functions are numbered on the above example and described as follows:

1. Section 1 is used for messages and prompts to the user.

2. Section 2 is used to display the menu of major functions that are available. The function that is active will appear in red.

3. Section 3 is used to display the menu of subfunctions available for the current function.

4. Section 4 is used to display major lists of information by the program. Typically found in this portion of the screen is the scroll area for drawing IDs or the output of the Analysis function.

5. Section 5 displays a help message informing the user of the available $<\mathrm{PF}>$ function keys.

6. Section 6 is used for keyboard input to the program. Move the cursor to this part of the screen to type information in response to prompts appearing in Section 1. 


\section{B3 SOFT MASTER COMMAND KEYS}

\section{B.3.1 <ENTER> KeY}

The Command screen displays a menu of the available functions, subfunctions, and lists. Any of these may be selected by moving the cursor to that screen location and pressing the <ENTER > key. The
current selection will appear in red.

\section{B.3.2 $\leq$ PF $>$ Function Kers}

Many of the most often used commands can be selected by using the $<P F\rangle$ function keys on the terminal keyboard. When using IRMA emulation software, the $\langle$ PF1 $>$ through $<P F 12>$ function keys are represented by the $<F 1>$ through $<F 12>$ keys on most keyboards, while $<$ PF13 $>$ through $<$ PF24 $>$ the quickest and easiest method of entering the come $\langle$ F1 $>$ through $\langle$ F12 $>$ keys, respectively. This is described below. Instructions for performing basic functions. The function keys and their actions are more information, contact the EDIS support group.

\section{Function Key}

Action

$<$ PFi $\quad$ HLP - Help. Turns on and off a display of the function key settings on the bottom
of the Graphic screen.

<PF4> MAX - Maximum View. Scales the window so that the entire drawing geometry fits
exactly on the display screen.

<PF5> IN - Zoom In. Rescales the screen to display the image in greater detail.

<PF6> OUT - Zoom Out. Rescales the screen to display less detail but more of the image.

<PF7> UP - Scroll Up. Scrolls up through the drawing list (on the Command screen) or moves the window upwards on the displayed geometry (on the Graphic screen).

<PF8> DOWN - Scroll Down. Scrolls down through the drawing list (on the Command screen) or moves the window downwards on the displayed geometry (on the Graphic
screen).

<PF9> SWAP - Swap Screens. Toggles between the Graphic screen and the Command screen with each depression of the function key.

$<$ PF10> CUR - Cursor. Toggles between the keyboard cursor and mouse cursor.

<PF11> MSG - Message. Displays the next line of a message in the Command Area such as the next line of a multiple line Analysis output.

PF12 $>$ PFX - Alternate Function. Invokes an alternate function for function keys $<$ PF1
through $<$ PF24 $>$ when pressed before through $<$ PF24 $>$ when pressed before one of these $<P F>$ keys. The PFX key is
active for one depression only. 
<PF13> END - End Function. Exits the current function to the next higher command level.

<PF14> REL - Relative Distance. Calculates the relative distance between the last two geometry selections.

<PF15> DSP - New Display. Clears the current Graphic screen of highlighted elements and other temporary annotation created by functions such as Analysis.

<PF16> BOX - Window Box. Defines a rectangular area on the Graphic screen selected by marking the opposite corners of the rectangle on the geometry and expands the defined rectangle to fill the screen.

<PF19> LF - Scroll Left. Moves the window to the left 3/4 screen on the displayed geometry.

<PF20> RG - Scroll Right. Moves the window to the right 3/4 screen on the displayed geometry.

<PF23> ERR - Error-Tutorial Key. Displays the current tutorial message if it is overlayed by an error message in the command area.

<PF24> Y/N - Yes/No. Provides a general-purpose alternative selection switch that is explicitly called for in a number of commands and subcommands.

\section{B.3.3 $\leq$ RESET $>\mathrm{Key}$}

Sometimes, after an error in entering commands, the keyboard will lock and $\mathrm{X}$ ?+, $\mathrm{X}-\mathrm{f}$, or $\mathrm{X}$ and a picture of a stick man will appear in the lower left corner of the screen. It is necessary to press the $<$ RESET > key to free the keyboard.

\section{B.3.4 Terminal Wait Mode}

After a command has been entered that requires the central host computer to perform a process that requires a wait, a picture of a clock will appear in the lower left corner of the screen. No action is required; this simply means that the user will have to wait for the results. 


\section{B.4 HOW TO USE SOFT MASTER}

\section{B.4.1 Swap Between the Command Screen and the Graphic Screen}

Press <PF9> to toggle between the Command screen and the Graphic screen at any time.

\section{B.4.2 View a Drawing or Overlay (Windowing)}

After a drawing or overlay has been selected, there are several viewing operations (described below) available from the Graphic screen. The geometry appearing on the screen at any one time is called a window.

1. Max Size - <PF4 $>$

When $<$ PF4 $>$ is pressed, the scale of the drawing is adjusted so that all of the geometry will fit on the screen at one time. This operation is useful for selecting parts of the drawing for closer viewing.

2. Window Move (Pan)

This operation allows you to reposition the Graphic window without changing the scale of the data. One way to do this is to position the cursor over a point on the drawing to be centered on the screen as follows:

a. Press $<$ PF12 $>$ and $<$ PF15 $>$ one after the other.

b. Move the cursor to the geometry that is to appear at the center of the screen.

c. Press $<$ ENTER $>$.

The Graphic window can also be repositioned by using the Up Move ( $<$ PF7 $>$ ), Down Move (<PF8 >), Left Move (<PF19>), and Right Move (<PF20>) commands. These commands move the Graphic window $3 / 4$ screen width in the direction specified.

3. Window Size (Zoom)

These operations allow you to cause the size of the geometry on the screen to appear larger or smaller. Use either method a or method $b$.

a. Method a.

i. Press $<\mathrm{PF} 12>$ and $<\mathrm{PF} 16>$ one after the other.

ii. Position the cursor. To make the geometry appear smaller, place the cursor in the upper half of the screen. To make the geometry appear larger, place the cursor in the lower half of the screen.

iii. Press <ENTER >. 
b. Method b.

i. Press <PF5 > to make the image double the displayed size or $<$ PF6> to make the image half the displayed size.

ii. $\quad$ Press $<$ ENTER $>$.

The <PF4> key quickly sizes the graphic window to display all of the current drawings within the screen boundaries.

4. Window Box

This operation allows you to select a portion of the geometry on the screen and have it expanded to the full screen.

a. Press $<$ PF16 $>$.

b. Move the cursor to one corner of the rectangle to be displayed.

c. Press <ENTER>.

d. Move the cursor to the opposite corner of the rectangle.

e. Press <ENTER>. The box will be enlarged to fill the Graphic window.

5. Keep - Save the Contents of the Screen

At any time, the window that appears on the screen can be saved for later recall. It is possible to keep as many as ten separate windows.

a. When it is desired to save the contents of the screen, press <PF9> to return to the Command screen.

b. Select the function WINDOW if it does not appear in red letters.

c. Select the subfunction KEEP.

d. The prompt KEY NUMBER TO KEEP CURRENT WINDOW will appear in section 1.

i. Move the cursor to section 5, under the help line.

ii. $\quad$ Type a number between 0 and 9.

iii. Press $<$ ENTER $>$.

e. Press <PF9> to return to the Graphic screen for further viewing. 
6. Restore

This command is used to swap between saved windows.

a. If the Graphic screen is current, press <PF9> to swap to the Command screen.

b. Select the function WINDOW, if it does not appear in red letters.

c. Select the subfunction RESTORE.

d. Move the cursor to section 6.

e. Type the number of a previously saved window.

f. Press <ENTER>.

g. Press $<$ PF9 $>$ to return to the Graphic screen to view the window.

7. Relative Analysis

This operation calculates the distance betwicen two geometric elements in the Graphics screen.
a. Press $\langle$ PF14 $>$.
b. Move the cursor to the first element to be analyzed.
c. Press $<$ ENTER $>$.
d. Move the cursor to the second element.
e. Press $<$ ENTER $>$.
f. $\quad$ Press $<$ PF14 $>$.
g. View relative analysis in the message area of the Graphic screen or press $<$ PF9 $>$ to view the relative analysis information in the list area of the Command screen.

8. Exit Soft Master.
a. Press $<$ PF13 $>$ to exit the current command level.
b. Press <PF13> again to exit the next command level.
c. Confirm exit with the Yes/No key, <PF24>. 


\section{B.4.3 Remove a Model from an Overlay}

Sometimes it is desirable to remove a model from an overlay that has been accumulated. Perhaps the wrong model was chosen, or the overlay is too busy. The default from EDIS is an overlay of the models associated with the drawing being viewed (when more than one model is associated with the drawing being viewed).

1. On the Command screen, select the function DISPLAY and the subfunction ACTIVE.

2. The list of models making up the overlay will be shown. Select any models that are to be removed from display.

3. Press <PF9> to return to the Graphic screen.

\section{B.4.4 Select More Than One Model for Overlay}

The various features of a building will occur on separate models. These models will all have the same name in the first 16 characters of the model name, but the last four characters of the name will differ uniquely. For instance, the exterior walls of a building will appear on one of these models, while the interior walls will appear on a different model. It is possible to see all of these features or to select only certain ones for viewing. The composite of all the drawings selected will appear on the Graphic screen, with each separate model shown in a different color.

1. On the Command screen, press $<$ PF12 $>$ and $<$ PF2 $>$ one after the other, and select the first model of the overlay.

2. Press $<P F 12>$ and $<P F 2>$ and select all the remaining models.

3. It is possible to use <PF9> at any time to monitor the building of the Graphic screen. 


\section{APPENDIX C: SPECIAL REOUIREMENTS FOR STORE AND DOWNLOAD}

To perform the Store and Download Document functions of EDIS, the following hardware and software requirements must first be met:

\section{Hardware}

Your PC must access EDIS through an IBM token ring local area network using the IRMALAN terminal emulation software.

Software

1. First, the IRMALAN terminal emulator must be loaded memory resident. This can be accomplished by entering the following command from DOS:

\section{TOKWS -R}

2. Next, the DCA FT/Express software must be loaded memory resident on the PC. This can be accomplished by entering the following command from DOS:

DCAXFER -R

Please contact your Engineering I I Representative, Karen Shaw, at 4-7869 for more iuformation agarding the Store and Download functions. 
APPENDIX D: HELP AND ERROR SCREENS 
D-1

LIST OF VALID EDIS CODES

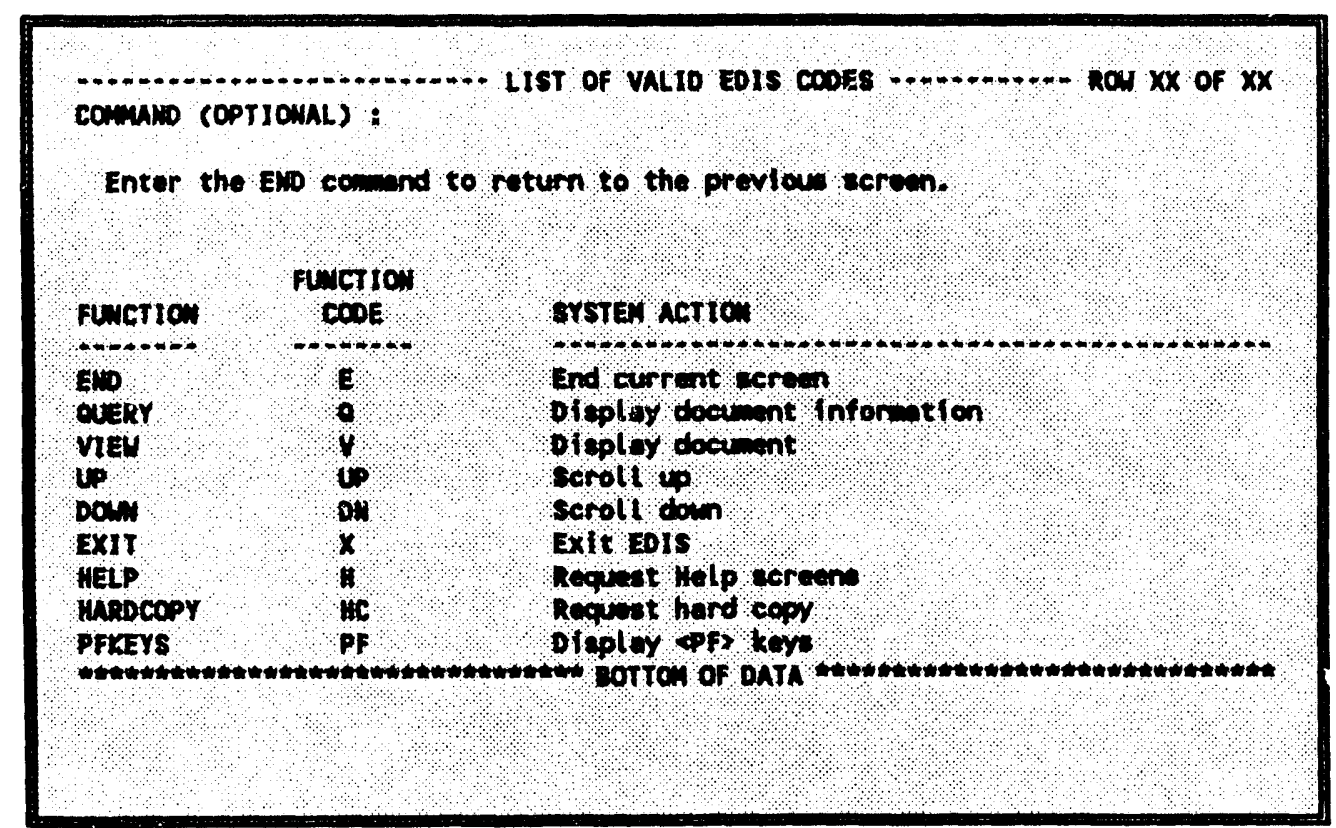

A partial list of these codes will be displayed, depending upon the screen from which this help screen is accessed. 


\section{PLANT LIST SCREEN}

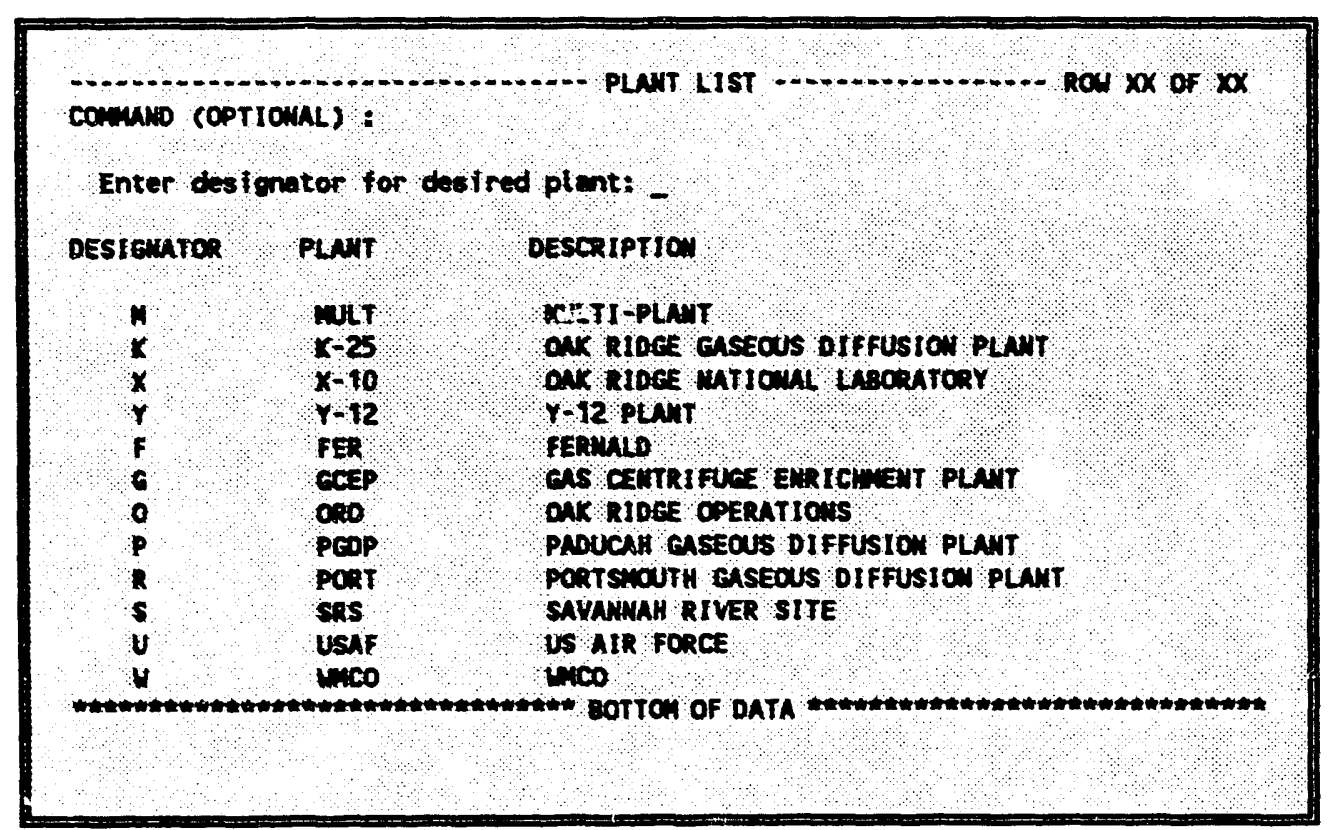

A partial list of these codes will be displayed, depending upon the screen from which this help screen is accessed. 
D-3

\section{PLOTTER ID SELECTION SCREEN}

Select Plotter 10 $\operatorname{rod} \times x$ of $x$

comand:

select the desired plotter code by typino, In the eelect field and preasing the EUTER key.

Enter the ED conand to return to the previoul saren.

select ploter 10 Plotter pescription

P1

- 1 P2

-1 P3

$-+\$ P 6$

catconp ploter at buitding Y $9733-1$

VERSATEC Ploter at Buil Ling $1-9733-2$

calcone plotter et euriding Y-9105

calconp plotter ot euritding $x-1580$

calcosp plotter ot buftding $x-1000$ 
DOCUMENT STORE FORMAT SEI.ECTION SCREEN

COMnano :

The following list containe valid current bocumant format codes requif red as input in the EDis store function. select one of the valif coded by entering on $x$ in the select fibld beside the eppropr iate code.

Enter the Elo comand to retum to the previous sereen.

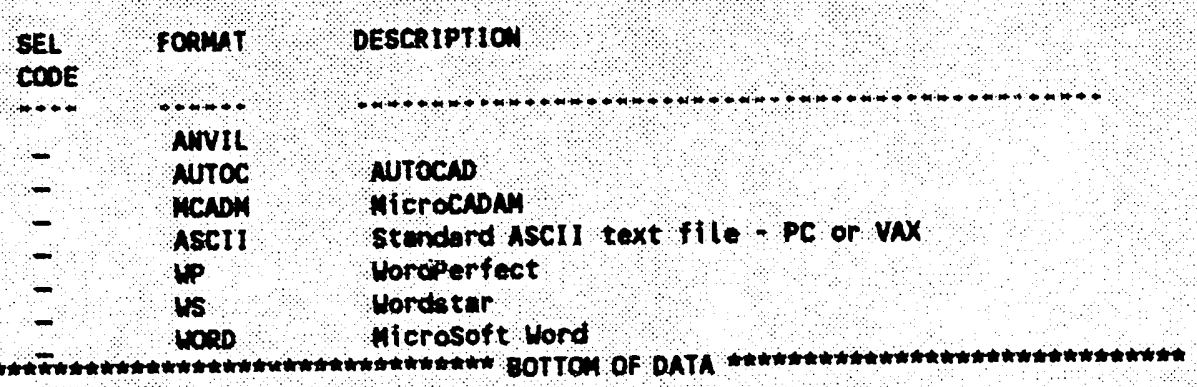




\section{CLASSIFICATION CODE LIST SCREEN}

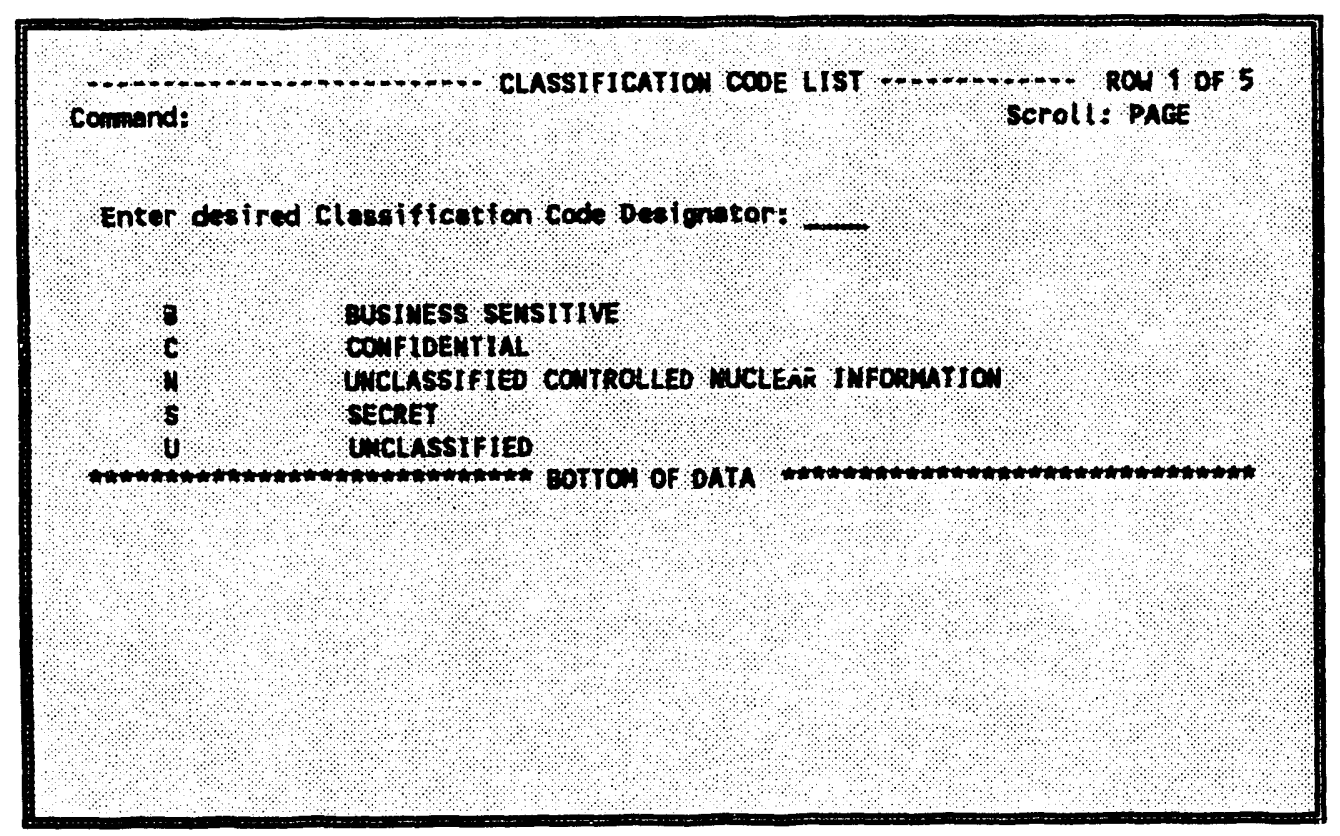




\section{SELECT BUILDING NUMBER SCREEN}

COMMAND (OPTIONAL):

SELECT BUILDING WUIBER

Rai 1 of 807

Select desired building by typine $X$ and pressing EWTER

Use UP and Daw cowands to view entire list, if neceseary.

SEL OUILOIMG EJN

surLoInG ware

CRBR-PO

720000

$K-1000 \quad 710000$

$-k-1001$

710010

- $x-1001-\lambda \quad 710010$

$x-1001 \cdot 8 \quad 710010$

- $\mathrm{x}-1001-\mathrm{C} \quad 710010$

$x-1001-0 \quad 710010$

K-1002 710020

- $x-1003 \quad 710030$

- K-1003-A 710030

$-<-1004-A \quad 710040$

- $k-1004-B \quad 710040$

$-\mathrm{K}-1004-\mathrm{C} \quad 710040$

$k-1004-0,710040$

CRBR - PROJECT OFFICE

CONFERENCE ROON (PORTAL \&)

NDIIN BUILDING

ROWINISTRATIO EUILOING - UIHG A

ADMIUISTRATIOH BUILDING - MING 8

ADNIWISTRATIOA BUTLDING - UING $c$

ADHINISTRATION BUILDING - YING D

CAFETERINLIBRARY JOFFICES

OISPEISARY

OISPENSARY OFfICE TRATLER

LABORATORY FACILITIEES

LABORATORY FACILITIES

LABORATORY FACILITIES

LABORATORY

LABORATORY STORARE BUTLDIMG 
commond:

SELECT PNRTICIPANT COOE

RON 1 of 121

Select eppropr iate compony by placing $X$ In SELECT end preesino ENTER Use UP and DOW comends, if necessary, to view entire fist.

$1, \mathrm{TBA}$

4.6. 2 ASsOCIATES

- retis

- Ast

DDMS CEAFT HERT7 HALKERCSURVEYING CO,

SDVAWCED SCIENCES INCORPORATED

MLERTIMG COMUMICATIOH OF NERICA

4 MRSHALL

NUERTCAN TECHMICAL ASSOCIATION

APPLIEO COAYIMG

WTO. PROCRAM TOOI

Avisco InCORPOR

8 \& D EQUTPHEMT CO

BARGS, UAGGOWER, SUMWER I CANINON

CONSTRUCTION CO.

BAYHOWT ENGINEERILKG

BECHTEL.

BLACX ADO VEATCH

BW WIEE WAYs coustruation $\mathrm{CO}$.

BOEING EMG.

BOEING/URAWIUH EMRICHMENT 


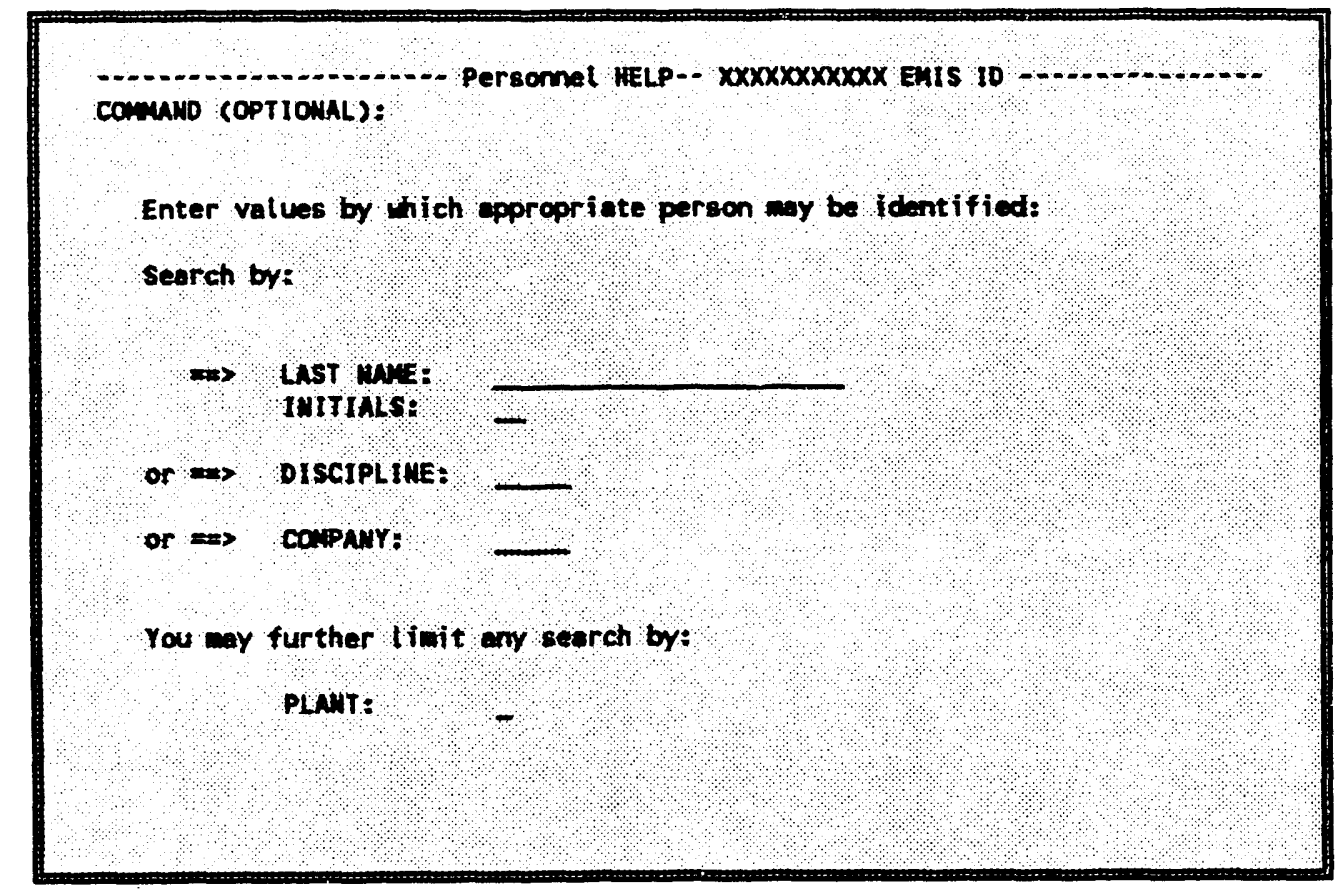

\section{SELECT EMIS ID SCREEN}

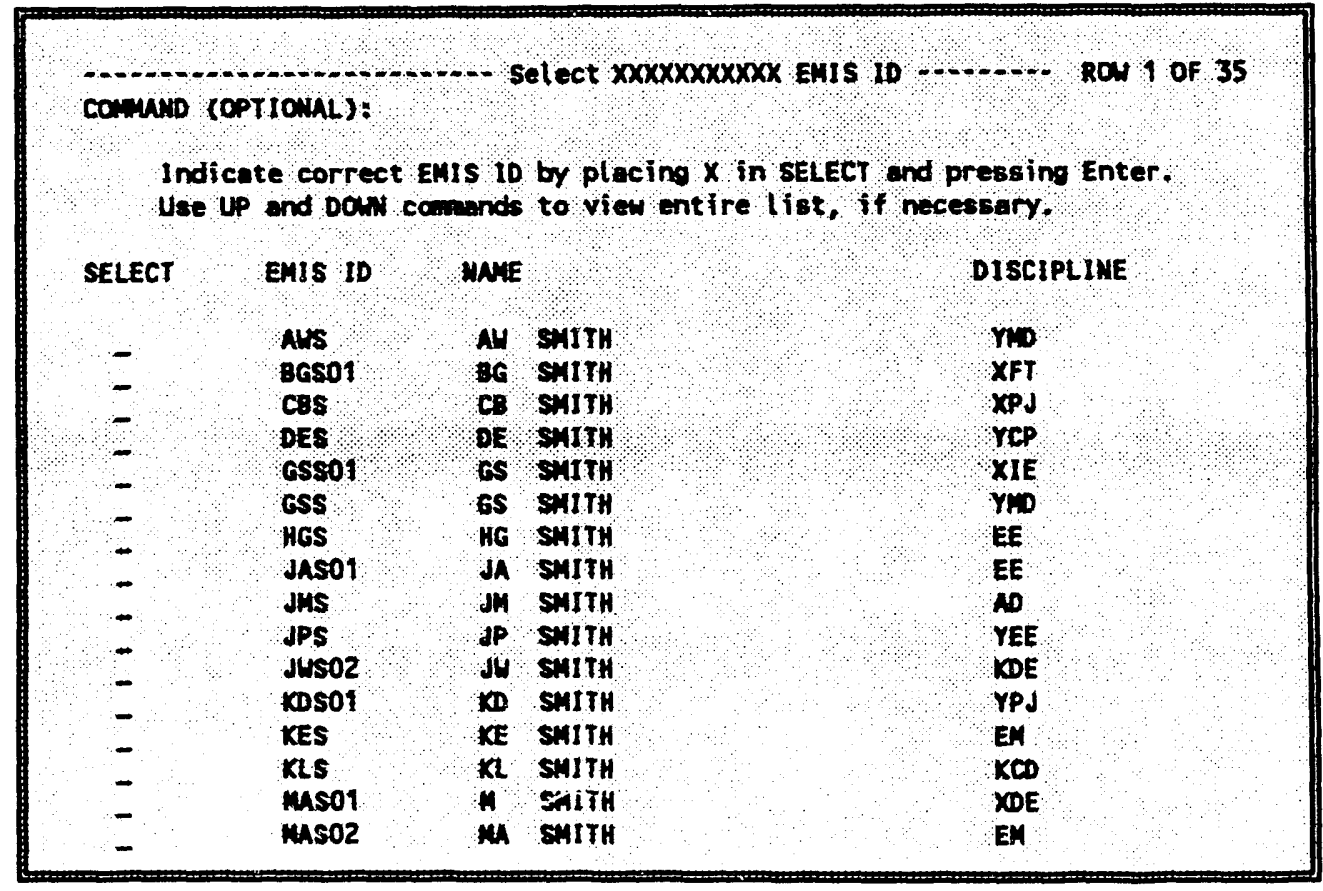




\section{SELECT DOCUMENT TYPE SCREEN}

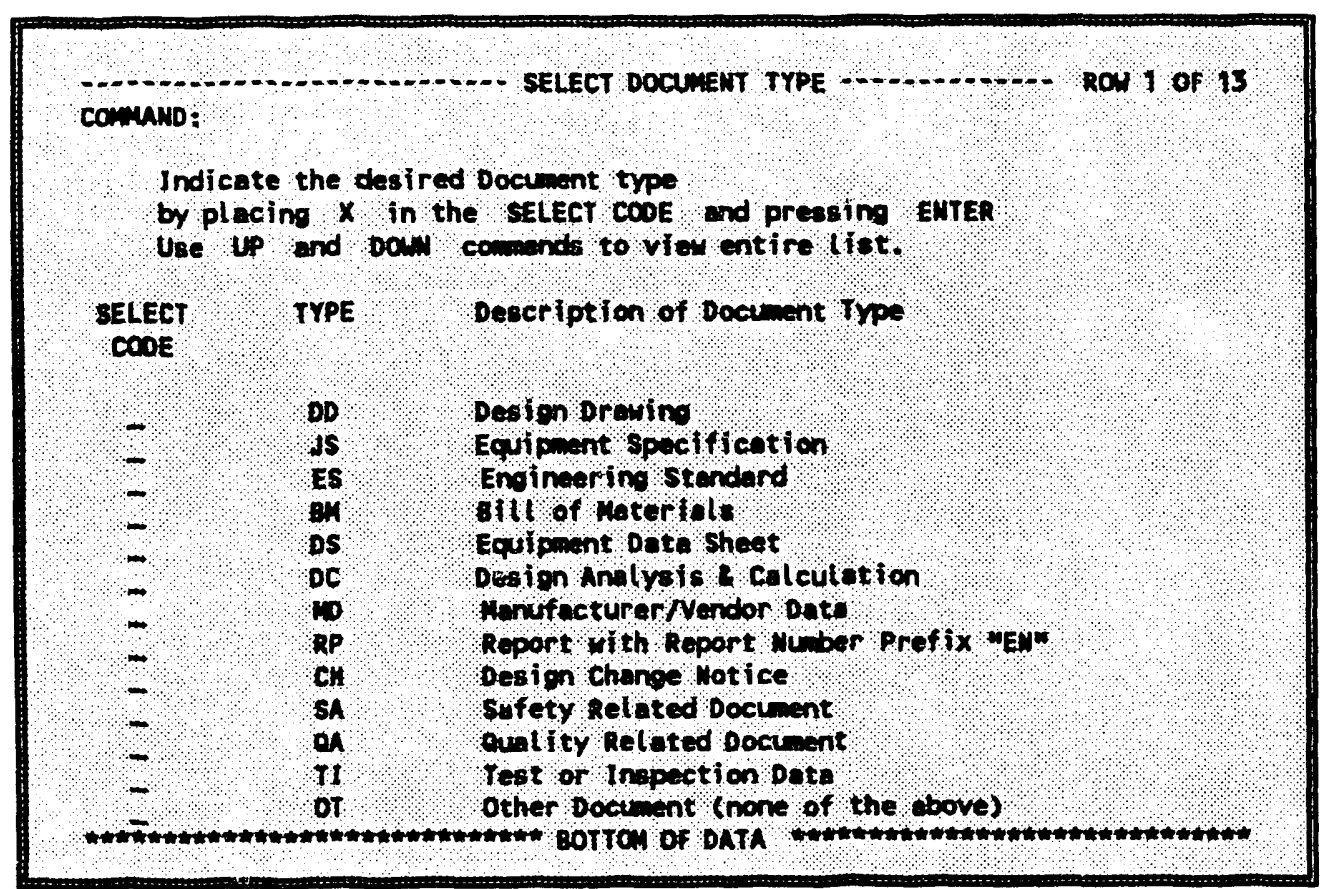

A partial list of these codes will be displayed for the Reserve system screens. 
SELECT DISCIPLINE CODE

Command:

Indicate the Desired Discipline by placing $X$ In sELECT and pressing ENTER Use up end Doum comend, If necessary, to view entire list.

_ AS $\quad$ APPLICATIOHS sUPPCRT

CIVIL ENGINEERIHG

ARCHITECTURAL, STRUCTURAL, EXPERIMENTAL

CHENTCAL PROCESS DESIEH

CHEMICAL TECHAOLOGY DIVISIOA

EMGIUEERING NHALYSIS

ENVIROAMENTAL COWTROL ENGINEERIMG

ELECTRICAL EMGINEERIMG

EHGIWEER ING MECHANICS

IHSTRUMENTATIOH AND CONTROL DIVISION ORNL

COMPUTER AIDED DESIEN

AECHANICAL DESIGH, EQUIPMENT

INSTRUMENT ENGIMEERING

HECHANICAL TECHNOLOGY ENGINEERING

PRCUUCTIOU CHEMICAL ND ENRICHUET PROCESS ENGIMEERIMG 


\section{SELECT FUNCTION CODE}

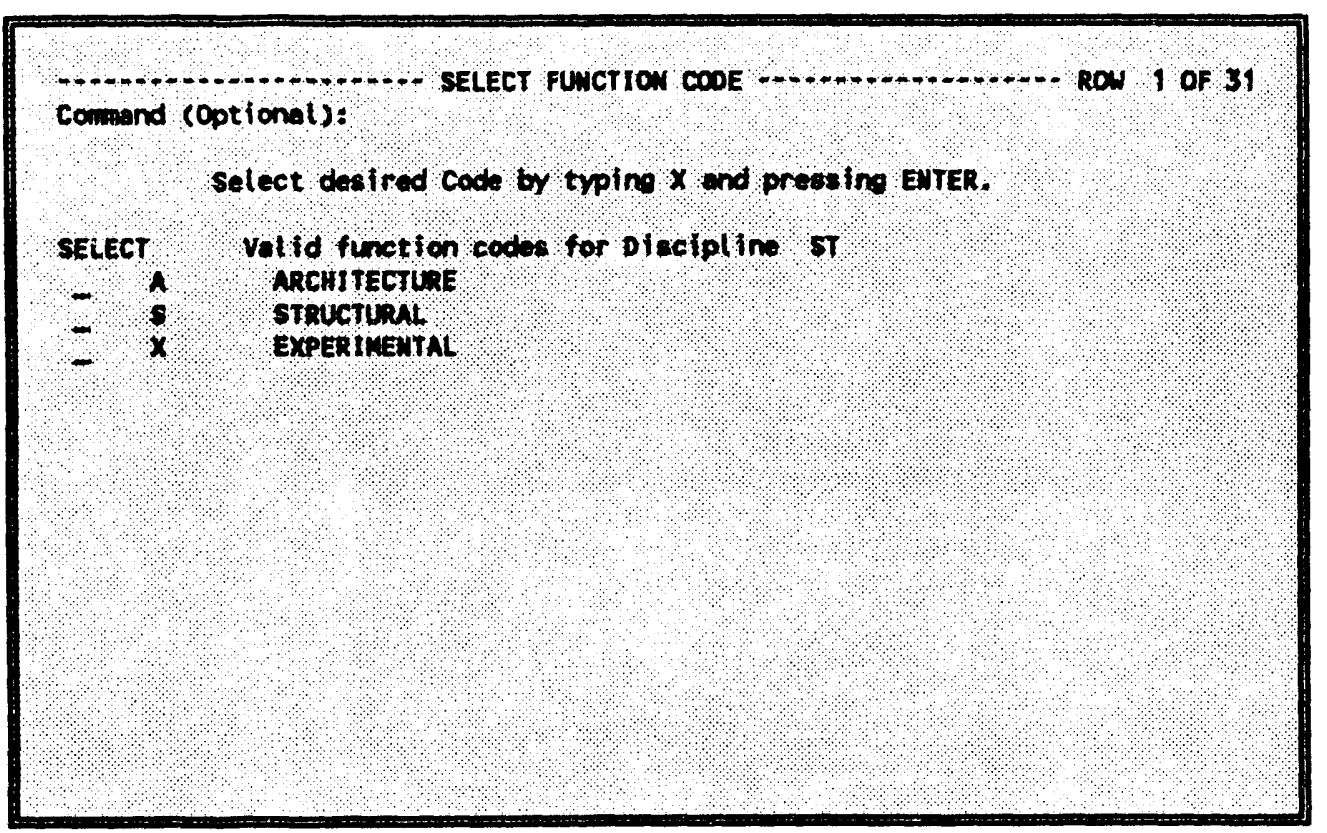

A unique list of codes exists for each discipline. A particular iist will be displayed, depending upon the discipline previously selected. This example is for discipline ST. 
SELECT ENGINEERING DISCIPLINE

command:

Enter code for the dealred Enolineering oleciplinet, (8lock 48)

CODE ENGINEERIUG OISCIPLINE

c - - - - - clvil, structural, and Architectural

E -....- Electrial

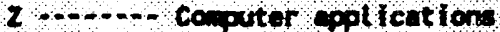

1 - - - - Instrunentotion

A .......-. Nechenical

P .......-. Engineering Mechentics

H ....... Environwentat controt

J -...- support Engineering

f ....... Hachine Desion 
SELECT NATURE OF WORK

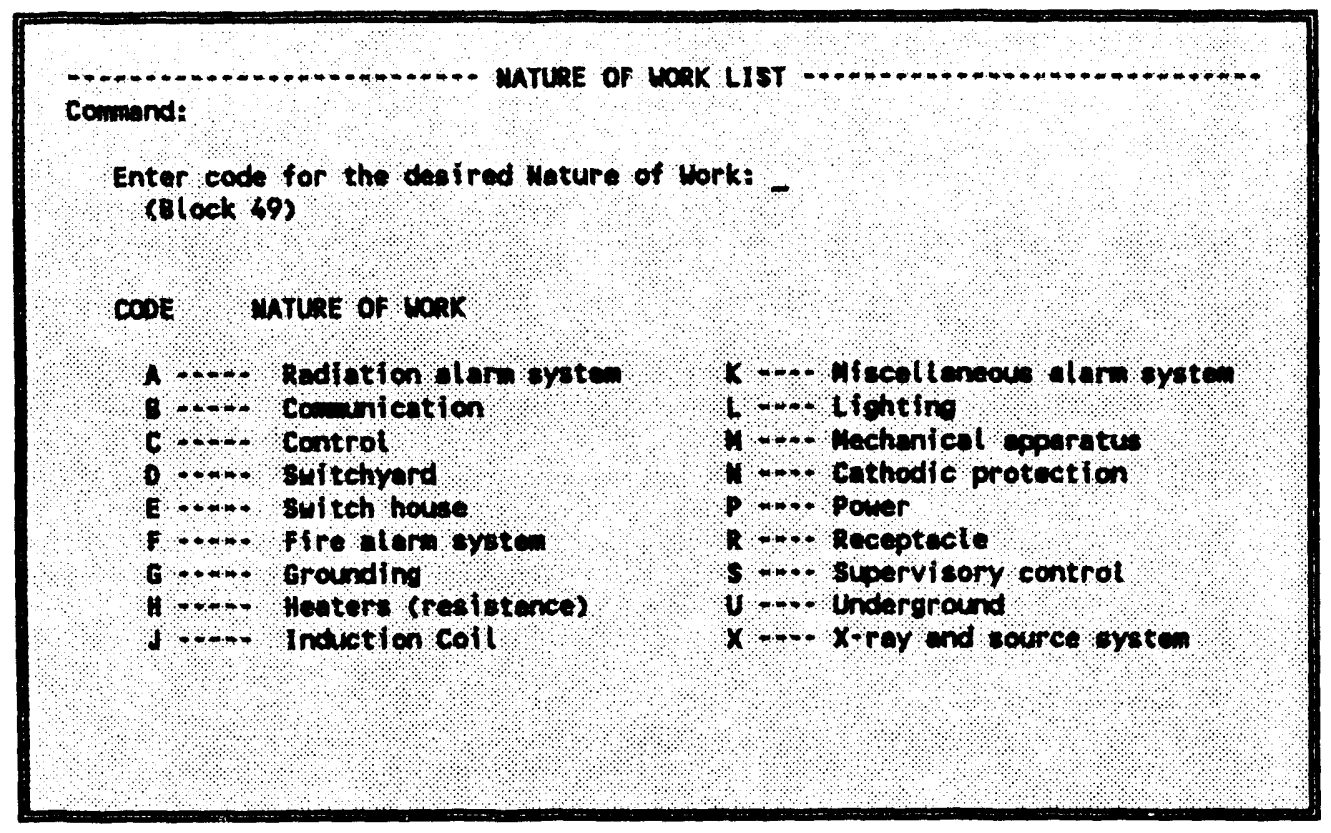

A partial list of these codes will be displayed, depending upon the Engineering Discipline previously selected (Block 48). 
SELECT NATURE OF WORK SUBSET

Command:

MATURE OF WORK SLIUSET LIST

Enter code for the desired Wature of Work subeet: (Block 50)

COOE WATURE OF WORK SUBSET

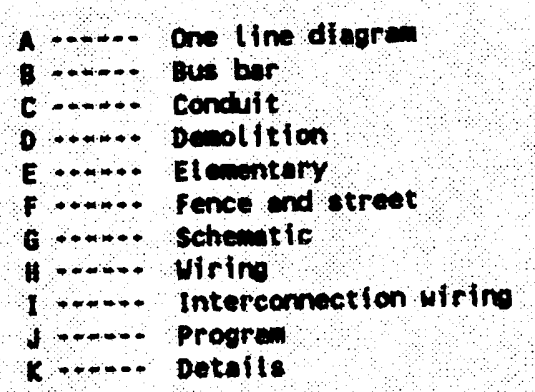

L -....- Loyout

4 -...- - Printed clecuit board

0 -..... outside distribution

P..... Photometit

R...... Receway (includet bus duct)

s ....... schedule

1 . -.... Equipment

4 ...... coble through

$x$...... Hiscel Inneou

z ...... Pictortal

k $-\ldots-\ldots$ Details

A partial list of these codes will be displayed, depending upon the Engineering Discipline previously selected (Block 48). 


\section{TITLE CLASSIFICATION VERIFICATION}

commano (OPTIONAL)

\section{Title claseification Vorlfication}

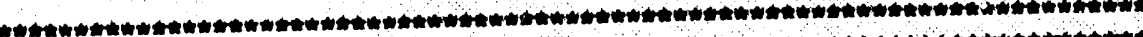
Were

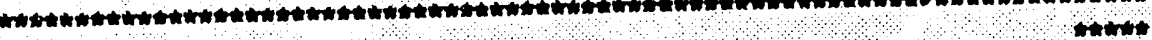

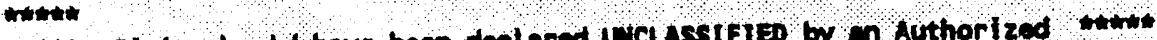

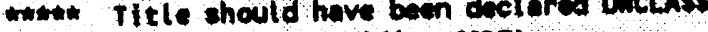

nwt Derivetive Clessifier (ADC),

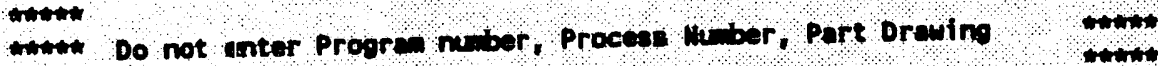

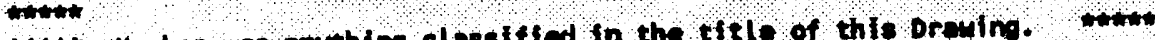

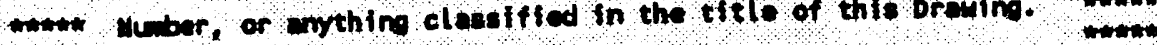

(1)

inturith

Correct Title if necesenry and press enten to continus.

month

nimint

mitrity

intom

Enter EID to cancel the drawing reservation or modification.

tritint

witw

ratim

whithe

rumber

Title:

rararor

ration

intintit

thinth

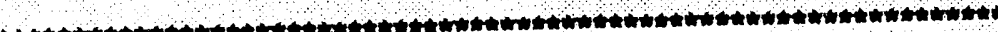

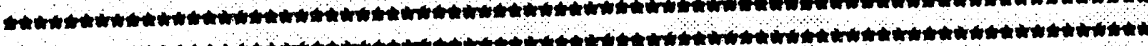

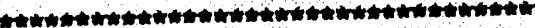




\section{UNRESERVE FAILURES}

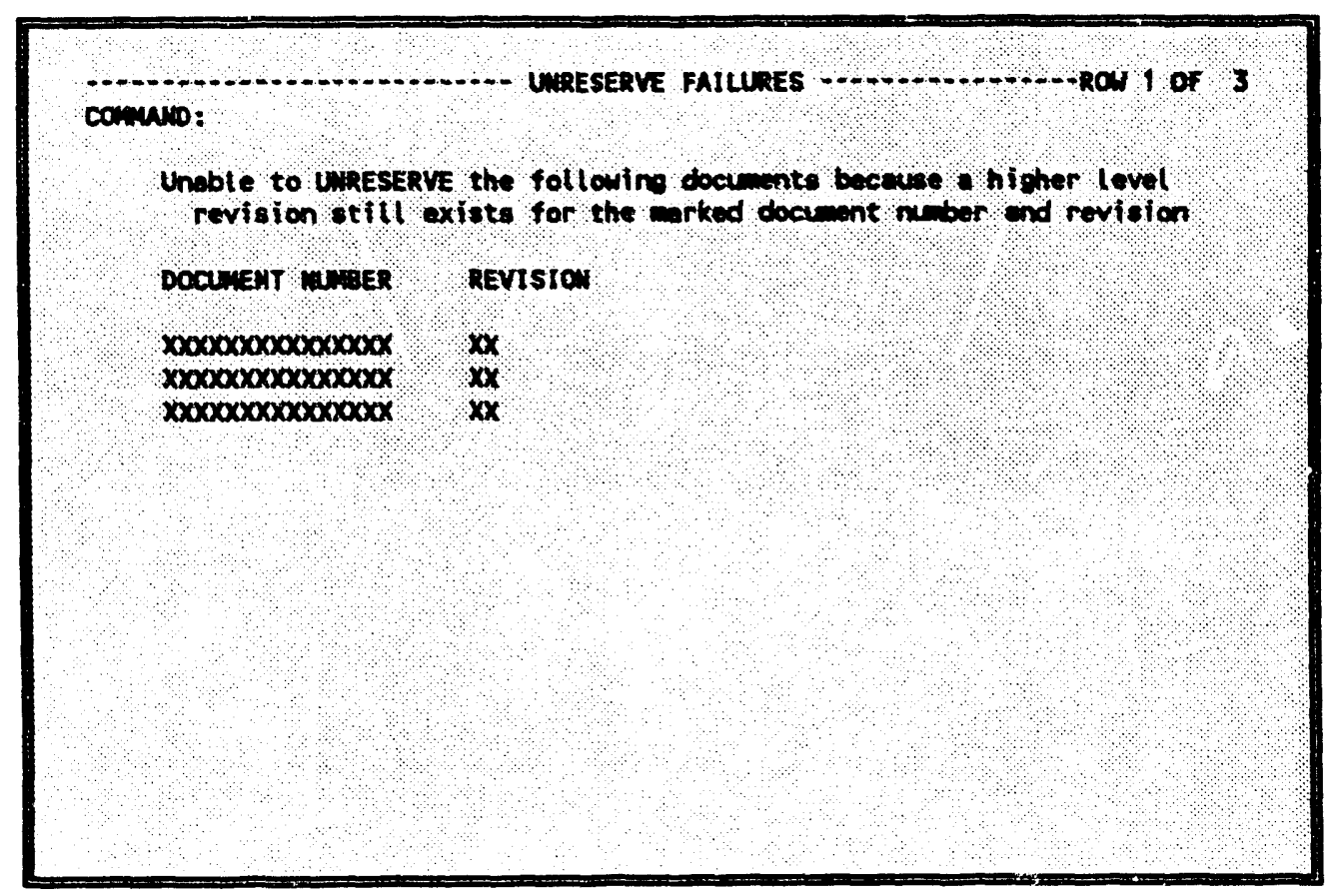




\section{REVISION PROBLEM}

COMMND (OPT IOUAL) $=-\mathrm{s}$ )

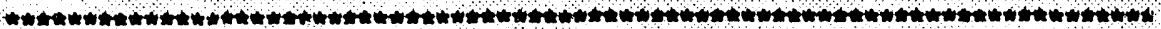

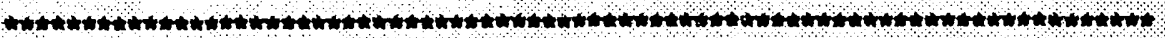

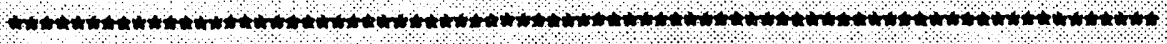
ontont

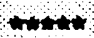

noworthe

nowint

nitim

ntatent

ontintin

roment

artintert

omatot

ontruns:

onimine

totment

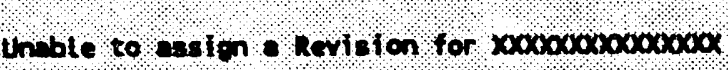

stints.

nt?

tonth

whnt

Insufficient infornation In 190 botabese to bulld new revision. thent

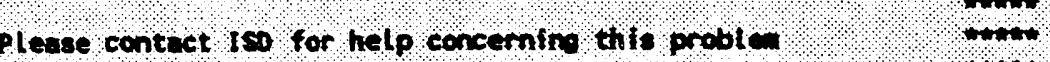

Error code:

For wore information plense eontect:

Karen shaw

$574-7869$

Hontgomery Lokey

$574-3590$

nothents

tratho

ant

thath

n+1 Tw who L

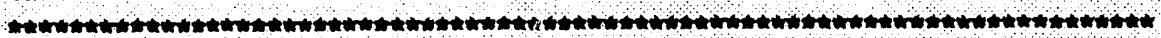

NOTE: This error message is presented due to the fact that the last alphabetic revision code is unavailable on the system and the assignment of a new revision is not possible. When this error screen appears, obtain the next revision from the face of the drawing and contact either of the individuals listed on the screen. 
UNRESERVE OR MODIFY FAILURES

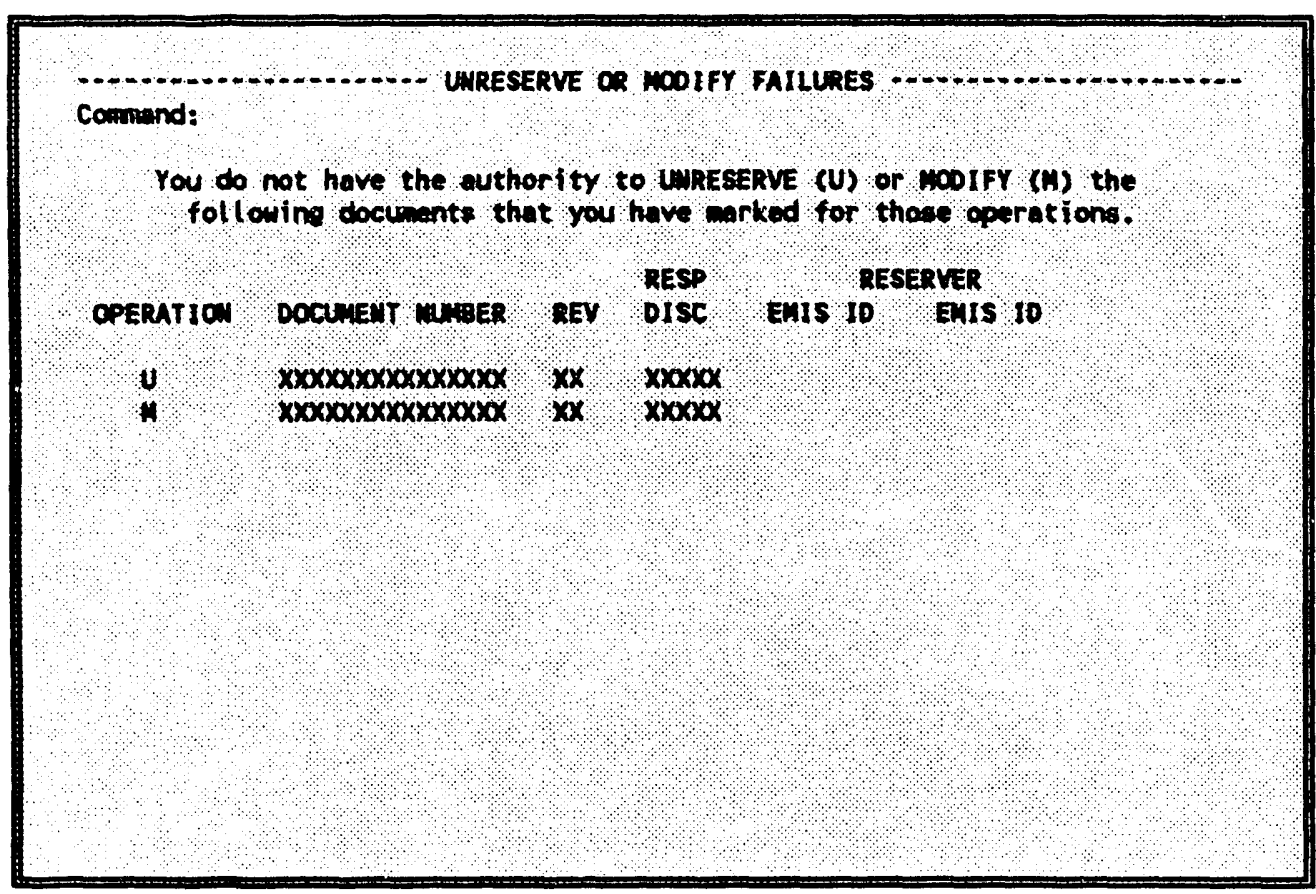




\section{DATABASE ERROR}

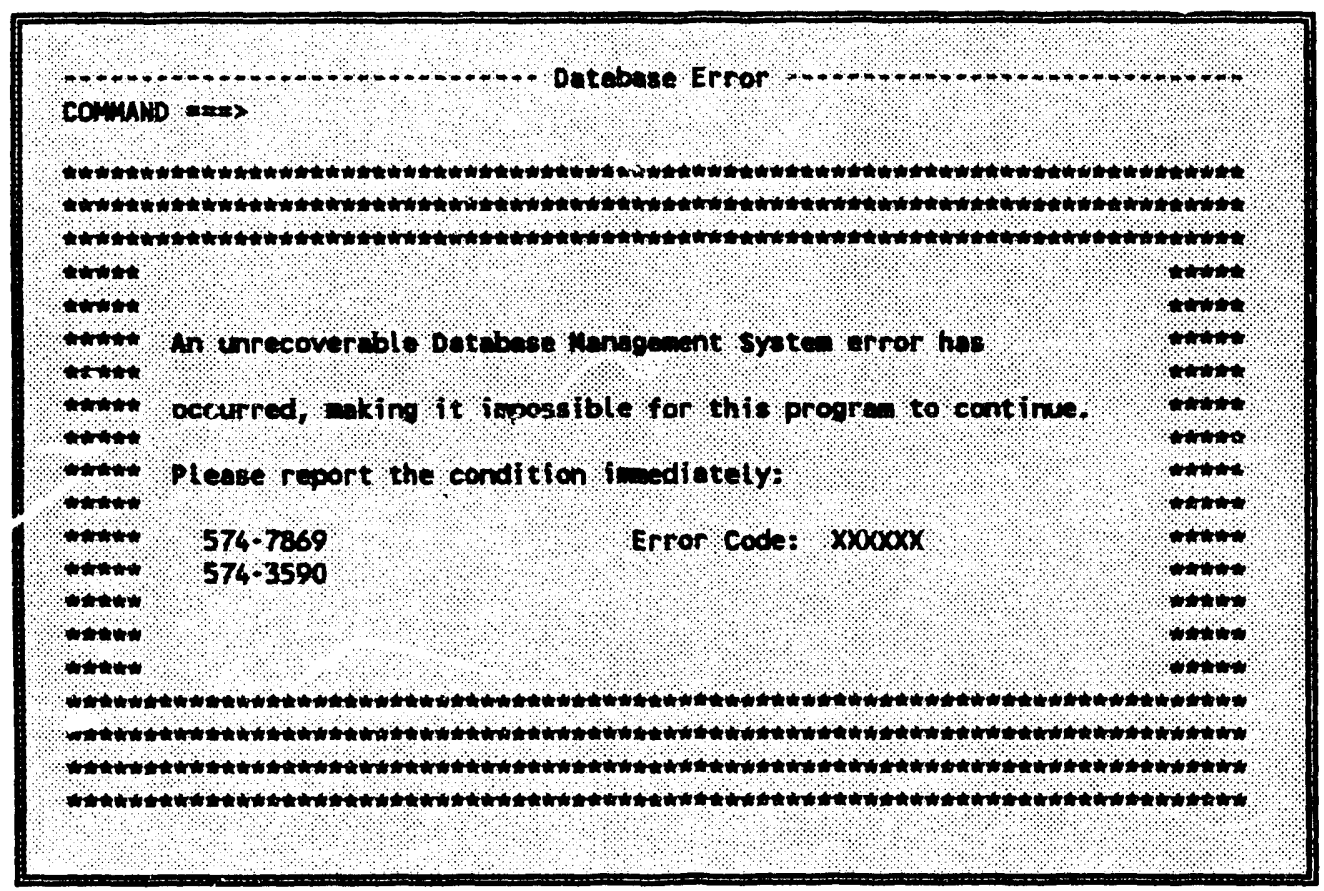




\section{DATABASE ERROR}

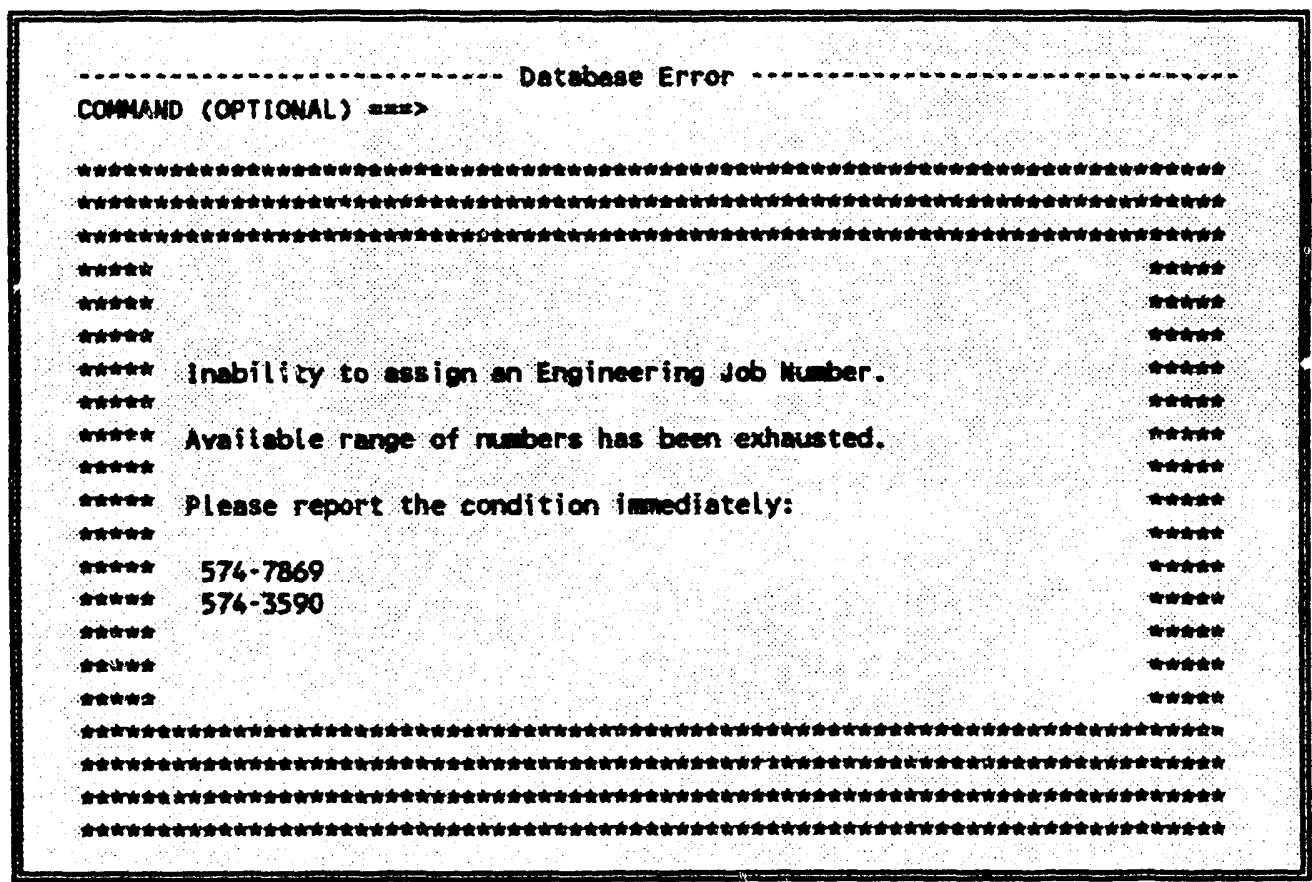


APPEHDDK E: EDIS DATA DICTIONARY 


\section{EDIS DATA DICTIONARY}

\section{Data Element}

\section{Access Date \\ Anticipated Release Date}

Block 1

Block 48

Block 49

Block 50

Building

Change Date

Change Control Number

Charge Number

Classification

Classification Date

Classifier ID

Company

Company Description

Configuration Control Number

Cost Center

Design Date

Designer

\section{Description}

The date on which the document image was last accessed.

The date on which the reserved document is expected to be released. (Abbreviated as Antic. Release Date.)

A code representing the category of the work contained in the document.

A code that identifies the Engineering discipline to which the document (design drawing) belongs.

A code that identifies the nature of the work contained in the document (applies to design drawing).

A code that signifies a subset of the nature of work being performed.

A sode uniquely identifying the building with which the document is associated. (Abbreviated as Bldg.)

The date on which the document index was last modifiel.

The identifying number of the project change order for which the revision is made.

A valid TSO computer charge number.

A code indicating the classification of the document. (Abbreviated as Class.)

The date on which the document's classification was approved. (Abbreviated as Class. Date.)

The EMIS ID of the person who approves the classification of the dociment. (Abbreviated as Class. ID.)

A code indicating the company responsible for the creation of the document.

The description associated with the company code.

A number that identifies the configuration control plan under which changes to the document are made.

A number associated with an Engineering Cost Center for which hard copies of documents may be charged.

The date on which the document was designed. Applies to design drawings only.

The same of the designer of the sriginal document. 


\section{EDIS DATA DICTIONARY}

\section{Data Element}

Disposition

Document Type

Document Title

Document Number

Draft Date

Draftsman

Drawing Size

ENN

ESO

Floor

Format Code

Function Code

Index Date

Initial Store Date

Issue Date

Last Store Date

Number of Sheets

Number of Models

\section{Description}

A code that indicates whether the hardcopy output is to be delivered via plant mail or the user is to be called to pick up the output.

A code that identifies a category of documents to which the document belongs. (Abbreviated as Doc. Type.)

A title that describes the document. (Abbreviated as Doc. Title.)

A number that uniquely identifies all documents referenced in the EDIS index. (Abbreviated as Doc. No.)

The date on which the document was drafted.

The name of the original drafter of the document.

A code describing the size of the document (applies to drawings only).

Engineering Job Number. An identifying number associated with buildings and special project activities.

The Engineering Service Order to which specific revision work done on the document is charged.

A code describing the building floor to which the drawing or document refr's.

A code indicating the format of the document: CADAM - CADAM Electronic Format; ANVIL - Anvil Electronic Format; FILM - Aperture Card or Microfilm; MAN - Hard Copy or Manually Generated; UNCAD Unspecified CAD Generated; OTHER - Unspecified.

A code, as specified in EP-C-03, "Drawing Numbering", indicating drawing type.

The date on which the document was entered into the EDIS Index.

The date on which an electronic copy of the document was first stored in the EDIS repository. (Abbreviated as Initial Store.)

The date on which the document was issued.

The date on which an electronic copy of the document was last stored in the EDIS Repository. (Abbreviated as Last Store.)

Indicates the total number of sheets that comprise a drawing.

The number of models associated with a CADAM drawing. 


\section{EDIS DATA DICTIONARY}

\section{Data Element}

Originator ID

Original Format

Originator Discipline

Originator's Company

PC Filename

Plant

Project Number

Plotter ID

Quantity

Reserve Date

Reserver ID

Responsible ID

Responsible Discipline

Revision Code

Revision Date

Send to EFM

\section{Description}

The EMIS ID of the originator of the document. (Abbreviated as Orig. ID.)

A code indicating the format in which the document was originally created. (See format code.) (Abbreviated as Orig. Format.)

The EMIS discipline code associated with the EMIS ID of the originator of the document. (Abbreviated as Orig. Disc.)

A code identifying the originator's company. (See company.)

A valid DOS filename. For the EDIS Store and Download functions this name includes the drive, directory path and file name (e.g., C:IMCADMPCFILESITEST.CAD).

A code indicating the plant to which the drawing pertains.

The EMIS project number with which the document is associated. (Abbreviated as Proj. No.)

A code indicating the plotter at which a requested hardcopy plot will be routed.

The number of copies requested by the user requesting the hardcopy function.

The date the document number was reserved in EDIS. This is automatically generated at reserve time. (Abbreviated as Resv. Date.)

The EMIS ID of the person who reserved the document. (Abbreviated as Resv. ID.)

The individual (normally the Eng. RED) responsible for the document. (Abbreviated as Resp. ID.)

The Engineering design discipline responsible for the document. (Abbreviated as Resp. Disc.)

A code that indicates the level of the document revision. Codes for revisions made by Martin Marietta are characters beginning at "A"; for architect/engineers, they are numbers beginning at "1." (Abbreviated as Rev. Code.)

A date that, in some cases, indicates a document's revision. Some text documents (maybe in a CADAM model) do not have revision codes. This field will be blank if an entry is made in the Revision code. (Abbreviated as Rev. Date.)

A code indicating if a copy of the document is to be sent to the EFM 


\section{EDIS DATA DICTIONARY}

\section{Data Element}

Sequence Letter Title

Sequence Letter

Sequence Number

Sheet Number

Size of Print

Software Version

Special Project Title

Status Code

Status Date

Storage Date

Storage Location

Subject Code

Type of Package

Vendor Code

Workorder

\section{Description}

system.

A descriptive title assigned to a specific special project sequence letter.

A letter used in the construction of a document number (refer to Engineering Procedure EP-C-03).

A sequential number assigned to a document number (refer to Engineering Procedure EP-C-03).

The number of the sheet of a multiple sheet document. This is defaulted to '001' for all single sheet documents or documents that are not design drawings. (Abbreviated as Sheet.)

Specifies whether a hardcopy request is to be printed in Half- or FullSize format.

A code identifying the version of the software that created a particular electronic format of a document.

Title of a special project.

A code indicating the stage of development of the document. (Abbreviated as Status.)

The date the sheet revision was stored in its current state of development.

The date that a particulse electronic format of a document was stored.

The storage location of a particular format of a document.

A code indicating subject of manufacturing or vendor data (document type MD).

A code indicating the type of design package associated with a specified project.

A code describing the vendor associated with document types MD (manufacturing or vendor data).

An Engineering Workorder number for which changes may be ass: rned. 


\section{DISTRIBUTION}

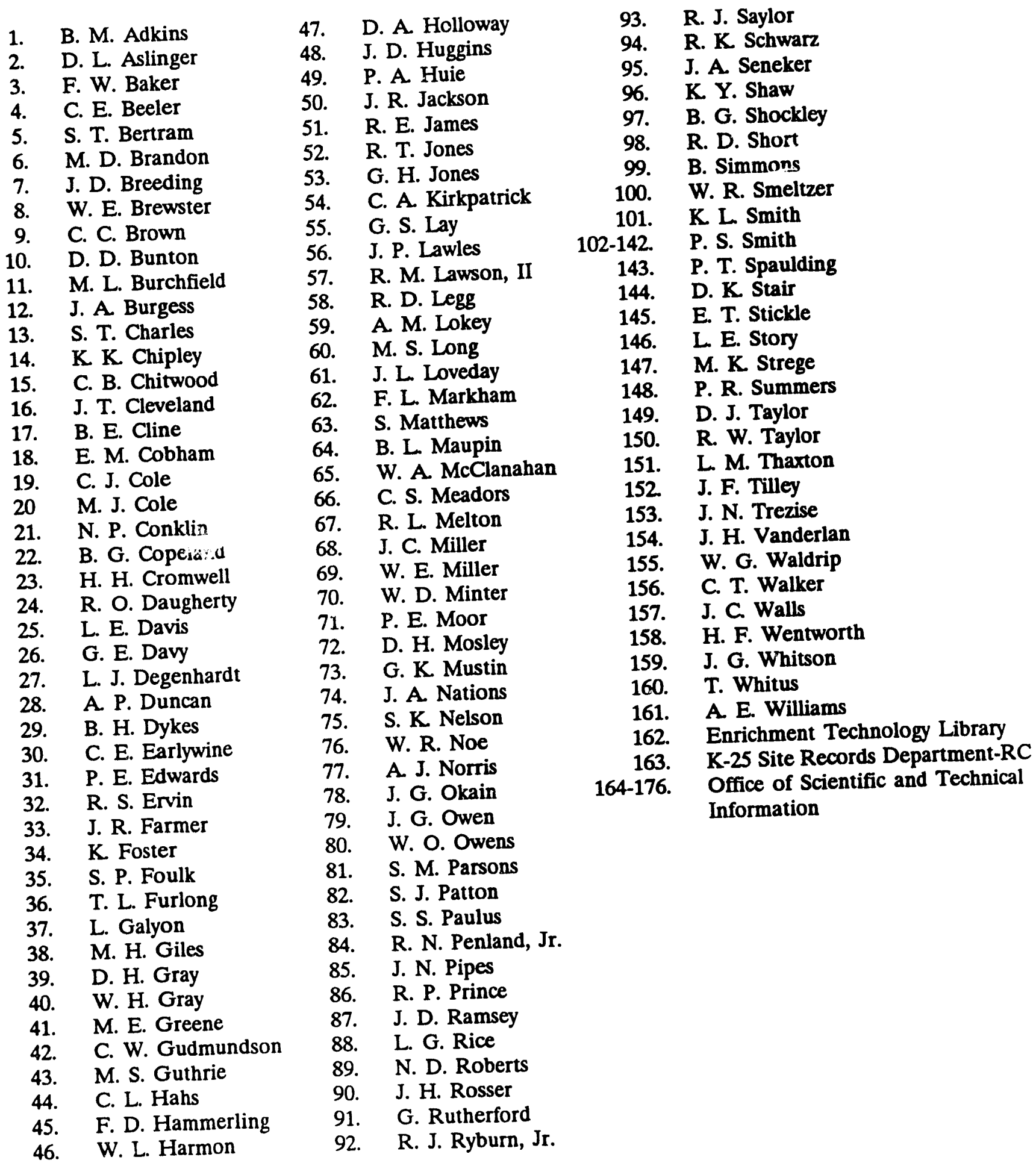



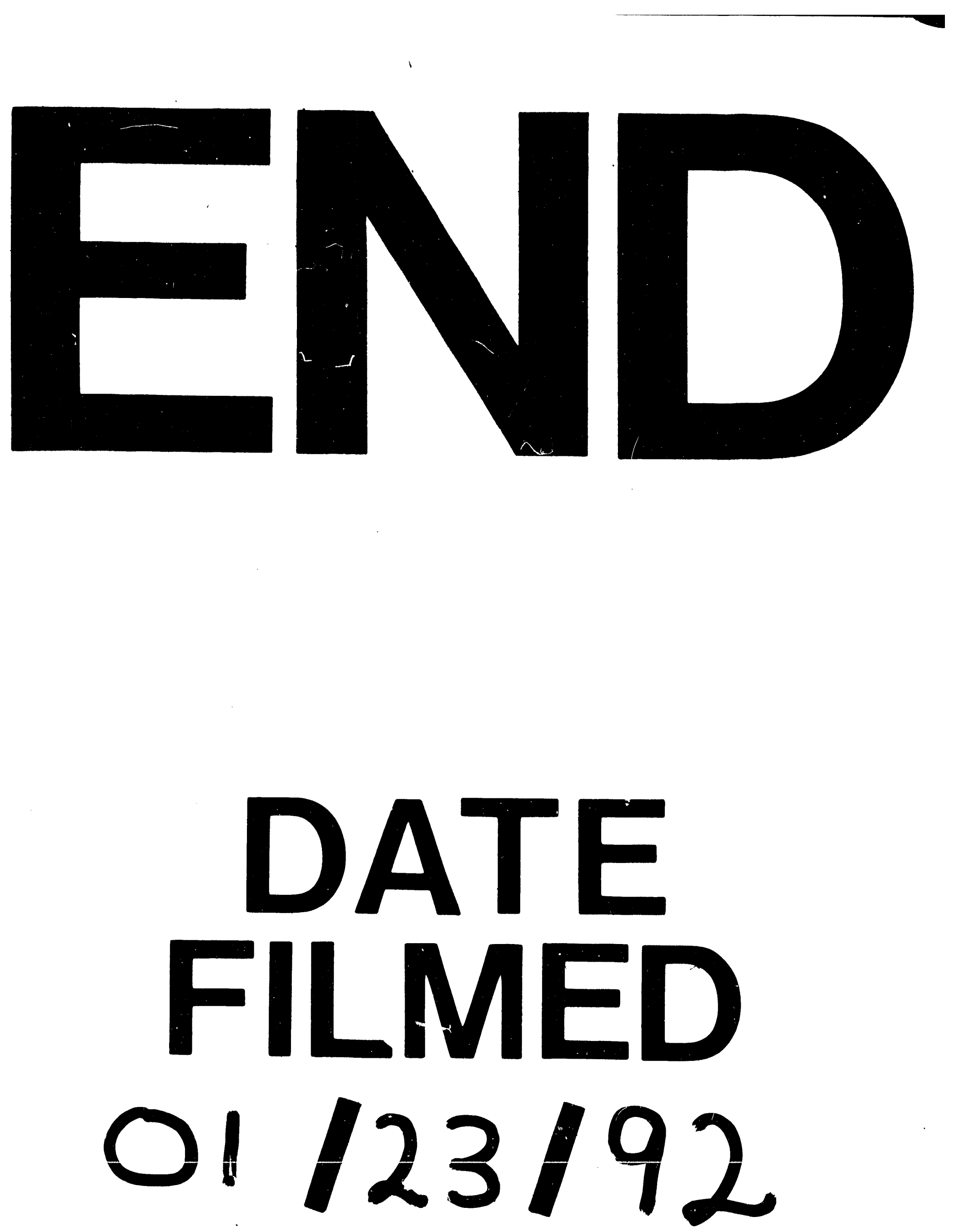
